\title{
Refinement and Application of a New Paleotemperature Estimation Technique
}

by

\section{7,1}

555

\section{Elisabeth Lynn Sikes}

B.A., Wesleyan University (1980)

M.S., University of North Carolina, Chapel Hill (1984)

Submitted in partial fulfillment of the

requirements for the degree of

Doctor of Philosophy

at the

\section{MASSACHUSETTS INSTITUTE OF TECHNOLOGY}

and the

\section{WOODS HOLE OCEANOGRAPHIC INSTITUTION}

June 1990

(C) Elisabeth L. Sikes, 1990

The author hereby grants to MIT and to WHOI permission to reproduce

MARINE BIOLOGICAL LABORATORY

LIBRARY

WOODS HOLE, MASS.

W. H. O. I. and to distribute copies of this thesis document in whole or in part.

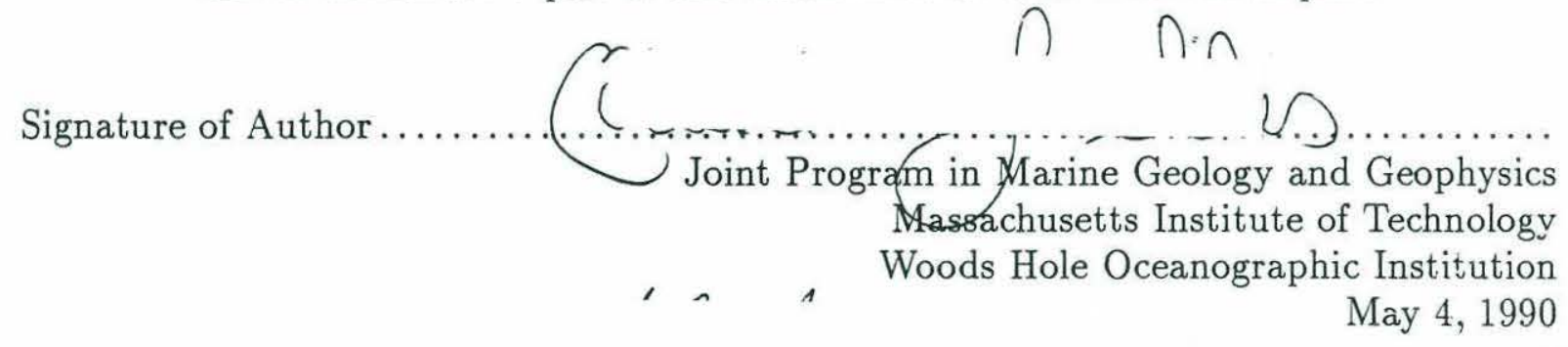

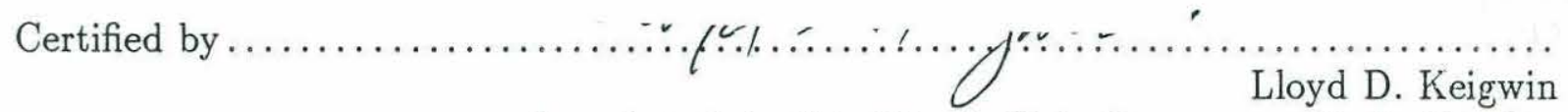
Associate Scientist, Woods Hole Oceanographic Institution Thesis Supervisor

Accepted by

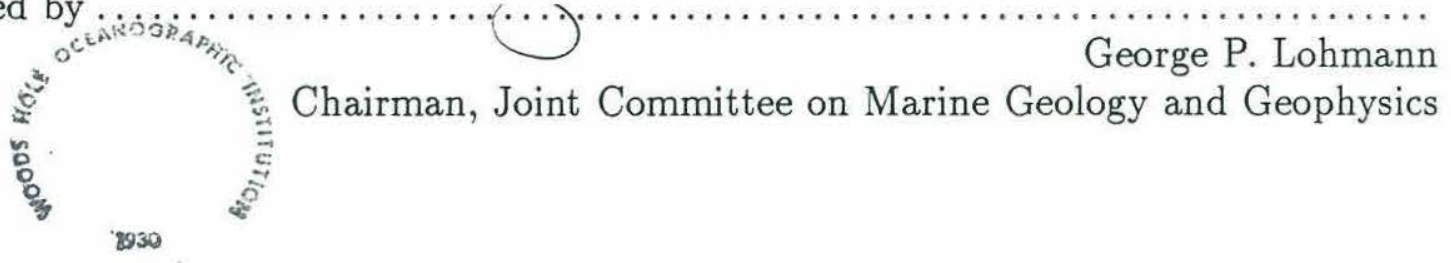




\title{
Refinement and Application of a New Paleotemperature Estimation \\ Technique \\ by
}

Elisabeth Lynn Sikes

\author{
Submitted to the Massachusetts Institute of Technology- \\ Woods Hole Oceanographic Institution \\ Joint Program in Marine Geology and Geophysics \\ on May 4, 1990, in partial fulfillment of the \\ requirements for the degree of \\ Doctor of Philosophy
}

\begin{abstract}
A recently developed technique for determining past sea surface temperatures (SST), based on an analysis of the unsaturation ratio of long chain $\mathrm{C}_{37}$ methyl alkenones $\left(\mathrm{U}_{37}^{k^{\prime}}\right.$ ) produced by Prymnesiophyceae phytoplankton, has been applied to late Quaternary sediment cores. Previous studies have shown that the $\mathrm{U}_{37}^{k}$ ratio of these alkenones is linearly proportional to the sea-water temperature in which the plankton grow, both in culture and water column samples. Furthermore, a reasonable correlation has been found between open ocean paleo-SST estimates based on $\mathrm{U}_{37}^{k}$ values and those derived from $\delta^{18} \mathrm{O}$, for the period spanning approximately the last 100,000 years (Brassell, 1986b). These results indicate this technique has potential for determining paleo-SST from analysis of alkenones extracted from marine sediments. In order to apply the $U_{37}^{k}$ method quantitatively, it is necessary to calibrate the method for sediment samples, and to assess how well the alkenones maintain their temperature signal under some common conditions of sediment deposition and sample handling. It is also necessary to determine the method's usefulness downcore, that is, back in time, by comparing it to established methods.

This study examined the effect on $\mathrm{U}_{37}^{k}$ of conditions that cause dissolution of carbonates in the sediment, and methods of storage and sample handling. These are two problems that must be resolved before the method can be applied rigorously and quantitatively to sediments for paleotemperature estimations. A comparison of duplicate samples collected and stored frozen versus those stored at room temperature for up to four years showed no resolvable differences in $\mathrm{U}_{37}^{k}$. Laboratory experiments of carbonate dissolution indicated there is no effect on $\mathrm{U}_{37}^{k}$ values under the acidic conditions that dissolve carbonates. Initial field results support this, but indicate more studies are necessary. The $\mathrm{U}_{37}^{k}$ "thermometer" was calibrated by analyzing $\mathrm{U}_{37}^{k}$ in coretops from widely varying open ocean sites. Sediment values of $\mathrm{U}_{37}^{k}$ reflected overlying SST for the appropriate season of the phytoplankton bloom, which for this study was assumed to be summer in high latitudes. These results fall on the same regression line for culture and water column samples derived by Prahl and Wakeham (1987), indicating that their equation $\left(\mathrm{U}_{37}^{k}=\right.$ $0.033 \mathrm{~T}+0.043)$ is suitable for use in converting $\mathrm{U}_{37}^{k}$ values in sediments to overlying SST for the season of coccolith bloom. Using this calibration for sediments, the $\mathrm{U}_{37}^{k}$ paleotemperature method can be quantitatively applied down core to open ocean sediments.
\end{abstract}


In the Equatorial Atlantic, $\mathrm{U}_{37}^{k}$ temperature estimates were compared to those obtained from $\delta^{18} \mathrm{O}$ of the planktonic foraminifer Globigerinoides sacculifer, and planktonic foraminiferal assemblages for the last glacial cycle. The alkenone method showed $\sim 1.56^{\circ} \mathrm{C}$ cooling at the last glacial maximum. This is about half the decrease shown by both the isotopic method $\left(\sim 3.40^{\circ} \mathrm{C}\right)$ and foraminiferal assemblages $\left(\sim 3.75^{\circ} \mathrm{C}\right)$, implying that, if $\mathrm{U}_{37}^{k}$ estimates are correct, SST in the equatorial Atlantic was only reduced slightly in the last glaciation.

In the Northeast Atlantic, $U_{37}^{k}$ temperature estimates show a profile downcore which is similar to the estimates from foram assemblages but with a constant offset toward warmer values throughout the core. $\mathrm{U}_{37}^{k}$ SST estimates are substantially warmer than foraminiferal estimates at all times, which may indicate inaccuracy in $\mathrm{U}_{37}^{k}$ temperatures at this site. $\mathrm{U}_{37}^{k}$ indicates a SST of $12^{\circ} \mathrm{C}$ for the late glacial and $18^{\circ} \mathrm{C}$ for the Recent, whereas assemblages give estimates of $9^{\circ} \mathrm{C}$ and $13^{\circ} \mathrm{C}$, respectively. At 12,700 yrs $\mathrm{BP}$, the $\mathrm{U}_{37}^{k}$ and foram assemblage methods indicate a $2^{\circ} \mathrm{C}$ warming. A temperature change of $2^{\circ} \mathrm{C}$ can account for only $0.44^{\circ} \%$ of the observed $1.2^{\circ} \% \circ \delta^{18} \mathrm{O}$ signal, indicating that the additional $0.8^{\circ} \%$ change in $\delta^{18} \mathrm{O}$ must result from changes in surface salinity most likely due to a meltwater lid. $U_{37}^{k}$ estimates show the major temperature shift from glacial to interglacial temperatures occured at about 9,000 yrs BP disagreeing with assemblage data which shows the shift to Holocene values at about 12,700 yrs BP. If $U_{37}^{k}$ temperature estimates are accurate, this disagreement may reflect differing habitats of flora and fauna under the unusual sea surface conditions in this area during the deglaciation.

Thesis Supervisor: Lloyd D. Keigwin

Title: Associate Scientist, Woods Hole Oceanographic Institution 


\section{Acknowledgments}

Primary financial support for this research came from the Ocean Ventures Fund (grant 25/ 85.08), without which this project would not have been possible. Funding supporting the labs of John Farrington (OCE 88-11409) and Lloyd Keigwin (OCE 83-08893 and ATM 84-14335) in which I worked also provided funding for part for this research.

My thanks go to the members of my committee, Ed Boyle, Bill Curry, and John Farrington. Each gave willingly of his time, expertise, and support as it was needed along the way, a gift that cannot be undervalued. John was especially generous in sharing his understanding of organic chemistry and in allowing me to camp-out in his lab for two years, both of which were instrumental to this project. Thanks also to my advisor, Lloyd Keigwin, who taught me by example to think critically, rely on myself, and to be demanding of both my work and that of others. For Lloyd too, this Ph.D. was a first - I think we've both learned a lot in $5 \frac{1}{2}$ years.

This being an interdisciplinary project, I worked in numerous labs and in every building on Quissett campus. In each place there were people whose help was instrumental, but I am especially grateful to those who slogged through the bulk of the analyses with me. Eben Franks taught me not only the essentials of mass-spec'ing, but also the extras in the life of an isotope wiz. Amy Pallant helped me learn some of the forams, and she also picked them with me, providing many hours of conversation and much valued friendship as well. Dan McCorkle was helpful in the initial phases of this work as "my post-doc" and has remained close at hand providing input at critical moments along the way. Mark McCaffery taught me all I know about organic geochemical techniques, and Jay Gooch taught me the finer points of GC'ing and data processing. Ellen Druffel has given me both advice and comfort and has been the role model that G \& G is lacking. I can only hope that I can someday repay her time, kindness and caring. Also, for their companionship all those days, thanks to Sheila, Rindy, Sam and Marla.

The caring and support of friends near and far has provided the glue that held me together as I made my way in the Joint Program. There was always some one who reached out or provided relief when things got too rough. Janet Hering, Ann Carey, Deb Backhus, Jan Zemba, and Sarah Green were roommates whose friendship has seen me through. They cared for me when I was around, and for my possessions when I wasn't. In a lifetime one would be lucky to have one such friend, I have five. A very, very special thanks goes to the Grays, Priscilla 
and Paul. Their love and concern has encouraged me to strive to be the best I can, and their example has taught me that concern for people, especially those around you, is as important as any science you do. Milton Skilton has been my solid and steady friend "on the outside", his giving and companionship has eased my way and lubed many miles, without him I'd have been lost. With Erik Brown I shared an office, a birthday, and an affection for the Red Sox, no one will ever match his irrepressible humor. Marti Jeglinski, Chris Bradley, Carl Friedrichs and Andy Trivett warmed many a Woods Hole winter night, and brightened many Woods Hole days. Thanks too to JoAnn, for sharing the trials at the end.

My family has always supported my desire for more education, even a Ph.D., despite the fact that they have no clue what I have been doing for all these years. Such total support from the Lovedays and the Sikes has been a cornerstone in my life, but especially I want to thank my sister Missi, the best one in the world, for always listening.

My most heartfelt thanks goes to John, whose love and confidence in me at the steepest point was the extra strength I needed to make it through. His faith in me has been so strong that even while half way around the world his support has been there when I needed it. For his warmth and companionship I have treasured John's friendship above all others - the best part is I get to keep him! 


\section{Contents}

1 Introduction $\quad 11$

1.1 The need for a new paleotemperature estimator . . . . . . . . . . . 11

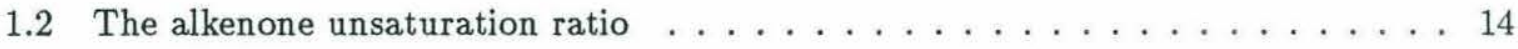

1.3 Application of $\mathrm{U}_{37}^{k}$ to paleothermometry . . . . . . . . . . . . 19

2 Core-Top Calibrations and Methodology Considerations $\quad 21$

2.1 Introduction . . . . . . . . . . . . . . . . . 21

2.2 Methods . . . . . . . . . . . . . . . . . . . . . 22

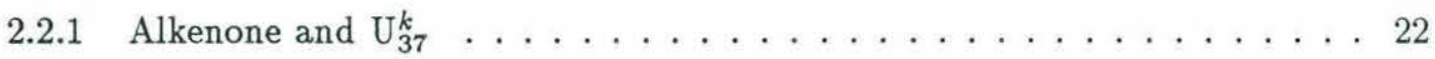

2.2 .2 Dissolution Experiments . . . . . . . . . . . . . . . 23

2.2.3 Calcium Carbonate Content of Sediments . . . . . . . . . . . . 25

2.3 Results and Discussion . . . . . . . . . . . . . . . . . 25

2.3.1 Sampling and Storage Artifacts . . . . . . . . . . . . . 25

2.3.2 Investigation of Dissolution Effects . . . . . . . . . . 28

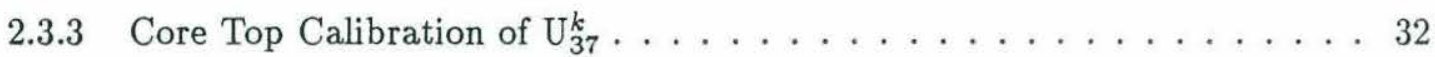

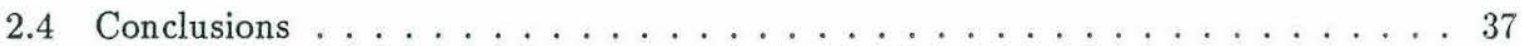

3 Past sea surface temperatures of the Equatorial Atlantic 39

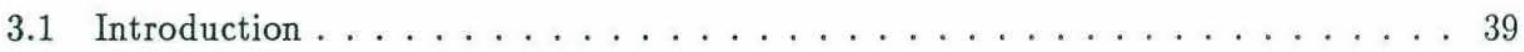

3.2 Methods . . . . . . . . . . . . . . . . . . . 42

3.2.1 Geochemical Techniques . . . . . . . . . . . . . . . 42

3.2.2 Foraminiferal Assemblage Temperature Estimates . . . . . . . . . . . 44

3.3 Results . . . . . . . . . . . . . . . . . . . . . . 45 
3.3 .1 Stratigraphy $\ldots \ldots \ldots \ldots \ldots \ldots \ldots \ldots \ldots \ldots \ldots$

3.3 .2 Oxygen Isotopes $\ldots \ldots \ldots \ldots \ldots \ldots \ldots \ldots \ldots \ldots$

3.3.3 Foraminiferal Assemblage Temperature Estimates . . . . . . . . . . . 49

3.3.4 Alkenone Unsaturation Ratios . . . . . . . . . . . . . . . 52

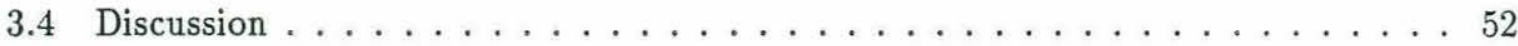

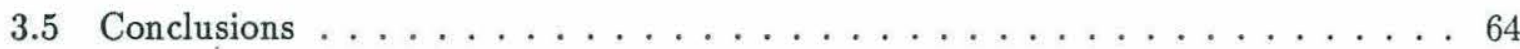

4 Sea surface temperature estimates of the Northeast Atlantic for the last half glacial cycle $\quad 66$

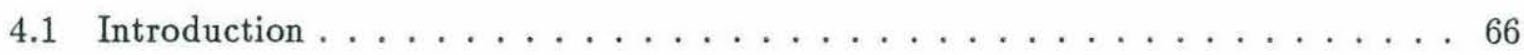

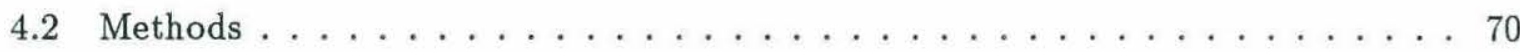

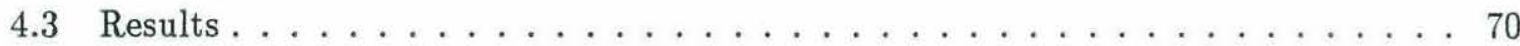

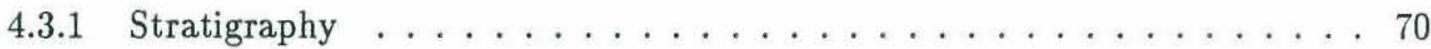

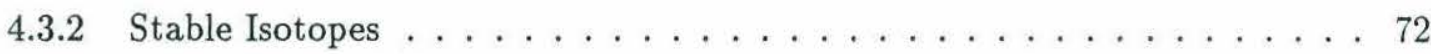

4.3.3 Foraminiferal Assemblage Temperature Estimates _ . . . . . . . . . 72

4.3.4 Alkenone Unsaturation Ratios . . . . . . . . . . . . . . . . 75

4.4 Discussion . . . . . . . . . . . . . . . . . 75

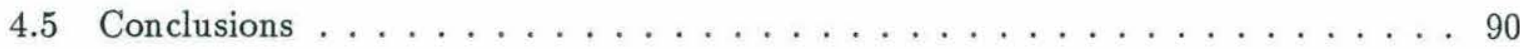

5 Summary 92

$\begin{array}{ll}\text { A Supplementary data for Chapter } 3 & 110\end{array}$

B Supplementary data for Chapter $4 \quad 119$ 


\section{List of Figures}

1-1 Temperature effects on $\delta^{18} \mathrm{O}$ in Equatorial Atlantic cores (after Mix and Ruddi-

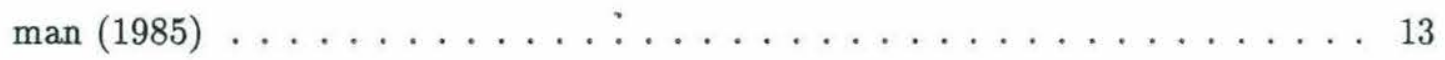

1-2 Structure and nomenclature of the $\mathrm{C}_{37}$ alkenones $\ldots \ldots \ldots$

2-1 Sample chromatograms of $\mathrm{C}_{37}$ alkenones . . . . . . . . . . . . . . . 24

$2-2$ Location of core-top samples . . . . . . . . . . . . . . . 26

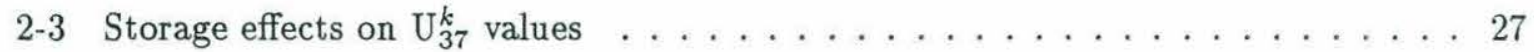

2-4 Effect of experimental $\mathrm{CaCO}_{3}$ dissolution on $\mathrm{U}_{37}^{k} \ldots \ldots \ldots$

$2-5$ Plot of $\mathrm{U}_{37}^{k}$ "accuracy" versus core depth . . . . . . . . . . . 33

2-6 Comparison of $U_{37}^{k}$ in sediments to results of Prahl and Wakeham (1987) . . . 34

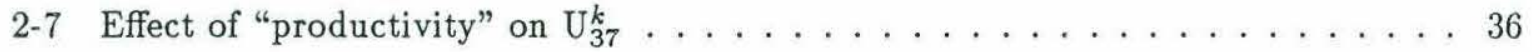

3-1 Thermocline control on foraminiferal assemblages, after McIntyre et al. (1989) . . 41

3-2 Location map of Equatorial Atlantic cores . . . . . . . . . . . . . . . . . 43

3-3 Stratigraphic control on core $12 \mathrm{PC} 51 \ldots \ldots \ldots \ldots$

3-4 $\mathrm{CaCO}_{3}$ results indicating loss of sediment from top of core $12 \mathrm{PC} 51 \ldots \ldots 8$

$3-5 \quad \delta^{18}$ Oof Globigerinoides sacculifer for core $12 \mathrm{PC} 51 \ldots \ldots$. . . . . . . . . . . 50

3-6 Modern analogue technique temperature estimates for core $12 \mathrm{PC} 51 \ldots \ldots 1$

3-7 Foraminiferal transfer function temperature estimates for core $12 \mathrm{PC} 51 \ldots \ldots 3$

$3-8 \quad \mathrm{U}_{37}^{k}$ temperature estimates for core $12 \mathrm{PC} 51 \ldots \ldots \ldots \ldots \ldots$

$3-9$ TOC and $\mathrm{C}_{37}$ alkenone concentrations for core $12 \mathrm{PC} 51 \ldots \ldots \ldots$

3-10 Temperature estimates for core $12 \mathrm{PC} 51 \ldots \ldots \ldots \ldots \ldots$

3-11 Comparison of $\mathrm{U}_{37}^{k}$ and modern analogue technique temperature estimates for

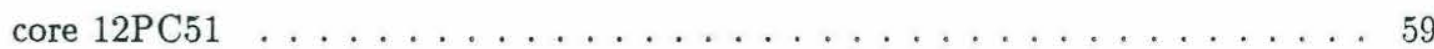


3-12 Comparison of $\mathrm{U}_{37}^{k}$ temperature estimates of core $12 \mathrm{PC} 51$ and M16415 . . . . 63

4-1 Location of cores in North Atlantic study . . . . . . . . . . . . . . . . 69

4-2 Stratigraphic control for core K51-29GGC . . . . . . . . . . . . . . . . 71

$4-3 \quad \delta^{18} \mathrm{O}$ results for core $29 \mathrm{GGC} \ldots \ldots \ldots \ldots \ldots \ldots \ldots \ldots \ldots$

4-4 Modern analogue technique SST estimates for core 29 GGC $\ldots \ldots \ldots \ldots$

$4-5 \quad \mathrm{U}_{37}^{k}$ temperature estimates for core $29 \mathrm{GGC} \ldots \ldots \ldots \ldots \ldots \ldots$

$4-6 \mathrm{C}_{37}$ alkenone concentrations for core $29 \mathrm{GGC} \ldots \ldots \ldots \ldots \ldots$

4-7 $\quad \delta^{18} \mathrm{O}$ and $N$. pachyderma $(s)$ abundances for core V23-81 . . . . . . . . . 80

$4-8$ Age - depth model for core 29 GGC $\ldots \ldots \ldots \ldots$. . . . . . . . . . 81

$4-9$ Temperature estimates for core 29 GGC $\ldots \ldots \ldots \ldots$

4-10 Comparison of $\mathrm{U}_{37}^{k}$ and analogue temperature estimates from core 29 GGC . . . 85 


\section{List of Tables}

2-1 Core-top calibration samples . . . . . . . . . . . . . . . 29

2-2 Results of $\mathrm{CaCO}_{3}$ dissolution experiment $\ldots \ldots \ldots \ldots \ldots$

3 -1 Primary numerical results for core $12 \mathrm{PC} 51 \ldots \ldots \ldots \ldots$

3 -2 stage 1 and 2 accumulation rates for core $12 \mathrm{PC} 51 \ldots \ldots \ldots \ldots$

$4-1$ Primary numerical results for core 29 GGC $\ldots \ldots \ldots \ldots$

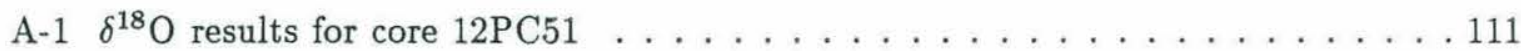

A-2 Faunal assemblage temperature estimates for core $12 \mathrm{PC} 51 \ldots \ldots 112$

A-3 Faunal counts for core 12PC51. . . . . . . . . . . . . . . 113

A-4 Faunal counts for core $12 \mathrm{PC} 51$, continued. . . . . . . . . . . . . 114

A-5 Faunal counts for core 12PC51, continued. . . . . . . . . . . . 115

A-6 Faunal counts for core 12 PC51, continued. . . . . . . . . . . . 116

A-7 Faunal counts for core 12 PC51, continued. . . . . . . . . . . . . 117

A-8 Faunal counts for core 12 PC51, continued. . . . . . . . . . . . 118

B-1 N. pachyderma (s) and total faunal abundances for core Knr51 29GGC . . . 120

B-2 Analogue SST estimates for core 29GGC . . . . . . . . . . . . . 121

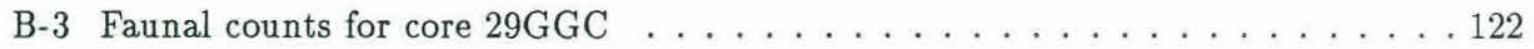

B-4 Faunal counts for core $29 \mathrm{GGC} \ldots \ldots \ldots \ldots$

B-5 Faunal counts for core 29GGC . . . . . . . . . . . . . . . . 124

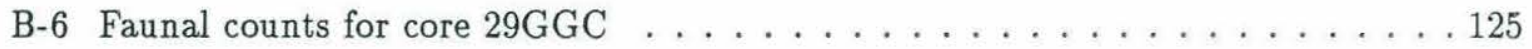




\section{Chapter 1}

\section{Introduction}

\subsection{The need for a new paleotemperature estimator}

Sea surface temperature (SST) is an extremely good and easily determined measure of modern climatic conditions. An understanding of paleo-SST is essential for understanding natural climatic change, while the ability of global atmospheric and oceanic circulation models to predict future climatic change on timescales of 100's to 1000's of years necessarily depends on reliable estimates of past climatic changes over comparable time scales. At present only two quantitative techniques are in use: faunal assemblages and oxygen isotopes. Each of these techniques has important limitations when used for paleo-thermometry, especially in the tropical and polar oceans where temperature changes are thought to be small.

The planktonic foraminiferal method of estimating past SST via the transfer function technique (Imbrie and Kipp, 1971) assumes faunas are related to a combination of oceanic parameters that relate linearly to SST. To be accurate this relationship must not change through time. Results of this method for the last glacial maximum indicate relatively small differences in global average SST, and warming in many low latitude areas (CLIMAP, 1981). These results are in contrast with land temperature estimates (based on pollen and tropical snow line depression, for example; Rind and Peteet,1985; their Table 1 and references therein) which indicate tropical temperatures must have been $5-6^{\circ} \mathrm{C}$ cooler at that time to agree with terrestrial data. Global circulation models indicate changes in atmospheric conditions, such as lapse rates, cannot account for the discrepancies between the two data sets (Webster and Streten, 1978; 
Hansen et al., 1984; Rind and Peteet, 1985).

Complications arise in using the faunal assemblage techniques when assemblages which have no modern analogues appear in the sediment record (Hutson, 1980). For example, during glacial times, equatorial locations contained "cool" assemblages which do not exist today, and paleotemperature estimates based on these assemblages are necessarily uncertain (Mix et al., 1986; Mix, 1987). Non-analogue assemblages may reflect not only temperature changes but subsurface changes in the upper ocean because the foraminifera on which assemblage estimates are based live at depths of up to $1000 \mathrm{~m}$ below the ocean surface (Fairbanks and Weibe, 1980). Individual species have preferred growth temperatures and may modify their depth or season of growth to follow that temperature (Fairbanks and Weibe, 1980; Fairbanks et al., 1980; Fairbanks et al., 1982). Therefore, transfer functions may over-estimate tropical temperature changes because they sense large thermocline effects rather than small SST changes (Mix, 1987).

At high latitudes and cold temperatures, foram faunas become monospecific, so below about $6^{\circ} \mathrm{C}$ SST cannot be estimated by foram transfer functions, leaving vast areas of high latitude ocean with no temperature estimations by this method (CLIMAP, 1976; 1981).

The oxygen isotope ratio preserved in a foraminifer's test is also a recorder of water temperature in the ocean. However, the potential for use of calcite formed in "equilibrium" with seawater is limited by the difficulty in accounting for large ice volume and (generally) smaller local signals (e.g. salinity) that affect the $\delta^{18} \mathrm{O}^{1}$ ratio in planktonic foriminifera. Previous estimates of ice volume effects on $\delta^{18} \mathrm{O}$ varied between $1.1^{\circ}$ oo (e.g. Bard et al., 1987) and $1.4^{\circ} \%$ (e.g. Imbrie et al., 1973). Work by Fairbanks (1989) indicates glacial to interglacial sea level change was $121 \mathrm{~m}$, which converts to $1.33^{\circ} \%$ oo at $0.11^{\circ}$ oo for each $10 \mathrm{~m}$ of sea level change (Fairbanks and Mathews, 1978), as the best estimate of the ice volume effect at this time.

If both the stable isotope and foram assemblage methods are proxies for SST they should agree in sign if not in magnitude. Mix and Ruddimann (1985) show that this is not always the case; in some Equatorial Atlantic sites $\delta^{18} \mathrm{O}$ values (when corrected for temperature changes

\footnotetext{
${ }^{1}$ The notation $\delta^{18} \mathrm{O}$ is defined as

$$
\delta^{18} O=\left(\frac{{ }^{18} \mathrm{O} /{ }^{16} O_{\text {sample }}}{{ }^{18} \mathrm{O} /{ }^{16} O_{\text {reference }}}-1\right) \times 1000
$$
}

and referred to the PDB standard in parts per mil $(\%)$. 


\section{V $15-168$}

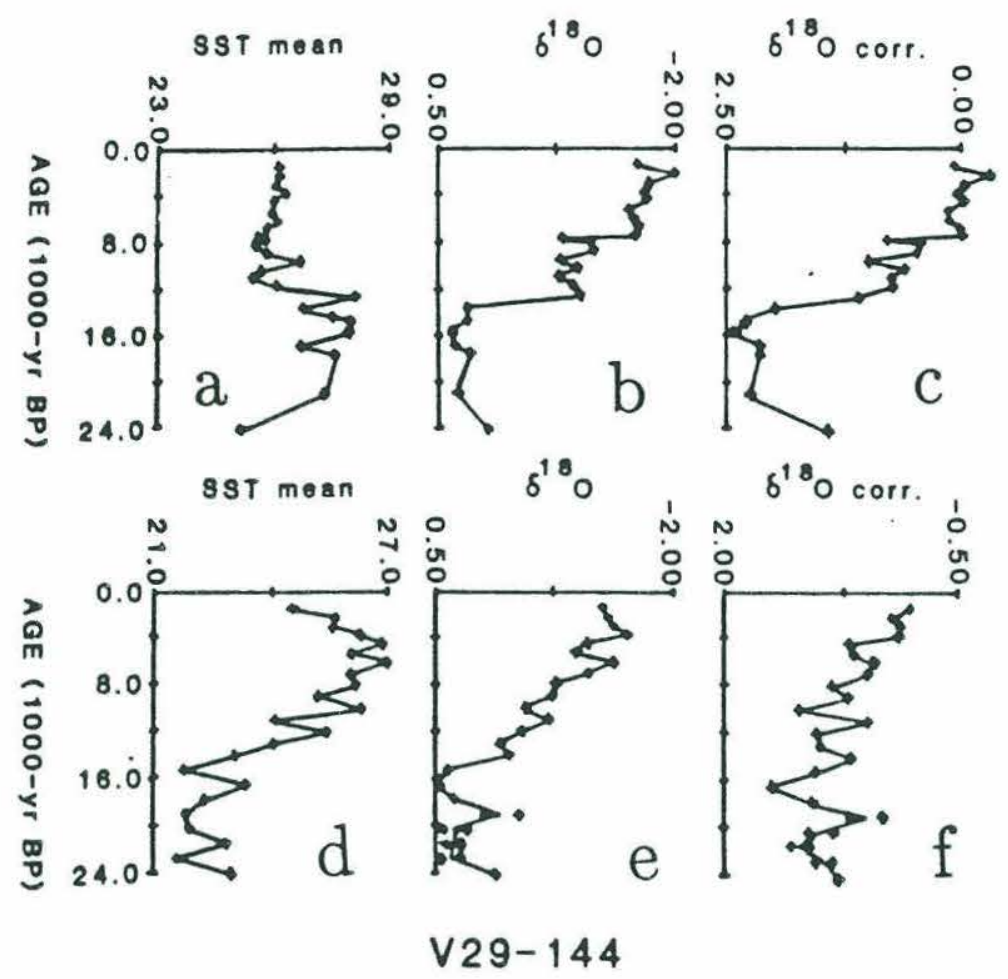

Figure 1-1: After Mix and Ruddiman (1985). Effects of temperature on $\delta^{18} \mathrm{O}$ records in Equatorial Atlantic cores V15-168 (top: $0^{\circ} 12^{\prime} \mathrm{N}, 39^{\circ} 54^{\prime} \mathrm{W}, 4219 \mathrm{~m}$ ) and V29-144 (bottom: $0^{\circ} 12^{\prime} \mathrm{S}, 6^{\circ} 03^{\prime} \mathrm{W}$, $2585 \mathrm{~m}$ ). Left (a \& d): mean sea surface temperature estimates based on planktonic foram assemblages converted to SST via transfer functions. Center (b \& e): oxygen isotope data measured on Globierinoides sacculifer. Right (c \& f): temperature corrected $\delta^{18} \mathrm{O}$ data. SST estimates "removed" from two similar $\delta^{18} \mathrm{O}$ curves results in two dissimilar ice volume records. When the $\delta^{18} \mathrm{O}(\mathrm{e})$ of core V29-144 is corrected for SST (d), the corrected $\delta^{18} \mathrm{O}$ record (f) indicates either there was very little change in the ice volume or, the SST change indicated by the assemblages is exagerated. This indicates dissagreement between the two methods and represents an extreme case in the data set of Mix and Ruddiman (1985).

with assemblage SST estimates) indicate no ice volume increase in the glaciation and in other locales SST "corrections" indicate a greatly exaggerated ice volume. The signal of one "paleotemperature" recorder cannot reasonably accomodate the other in this situation (Figure 1-1). Although a thorough re-evaluation of different faunal assemblage SST estimators showed them to be internally consistent (Prell, 1985), the fact that the transfer functions disagree with data from other marine and non-marine sources emphasizes that an independent marine based estimator is necessary.

In addition to these uncertainties, both planktonic foraminiferal assemblages (Adelseck, 
1977; Berger and Killingley, 1977) and $\delta^{18} \mathrm{O}$ of individual species (Bonneau et al., 1980) are subject to alteration by dissolution during sinking and after deposition. Studies have shown that dissolution shifts the foram assemblage towards a colder aspect by dissolving "warm" forams which have more fragile tests, an effect whose magnitude depends on the initial assemblage (Adelseck, 1977). Dissolution of foram tests appears to increase $\delta^{18} \mathrm{O}$ of some species up to $0.60^{\circ} \%$, equivalent to a $2-3^{\circ} \mathrm{C}$ cooling (Berger and Killingley, 1977; Bonneau et al., 1980). Dissolution effects in deep North Pacific cores are significant enough that CLIMAP (1981) used siliceous microfossils for paleotemperature estimates in those locations. Thus, analysis of a partially dissolved sample by either $\delta^{18} \mathrm{O}$ or transfer function methods can produce a signal that is shifted to colder values by some variable and unknown amount.

\subsection{The alkenone unsaturation ratio}

A new paleotemperature estimation technique is needed to address situations where established methods give equivocal results due to the complicating effects of ice volume, ecological niche interpretation, or post-depositional diagenetic changes. Alkenone unsaturation ratios show promise as such a new technique. Marlowe et al. (1984) and Brassell et al. (1986b) describe a particular class of lipids, namely long chain unsaturated ketones (the $n-C_{37}-C_{39}$ ketones of hexatriancontadienic acid; $\mathrm{C}_{37: 2}$ ), with promise for paleotemperature estimation. This unsaturation level, $\mathrm{U}_{37}^{k}$, is defined as the ratio of ketone concentrations as follows (Brassell et al., 1986b):

$$
U_{37}^{k}=\frac{\left[C_{37: 2}\right]-\left[C_{37: 4}\right]}{\left[C_{37: 2}\right]+\left[C_{37: 3}\right]+\left[C_{37: 4}\right]}
$$

These compounds are useful for quantitative temperature estimates because $\mathrm{U}_{37}^{k}$ is not the absolute amount of the alkenones; it is instead the relative amounts of these compounds expressed at a ratio. Although the total abundance of these compounds is subject to as many varying sources and sinks as total sedimentary organic carbon, it appears that the alkenones are chemically similar enough that there is no difference in their preservation in the sediment record (Prahl et al., 1989). Thus, although the total level of alkenones may be of questionable value as a tracer (Marlowe, 1984; Prahl et al., 1989), the unsaturation ratio in sediments appears related to $\delta^{18} \mathrm{O}$ records for at least the last few glacial cycles (Brassell et al., 1986 

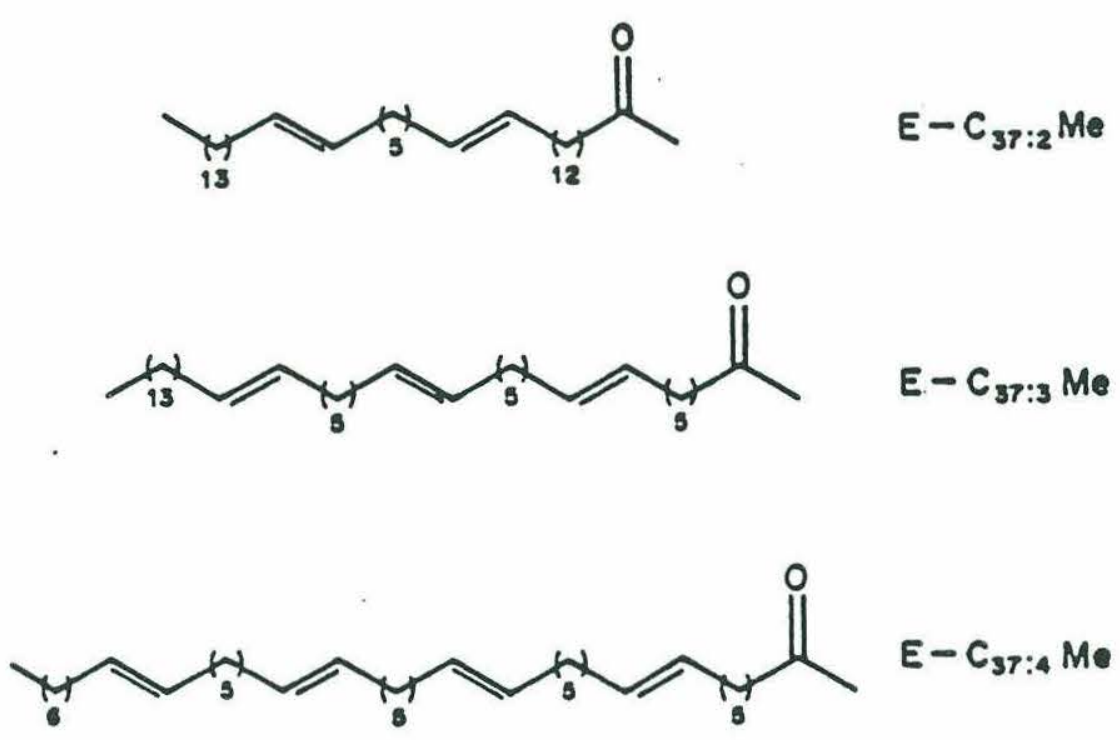

Nomenclature of the $\mathrm{U}_{37}^{k}$ alkenones

Formula Abbreviation Name number

I $\quad \mathrm{C}_{37: 2} \mathrm{Me}$ heptatriaconta-15,22-diene-2-one

II $\quad \mathrm{C}_{37: 3} \mathrm{Me}$ heptatriaconta-8,15,22-triene-2-one

III $\quad \mathrm{C}_{37: 4} \mathrm{Me}$ heptatriaconta-8,15,22,29-tetraene-2-one

Figure 1-2: Structure of the long chain alkenones of the Prymnesiophyceae, illustrating the location of the double bonds (after Rechka and Maxwell, 1987). Note the double bonds are trans not cis configuration.

a\&b). Of importance to the use of these alkenones in paleotemperature work are the results of Marlowe (1984) and Brassell et al. (1986b), which indicate these compounds must be resistant to breakdown in sediments because they are found in sediments as old as Cretaceous. This resistance may in part be due to the trans-configuration of the double bonds in the side chain, which is uncommon in biosynthesized compounds (Figure 1-2; Rechka and Maxwell, 1987).

The linear dependance of $\mathrm{U}_{37}^{k}$ on SST has been demonstrated by laboratory culture experiments on Emiliania huxleyi and analyses of water column particulate material (from sediment traps set at depths of 50-5028 m; Prahl and Wakeham, 1987). This relationship in laboratory studies is $0.040 \pm 0.02 \mathrm{U}_{37}^{k}$ units per ${ }^{\circ} \mathrm{C}$ and approximately $0.033 \mathrm{U}_{37}^{k}$ units for field samples 
across the temperature range of $8-25^{\circ} \mathrm{C}$ (Prahl and Wakeham, 1987). This method, accurate to $\pm 0.5^{\circ} \mathrm{C}$ in laboratory studies, should be about as precise as CLIMAP paleotemperature estimates $\left(\sim \pm 2^{\circ} \mathrm{C}\right)$ in sediments given the scatter in Prahl and Wakeham's (1987) field data. Prahl et al. (1988) defined the parameter $\mathrm{U}_{37}^{k^{\prime}}$, which eliminates $\mathrm{C}_{37: 4}$ alkenones from the $\mathrm{U}_{37}^{k}$ equation, because this improves the linearity of the correlation in culture studies below $15^{\circ} \mathrm{C}$. $\mathrm{C}_{37: 4}$ alkenones are not present except at the coldest temperatures (below about $4^{\circ} \mathrm{C}$ ) and are rarely encountered in sediment samples analyzed to date, therefore $\mathrm{U}_{37}^{k}$ and $\mathrm{U}_{37}^{k^{\prime}}$ are essentially the same in most sediment analyses.

Production of the $\mathrm{C}_{37}$ alkenones is believed to be restricted to Prymnesiophyceae algae (Volkman et al., 1980 a\&b; Marlowe, 1984; Marlowe et al., 1984 a\&b). A very limited number of Prymensiophyceae are known to produce the $\mathrm{C}_{37}$ alkenones, to date only Chrysotila lamellosa, Isochrysis galbana, two unidentified species of Isochrysis, and Emiliania huxleyi are known to syntehsize $\mathrm{C}_{37}$ alkenones (Marlowe et al., 1984). Of these several species of Prymnesiophyceae algae which are known to produce the $\mathrm{U}_{37}^{k}$ alkenones, E. huxleyi is the only known coccolithophore. The others are a little studied group considered diffucult to identify (Marlowe et al., 1984). There is some indication the Isochrysis species may show a different response to temperature in their unsaturation ratios from E. huxleyi (Marlowe et al., $1984 \mathrm{a} \& \mathrm{~b}$ ). However, these other species are known only from coastal and fresh water environments, and their importance in coastal phytoplankton populations is unknown (Marlowe, 1984; Marlowe et al., 1984). Work of Okada and McIntyre (1979) shows E. huxleyi to be between $60-80 \%$ of the annual standing crop of coccolithophorids in the North Atlantic and it is the most abundant and cosmoplitan species in the open ocean (Raymont, 1980). The relative unimportance of other species' input on the $\mathrm{U}_{37}^{k}$ signal in the open ocean or alternately, their similarity in temperature response, is borne out by the excellent agreement of $U_{37}^{k}$ field data and culture results (Prahl and Wakeham, 1987).

One potential advantage of $\mathrm{U}_{37}^{k}$ as a temperature indicator over faunal assemblages is that it should reflect the temperatures of only the surface-most levels of the mixed layer. As phytoplankton, the Prymnesiophyceae are restricted to the photic zone (about $200 \mathrm{~m}$ or less; Okada and Honjo, 1973; Honjo and Okada, 1974). In subtropical to polar waters the relationship of the bulk of the coccolithophorid portion of the phytoplankton to surface-most waters is straight 
forward. At high latitudes, coccolithophores can be as much as $10^{2}$ to $10^{5}$ times more abundant in the top $10 \mathrm{~m}$ than at $100 \mathrm{~m}$ depth (Honjo and Okada, 1974; Okada and McIntyre, 1979) and concentrations in surface waters çan be more than 1 million cells per liter during blooms (Berge, 1962; Milliman, 1980, Mitchell-Innes and Winter, 1987). With decreasing latitude, increasing numbers of E. huxleyi and other species are found deeper, but their abundance at $100 \mathrm{~m}$ is never more than $2 / 3$ that of the surface levels (Honjo and Okada, 1974; Okada and McIntyre, 1979). Although increasing numbers of phytoplankton are found deeper in tropical waters, these waters have a permanent and relatively deep thermocline even in zones of equatorial upwelling (Wyrtki and Eldin, 1982). Surface mixed layer profiles at the equator in the Atlantic indicate temperatures at $90 \mathrm{~m}$ are usually less than $1^{\circ} \mathrm{C}$ lower and are rarely more than $2^{\circ} \mathrm{C}$ lower than surface waters (Fuglister, 1960). These data indicate $U_{37}^{k}$ temperature estimates which are based on Prymnesiophyceae should reflect the temperatures of only the upper most layers of the surface mixed layer in most situations.

In some low latitude areas the thermocline is within the euphotic zone (Herbland and Voituriez, 1979; Curry et al., 1983; Herbland et al., 1987; Oudot and Morin, 1987). This occurs especially on the eastern end of equatorial upwelling areas that impinge on low latitude coastal upwelling areas (Wyrtki, 1981; Herbland et al., 1987; Oudot and Morin, 1987), and coastal upwelling zones (e.g. Peru). In these areas the chlorophyll maximum and nitracline are close to or within the thermocline (Herbland and Voituriez, 1979; Herbland et al., 1987; Oudot and Morin, 1987). Although the chlorophyll maximum is often a biomass maximum (Herbland and Voituriez, 1979), the correlation with maximum primary productivity is not as strong, especially in coastal waters (Cullen and Epply, 1981). In the tropical Atlantic where the thermocline is deeper than $60 \mathrm{~m}$ the nitracline, chlorophyll maximum, and primary productivity maximum are consistently shallower than the thermal gradient maximum (Herbland and Voituriez, 1979). In the central equatorial Atlantic, the primary productivity maximum is in the top $30 \mathrm{~m}$, about $30 \mathrm{~m}$ shallower than the chlorophyll maximum (Bauerfiend, 1987). Thus, although a substantial portion of the phytoplankton may be found deeper at low latitudes, it appears the bulk of the primary productivity may be occuring at shallow depths.

Nannoplankton ( $\leq 20 \mu \mathrm{m}$, which includes the Prymnesiophytes) are $90 \%$ of the primary producers in equatorial upwelling zones, and are about $60 \%$ of more coastal populations in 
equatorial areas (Herbland et al., 1987). Nannoplankton are known to be a substantial portion of phytoplankton in upwelling zones as well (Mitchell-Innis and Winter, 1987), hence their ability to provide a $\mathrm{U}_{37}^{k}$ record in such intense upwelling areas as Peru (Farrington et al., 1988).

Changing the unsaturation levels of the $\mathrm{C}_{37}$ ketones with temperature are believed to be a method for membrane regulation in the phytoplankton (Marlowe, 1984), though this has not been proven. An important result of the studies of Prahl et al. (1988) is that cultures of E. huxleyi show an immediate response in unsaturation levels with a change in temperature. This ensures that $\mathrm{U}_{37}^{k}$ values provide a temperature signal for the actual time of growth of the phytoplankton, rather than some memory effect of a dormant period. The growth temperature does not affect the proportion of alkenones per cell, although cells grown at warmer temperatures are smaller. Varying the growth conditions (light and nutrients) is known to alter the temperature effect on $\delta^{18} \mathrm{O}$ calcified by coccolithophores (Dudley and Goodney, 1979), however, culture work on E. huxleyi by Marlowe (1984), indicates that sampling at different growth stages and growing cultures under different nutrient regiemes does not affect the relative concentrations of the $\mathrm{C}_{37}$ alkenones in the organisms.

An important assumption which must be made in calculating paleo-SST estimates, whether they be based on foraminiferal assemblages, isotopes, or $U_{37}^{k}$, is the season that the estimate represents. Most logically this would be the season of growth of the organism on which the technique is based. At high latitudes $\left(40-60^{\circ} \mathrm{N}\right)$ in the North Atlantic, maximum abundances of E. huxleyi occur in the summer. Major blooms that last as little as 3-4 weeks are known to occur in early June (Milliman, 1980; Holligan et al., 1983) and August (Okada and McIntyre, 1979). At mid-latitudes, maximum coccolith abundances occur in early autumn, and in the late fall or early winter, whereas in tropical latitudes, they are most abundant in late winter to early spring (Okada and McIntyre, 1979). Based on these data, it has been assumed for all samples in this study, that coccolithophorids reach maximum abundance in summer in high lattitudes, summer to autumn in mid latitudes, and in fall to winter in tropical locations (Smayda, 1980). Thus, as a first approximation, it is assumed for all locations that the $\mathrm{U}_{37}^{k}$ ratio in the sediment record reflects warm season SST. 


\subsection{Application of $\mathrm{U}_{37}^{k}$ to paleothermometry}

Since the initial work of Brassell et al. (1986 a\&b), published work designed to refine the use of the $\mathrm{U}_{37}^{k}$ ratio as a quantitative paleo-thermometer has been restricted to the culture and water-column studies by Prahl and Wakeham (1987) and Prahl et al. (1988), and the study of diagenetic effects by Prahl et al. (1989a). Although in inital observations $\mathrm{U}_{37}^{k}$ appears to record accurately coastal ocean SST in recent sediments off Peru (Farrington et al., 1988) and during the last glacial maximum (Prahl and Wakeham, 1987; Prahl et al., 1988), there is some indication that the alkenone based method may be inaccurate in the Gulf of Mexico in the last glaciation. The $\mathrm{U}_{37}^{k}$ results of Jasper and Gagosian (1989) show an $8^{\circ} \mathrm{C}$ drop, while $\delta^{18} \mathrm{O}$ constraints imply the maximum change in temperature could not have been more than $2^{\circ} \mathrm{C}$. Jasper and Gagosian postulate that this discrepancy may be due to a change in flora from pelagic to neritic with the extreme change in enviroment there, but this is difficult to assess before more quantitative tests are conducted on the $U_{37}^{k}$ of alkenones extracted from sediments. Though these studies, with reservations, have used Prahl and Wakeham's (1987) conversion equation in sediments, no study has shown that use of the calibration based on water column samples is accurate or valid in sediments. Nor has any study attempted to assess the accuracy of $\mathrm{U}_{37}^{k}$ as an SST indicator back in time by comparing it quantitatively to established SST indicators in the sediment record.

The objective of this study has been to develop the $\mathrm{U}_{37}^{k}$ method for quantitative use in sediments and then to apply the method down core at two climatically distinct locations to assess its accuracy in the late Quaternary. The results of the study fall into two categories: development and application. Refinement of the method for quantitative use in sediments is the topic of Chapter 2. The possible effects that the dissolution of carbonates may have on $\mathrm{U}_{37}^{k}$, and the possible artifacts due to sampling and storage treatment, are addressed and appear to have little to no effect on the temperature signal preserved in the sediment. A calibration of the $\mathrm{U}_{37}^{k}$ in sediments to overlying SST provides a "thermometer" which is then applied to two different sites

in chapters 3 and 4 . In both downcore applications, $\mathrm{U}_{37}^{k}$ temperature estimates are compared to temperature estimates derived from $\delta^{18} \mathrm{O}$ of foraminifera tests, and foraminiferal assemblage SST estimations. Chapter 3 examines the SST history of the Equatorial Atlantic over the last 
half glacial cycle. $\mathrm{U}_{37}^{k}$ temperature estimates indicate only half the glacial cooling that the other methods indicate. The examination of SST from the high latitude North Atlantic in Chapter 4 demonstrates that $\mathrm{U}_{37}^{k}$ successfully records the major shift in SST there between the glacial and interglacial climatic regimes while indicating relatively cooler SST in the deglaciation than faunal estimates. In both locations, $U_{37}^{k}$ estimates do not exactly follow those of the other methods, allowing insight into other effects controlling SST estimates, if $\mathrm{U}_{37}^{k}$ estimates are correct. 


\section{Chapter 2}

\section{Core-Top Calibrations and}

\section{Methodology Considerations}

\subsection{Introduction}

The $\mathrm{C}_{37}$ alkenones were first described as novel compounds and biomarkers by Volkman et al. (1980a). Marlowe (1984) established the temperature dependence of their unsaturation, and the work of Brassell et al. (1986 a\&b), defined the parameter $\mathrm{U}_{37}^{k}$ and showed it to vary downcore with other climatic indicators. The first quantitative work designed to refine the $\mathrm{U}_{37}^{k}$ ratio for use as a paleo-thermometer was the culture and water-column studies by Prahl and Wakeham (1987) and Prahl et al. (1988), which established that $\mathrm{U}_{37}^{k}$ varies linearly with temperature. That work opened the door for use of $\mathrm{U}_{37}^{k}$ as a paleo-thermometer. Work by Prahl et al. (1989a) in the sub-tropical Atlantic assessed the effects of degradation of the alkenones under varying redox conditions which indicated that temperatures recorded by the alkenones are not affected by early sedimentary diagenesis.

These previous studies indicate that the alkenones accurately record water temperature at the time of biosynthesis, and that normal sedimentation processes do not change the $\mathrm{U}_{37}^{k}$ record of a given sediment package after deposition. However, in order to apply the $\mathrm{U}_{37}^{k}$ method as a reliable, quantitative estimator of paleo-SST from marine sediments, the method must be calibrated for sediment-derived alkenones. $\mathrm{U}_{37}^{k}$ would be particularly useful if it could be established that it is not affected by the conditions that dissolve calcium carbonate. Dissolution 
of $\mathrm{CaCO}_{3}$ makes methods that rely on carbonate tests, such as $\delta^{18} \mathrm{O}$ and foram assemblages, unreliable. $\mathrm{U}_{37}^{k}$ would also be more widely applicable if the analyses could be performed on the average geological core, which is handled differently from typical samples taken for organic geochemical analyses. Because the $\mathrm{U}_{37}^{k}$ ratio appears so stable (Prahl et al., 1989a), it is easy to assume that sample handling might not affect $U_{37}^{k}$. However, since handling is known to be an important factor for many organic compounds that are more labile, the effects on alkenones due to core sampling, storage and handling must be tested before they can be discounted.

This chapter presents the results of three investigations designed to refine the $U_{37}^{k}$ method for rigorous application to paleotemperature investigations in the sediment record. These are: sampling and storage effects on $\mathrm{U}_{37}^{k}$, effects of dissolution of carbonates on $\mathrm{U}_{37}^{k}$, and calibration of $U_{37}^{k}$ in core-top sediments.

\subsection{Methods}

\subsubsection{Alkenone and $\mathrm{U}_{37}^{k}$}

In this study, alkenones were recovered from surface sediments and analyzed by techniques based on those of Farrington et al. (1988). Approximately $10 \mathrm{~g}$ of wet sediment (or more; up to $30 \mathrm{~g}$ for organic poor sediments) were weighed into $50 \mathrm{ml}$ centrifuge tubes with known amounts of internal standards $\left(\mathrm{C}_{19}\right.$-one) added for later determination of percent recovery. Unbound lipids were extracted using successively less polar solvent mixtures composed of isopropanol, $\mathrm{MeOH}_{-} \mathrm{CHCl}_{3}(1: 1)$, and $\mathrm{MeOH}-\mathrm{CHCl}_{3}$ (1:3) by sonication for 10 minutes with each solvent using a Tekmar sonic disrupter probe inserted into the centrifuge tube. After each extraction the samples were centrifuged, the supernatent decanted, and the extracts combined. Neutral lipids were partitioned by combining with an aqueous $\mathrm{NaCl}$ solution in a separatory funnel, shaking and drawing off the chloroform layer. This was repeated twice with an additional $25 \mathrm{ml}$ of chloroform and the resultant extracts were concentrated by evaporating to near dryness.

Sample extracts were separated into lipid classes using column chromatography. A Cu/silica gel column, consisting of activated copper and 5\% deactivated silica gel (BioRad-BioSil, 100200 mesh) was wet packed in hexane. Fractionation was accomplished by loading the sample extract dissolved in hexane onto the column and eluting sequentially with hexane, hexane- 
toluene (3:1), hexane-toluene (1:1), hexane-ethylacetate (95:5), hexane-ethylacetate (90:10), hexane-ethylacetate (85:15), and then flushing sequentially with ethylacetate and methanol. Fractions 5 and 6 (hexane-ethylacetate $90: 10$ and 85:15) contained the alkenones and were collected and analysed together. All fractions were then evaporated to near dryness, and brought up in hexane for GC analyses. The alkenone fractions were analyzed by high resolution glass capillary chromatography on a J\&W Scientific Durabond DB-5, 30 m fused silica capillary column mounted in a Carlo Erba 4160 gas chromatograph equipped with a flame ionization detector. Samples were injected on-column at $100^{\circ} \mathrm{C}$ and run at $5^{\circ} \mathrm{C} / \mathrm{min}$ to $320^{\circ} \mathrm{C}$ with hydrogen as a carrier gas. Data were collected and processed using VG Laboratories Multichrom software and quantitation was through internal response factors, based on an internal quantitation standard added prior to injection. $U_{37}^{k}$ values were calculated from peak areas on GC traces using the $U_{37}^{k^{\prime}}$ working formula established by Prahl and Wakeham (1987). Figure 2-1 shows some example partial chromatograms. With these techniques analytical precision based on the multiple extraction, processing and injection of duplicates of the same sediment sample is $\pm 0.017 \mathrm{U}_{37}^{k}$ units (equal to $0.5^{\circ} \mathrm{C}$ ).

For final compound identification, representative samples from areas where previous GCMS confirmation had not been reported, were analyzed by gas chromatography/mass spectrometry (GCMS). Electron impact mass spectrometry was carried out using a Finnigan 4510 quadrapole mass spectrometer interfaced with a Carlo Erba 4160 GC using helium as a carrier gas. Mass spectral data were collected and processed on a Data General 3/12 equipped with the Incoss Data system. Positive identification of the $\mathrm{C}_{37}$ alkenones were based on comparison with mass spectra in Marlowe (1984) and de Leeuw et al. (1980).

\subsubsection{Dissolution Experiments}

Controlled dissolution experiments of $\mathrm{CaCO}_{3}$ were conducted in the laboratory to test the effects on alkenone ratios of acid conditions that destroy $\mathrm{CaCO}_{3}$. Batch experiments of quadruplicate analyses for each dissolution condition ( 2 used for alkenone analyses and 2 for $\mathrm{CaCO}_{3}$ analyses) were performed in $50 \mathrm{ml}$ centrifuge tubes on 10-20 g of sediment. Identical sample weights were used for each desired dissolution level. First, $5-10 \mathrm{ml}$ of water was added to the sediment. Then an amount of concentrated $\mathrm{HCl}$, calculated to give the desired degree of dissolution, was 

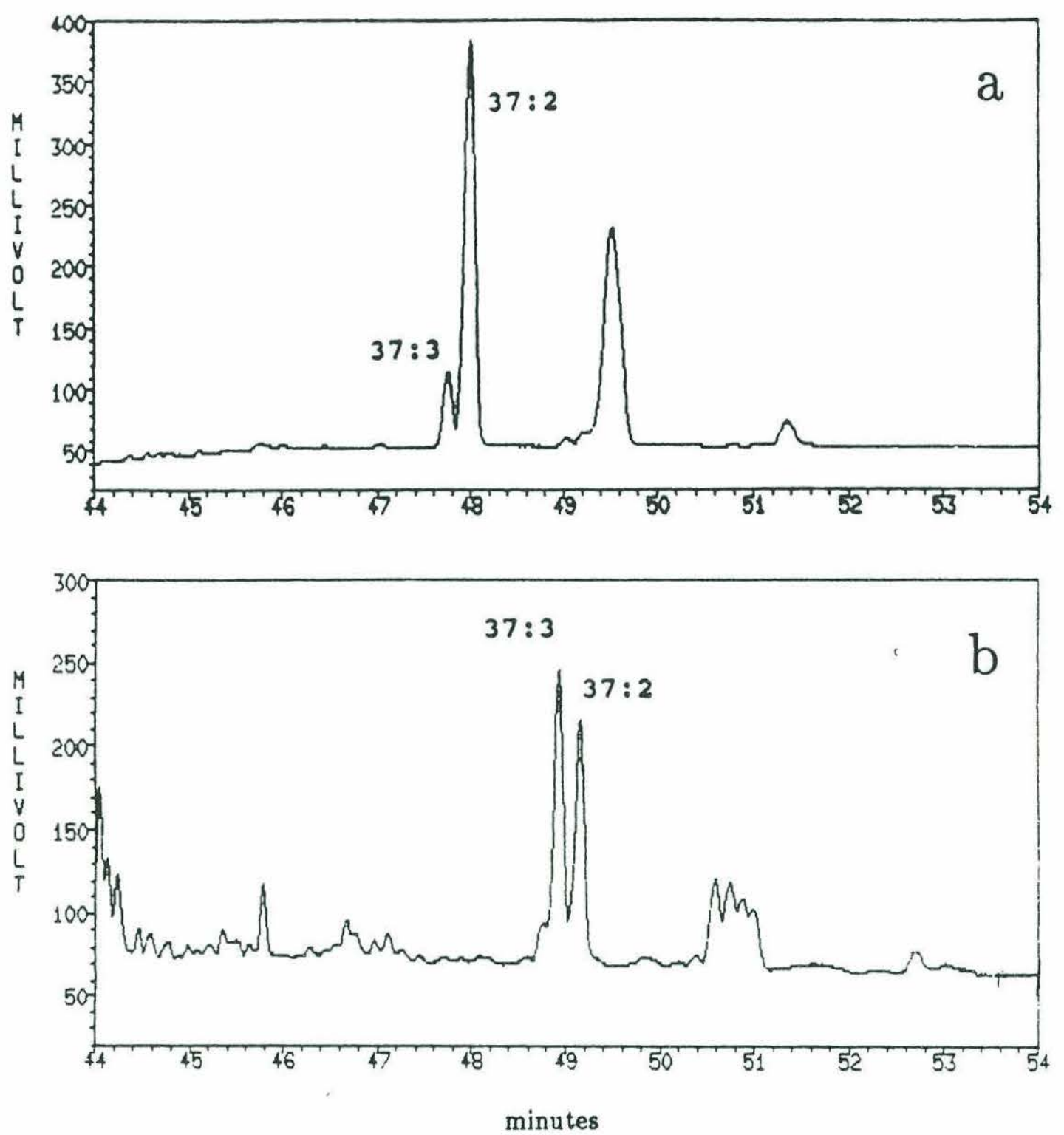

Figure 2-1: Partial chromatograms illustrating cool and warm samples. a). Sample 14Gyre86 12PC51 $20-22 \mathrm{~cm}, \mathrm{U}_{37}^{k}=0.862, \mathrm{~T}^{\circ} \mathrm{C}=24.8$. b). Sample Knr51 29GGC $140-141 \mathrm{~cm}, \mathrm{U}_{37}^{k}=0.468, \mathrm{~T}^{\circ} \mathrm{C}=$ 12.9. Differences in retention time are due to normal changes in the column which occur over time. Changes also occur when the column is shortened to maintain the quality of the chromatography, and there are frequently differences in retention times between columns. These two chromatograms were run approximately three months apart. 
added dropwise to the solution, stirring between drops until the reaction stopped. The samples were allowed to sit overnight, decanted, and subsequently analyzed for alkenones and percent calcium carbonate.

\subsubsection{Calcium Carbonate Content of Sediments}

Calcium carbonate carbonate was measured using a differential pressure technique based on that of Jones and Kaiteris (1983). Samples were crushed and dried before weighing out 350$400 \mu \mathrm{g} \pm 0.02$ of sediment and loading into the reaction chamber. Samples were placed into the bottom of the reaction chamber and $3 \mathrm{ml}$ of concentrated $\mathrm{H}_{3} \mathrm{PO}_{4}$ was placed in the side arm of the reaction flask. The reaction chamber was closed and evacuated, then the acid was tipped out of the side arm and the reaction was allowed to proceed for $1.5 \mathrm{hrs}$, agitating every 20 mins. The pressure of the evolved gas was measured, and the $\mathrm{CaCO}_{3}$ content was calculated from the volume of $\mathrm{CO}_{2}$ produced. Results obtained with this method are accurate to $\pm 0.5 \%$.

\subsection{Results and Discussion}

\subsubsection{Sampling and Storage Artifacts}

In the initial $\mathrm{U}_{37}^{k}$ analyses in sediments by I. Marlowe (Brassell et al., 1986a; G. Eglinton, pers. comm., 1986) there appeared to be no effect on $\mathrm{U}_{37}^{k}$ from core storage in " $\mathrm{D}$ " tubes at room temperature. However, there were no samples of fresh or frozen sediment with which to make a comparison. The methods used to sample and store sediments for organic geochemical analyses vary dramatically from those in standard practice for cores taken for use in geological studies. When sampling for lipid analyses solvent-rinsed, non-plastic utensils and containers are used. Collected samples are frozen immediately and kept frozen until analyzed. All these measures are taken to prevent contamination and degradation of the organic material. Because of the greater ease of storing cores in plastic liners at room temperature, and the vast number of cores already collected and stored this way, it would be desirable to use samples from these cores for $\mathrm{U}_{37}^{k}$ analyses. The alkenones on which $\mathrm{U}_{37}^{k}$ is based are sufficiently different from the compounds released by the degradation of plastics or common laboratory components, that interference by laboratory or analytical procedural contaminants is not common if reasonable precautions and 


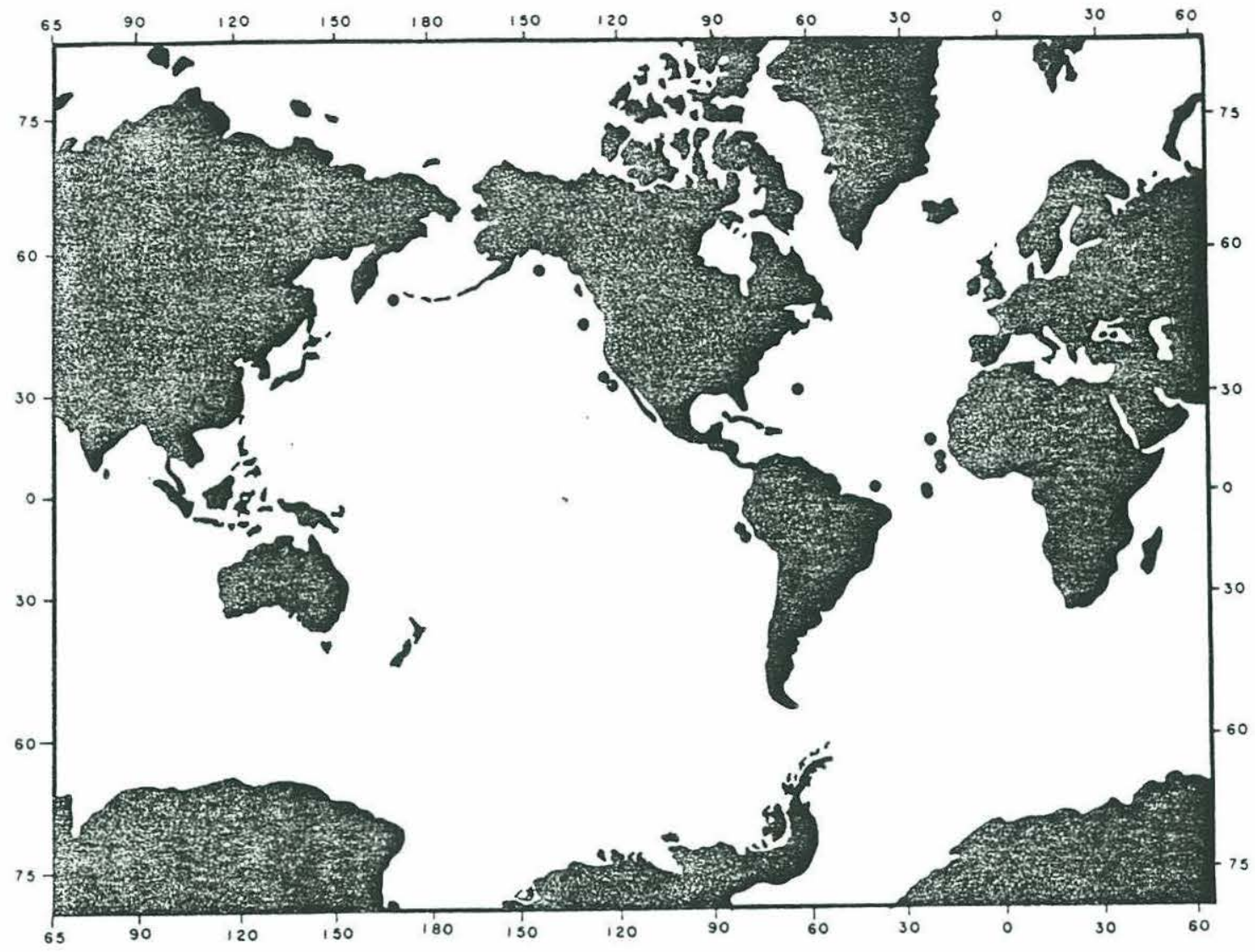

Figure 2-2: Location of core-top samples taken world-wide for both the sample storages effects study and the calibration study.

high resolution GC and GCMS are used in the analyses. However, the question of whether the alkenones themselves degrade must still be addressed.

Early diagenesis and remineralization of labile organic matter in general, and specific labile organic compounds in particular, occurs rapidly (within days to a few years) under most depositional conditions followed by much slower, longer term biotransformation and remineralization in diagenesis (Berner 1980, Romankevich 1984). Obviously, it is impossible to go back and simulate decades of frozen and unfrozen storage for sediment samples of interest. Thus, it seems reasonable as a first step to investigate storage effects on $U_{37}^{k}$ over a several year time span. Accordingly, ten pairs of samples taken from widely varying locations (Figure 2-2; Table 2-1), one stored at room temperature, the other frozen upon sampling and kept frozen until analysis, were analysed for $U_{37}^{k}$ (Figure 2-3). The oldest of these pairs (Knr-110BC84) was 4 years at 


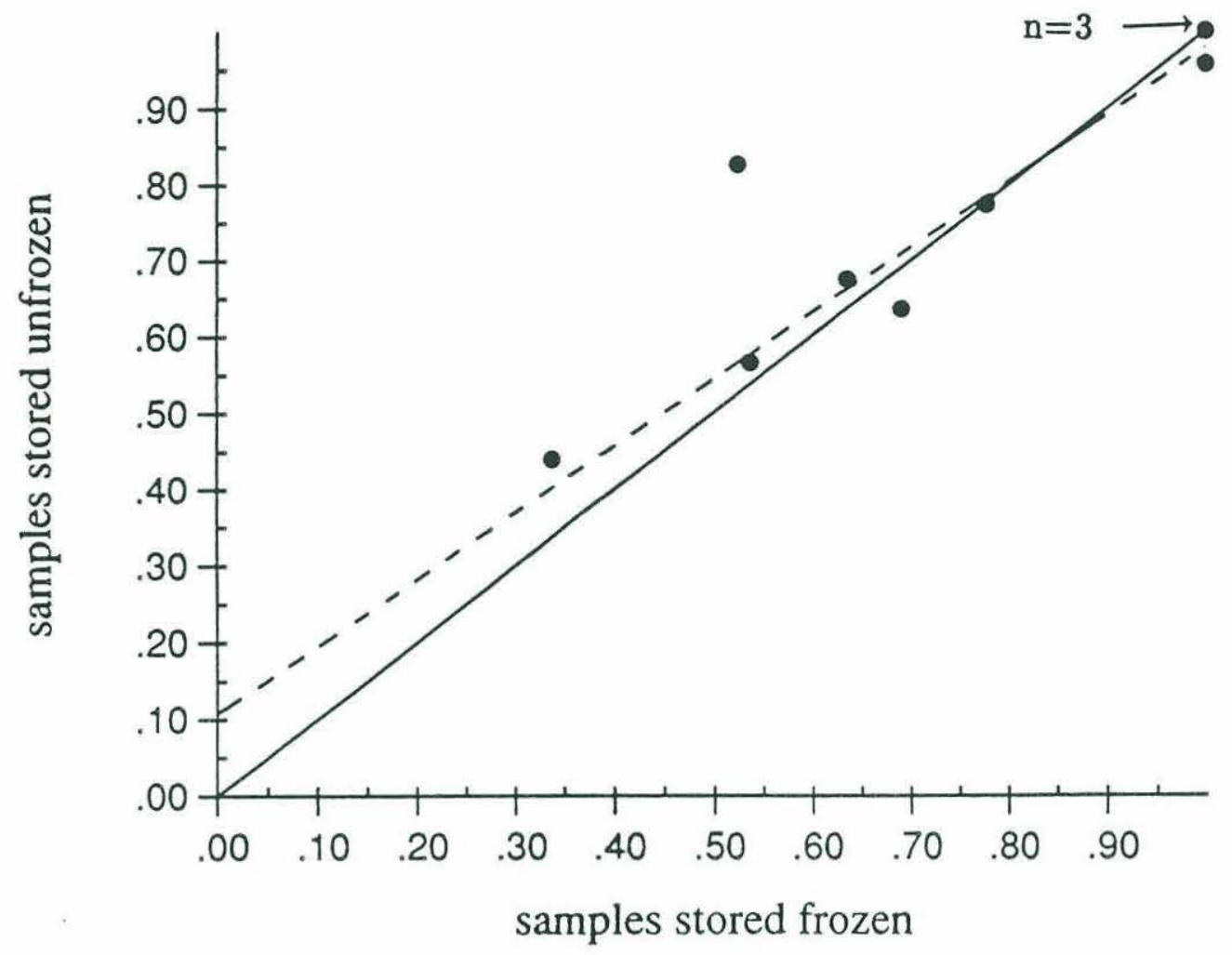

Figure 2-3: $\quad U_{37}^{k}$ values for frozen versus unfrosen pairs of samples. Solid line is that along which pairs with identical $\mathrm{U}_{37}^{k}$ values would lie, dotted line is the actual regression for the data (slope of 0.871 ), not including the out-lying sample. The maximum difference between the ideal and actual regression for these data is $.108 \mathrm{U}_{37}^{k}$ units $\left(2.5^{\circ} \mathrm{C}\right)$ to warmer, at coldest temperatures. For the point indicated, three sample pairs had identical values.

the time of analysis, the youngest (RNDB-24GGC), 2 months.

Based on these analyses the difference in $U_{37}^{k}$ between the two methods of storage is within the reproducibility of the method, with the exception of one sample which had been in storage only 2 months (Figure 2-3). The linear regression of these data indicates that storage of sediment at room temperature as opposed to storing samples frozen would be expected to shift values slightly to warmer. This shift would have the greatest effect at coldest temperatures, and is less than the expected errors of the method $\left( \pm 1.5^{\circ} \mathrm{C}\right.$ Prahl and Wakeham, 1987) above $8^{\circ} \mathrm{C}$. Although these results indicate that storage at room temperature may significantly offset $\mathrm{U}_{37}^{k}$ values to warmer at coldest temperatures, core-top calibration results in this study (see below), argue against such an effect. 
Linear regression for the total data set produces a line of slope 0.76 , which is different from the ideal by a maximum of $0.21 \mathrm{U}_{37}^{k}$ units at coldest temperatures. The total variance $\left(\sigma^{2}\right)$ in this data set is $0.073 \mathrm{U}_{37}^{k}$ units (equivalent to $\pm 1.8^{\circ} \mathrm{Cwhich}$ yields a $\sigma=6.7^{\circ} \mathrm{C}$ ) and $\mathrm{r}=0.909$. If the out-lying sample is ignored the slope is improved to 0.87 , and the regression is different from the ideal by a maximum of $0.11 \mathrm{U}_{37}^{k}$ units at $0^{\circ} \mathrm{C}$, total variance is then $0.006 \mathrm{U}_{37}^{k}$ units or $\pm 0.16^{\circ} \mathrm{C}, \sigma=0.08\left( \pm 2.0^{\circ} \mathrm{C}\right.$, and $\mathrm{r}=0.989$.

\subsubsection{Investigation of Dissolution Effects}

Dissolution of $\mathrm{CaCO}_{3}$ affects the reliability of foram-based paleotemperature techniques, making results appear cooler (Adelseck, 1977; Berger and Killingly, 1977, Bonneau et al., 1980). If $\mathrm{U}_{37}^{k}$ is not affected by the conditions that cause carbonate dissolution it would make available for paleotemperature analyses areas of the ocean where carbonates are badly dissolved. The principle concern with carbonate dissolution vis à vis $U_{37}^{k}$ is the differential release of either the $\mathrm{C}_{37: 2}$ or $\mathrm{C}_{37: 3}$ methyl ketones, thereby altering or smearing the temperature record. Sediment from Walvis Bay (AII 93/3, Station 8, core 13, 5-9 cm) collected in 1975 and frozen since that time at $-10^{\circ} \mathrm{C}$ to $-20^{\circ} \mathrm{C}$, was selected for laboratory dissolution experiments based on its mid-range SST $\left(\sim 18^{\circ} \mathrm{C}\right)$, high alkenone content $(\sim 4200 \mathrm{ng} / \mathrm{g} \mathrm{37:3}$ and $\sim 6000 \mathrm{ng} / \mathrm{g} 37: 2$; total organics $\sim 2 \%$ ) and moderately high carbonate content $(66 \%)$. For these experiments, carbonate was dissolved rapidly at low $\mathrm{pH}$ in order to achieve the desired amounts of dissolution in a reasonable length of time. Extraploation to sea-floor conditions of dissolution is based on the assumption that if there was little or no change in the $U_{37}^{k}$ under such extreme conditions then milder dissolution conditions in natural systems would have even less effect.

Results from these laboratory experiments show no change in temperature recorded by the alkenones with carbonate loss (Figure 2-4, Table 2-2). This suggests that dissolution does not affect the $\mathrm{U}_{37}^{k}$ ratio and so, by extension, sea surface temperatures determined by this technique. The average temperature for these analyses was $17.4^{\circ} \mathrm{C} \pm 0.90^{\circ} \mathrm{C}\left(0.618 \mathrm{U}_{37}^{k}\right.$ units $\left.\sigma=0.036\right)$. If a linear regresion is done on these data, $r=0.400$, which indicates some correlation with dissolution amount, but less than half the variation in the data can be attributed to dissolution. The slope of the line is $0.0004 \mathrm{U}_{37}^{k}$ units per percent dissolution, clearly indicating no significant change in $\mathrm{U}_{37}^{k}$ values with dissolution amount. There is also no systematic change in alkenone 


\begin{tabular}{|c|c|c|c|c|c|c|c|c|c|}
\hline Sample & $\begin{array}{l}\text { How } \\
\text { Stored }\end{array}$ & $\begin{array}{l}\text { Storage } \\
\text { Time } \\
\text { (years) }\end{array}$ & Location & $\mathrm{U}_{37}^{k}$ & $\begin{array}{c}\mathrm{U}_{37}^{k} \text { comperature } \\
\left({ }^{\circ} \mathrm{C}\right)\end{array}$ & $\begin{array}{c}\text { Estimated } \\
\text { SST } \\
\left({ }^{\circ} \mathrm{C}\right)\end{array}$ & Latitude & Longitude & $\begin{array}{l}\text { Depth } \\
\text { (m) }\end{array}$ \\
\hline $2 \mathrm{BC} 5-3$ & Frozen & 1.2 & Eq. Atlantic & 1.000 & 29.00 & 28.50 & $14^{\circ} 41^{\prime} \mathrm{N}$ & $17^{\circ} 50^{\prime} \mathrm{W}$ & 1445 \\
\hline $2 \mathrm{BC} 5-6$ & Unfrozen & 1.2 & Eq. Atlantic & 1.000 & 29.00 & 28.50 & $14^{\circ} 41^{\prime} \mathrm{N}$ & $17^{\circ} 50^{\prime} \mathrm{W}$ & 1445 \\
\hline $4 \mathrm{BC} 14-3$ & Frozen & 1.2 & Eq. Atlantic & 1.000 & 29.00 & 28.50 & $09^{\circ} 14^{\prime} \mathrm{N}$ & $17^{\circ} 00^{\prime} \mathrm{W}$ & 1011 \\
\hline $4 \mathrm{BC} 14-4$ & Unfrozen & 1.2 & Eq. Atlantic & 0.958 & 27.70 & 28.50 & $09^{\circ} 14^{\prime} \mathrm{N}$ & $17^{\circ} 00^{\prime} \mathrm{W}$ & 1011 \\
\hline $5 \mathrm{BC} 17-1$ & Frozen & 1.2 & Eq. Atlantic & 1.000 & 29.00 & 28.50 & $08^{\circ} 49^{\prime} \mathrm{N}$ & $17^{\circ} 16^{\prime} \mathrm{W}$ & 3749 \\
\hline $5 \mathrm{BC} 17-2$ & Unfrozen & 1.2 & Eq. Atlantic & 1.000 & 29.00 & 28.50 & $08^{\circ} 49^{\prime} \mathrm{N}$ & $17^{\circ} 16^{\prime} \mathrm{W}$ & 3749 \\
\hline MWSC2 & Frozen & 0.5 & Peru & 0.775 & 22.30 & 22.00 & $11^{\circ} 04^{\prime} \mathrm{S}$ & $78^{\circ} 03^{\prime} W$ & 255 \\
\hline MWSC2 & Unfrozen & $\cdot 0.5$ & Peru & 0.778 & 22.20 & 22.00 & $11^{\circ} 04^{\prime} \mathrm{S}$ & $78^{\circ} 03^{\prime} \mathrm{W}$ & 255 \\
\hline MWSC7 & Frozen & 0.5 & Peru & 0.636 & 17.98 & 18.00 & $14^{\circ} 56^{\prime} \mathrm{S}$ & $75^{\circ} 37^{\prime} \mathrm{W}$ & 105 \\
\hline MWSC7 & Unfrozen & 0.5 & Peru & 0.675 & 19.10 & 18.00 & $14^{\circ} 56^{\prime} \mathrm{S}$ & $75^{\circ} 37^{\prime} \mathrm{W}$ & 105 \\
\hline $110 \mathrm{KBC} 84$ & Frozen & 4 & W. Eq. Atlantic & 1.000 & 29.00 & 29.00 & $04^{\circ} 22^{\prime} \mathrm{N}$ & $43^{\circ} 31^{\prime} \mathrm{W}$ & 2947 \\
\hline $110 \mathrm{KBC} 84$ & Unfrozen & 4 & W. Eq. Atlantic & 1.000 & 29.00 & 29.00 & $04^{\circ} 22^{\prime} \mathrm{N}$ & $43^{\circ} 31^{\prime} \mathrm{W}$ & 2947 \\
\hline $134 \mathrm{KBC} 53$ & Frozen & 0.3 & Black Sea & 0.511 & 14.20 & 15.00 & $42^{\circ} 41^{\prime} \mathrm{N}$ & $37^{\circ} 37^{\prime} \mathrm{E}$ & 2154 \\
\hline PAR87A-8A & Unfrozen & 2 & Gulf of Alaska & 0.422 & 11.50 & 9.00 & $54^{\circ} 13^{\prime} \mathrm{N}$ & $148^{\circ} 49^{\prime} \mathrm{W}$ & 3446 \\
\hline PAPA C4: & Frozen & 2 & PAPA N.E. Pacific & 0.303 & 7.90 & 10.00 & $49^{\circ} 26^{\prime} \mathrm{N}$ & $136^{\circ} 39^{\prime} \mathrm{W}$ & 3740 \\
\hline K134BC34 & Frozen & 0.6 & Black Sea & 0.338 & 8.95 & 12.00 & $42^{\circ} 16^{\prime} \mathrm{N}$ & $37^{\circ} 32^{\prime} \mathrm{E}$ & 2060 \\
\hline $\mathrm{K} 134 \mathrm{BC} 34$ & Unfrozen & 0.6 & Black Sea & 0.440 & 12.03 & 12.00 & $42^{\circ} 16^{\prime} \mathrm{N}$ & $37^{\circ} 32^{\prime} \mathrm{E}$ & 2060 \\
\hline RNDB24GGC & Frozen & 0.2 & N.W. Pacific & 0.525 & 14.60 & 11.00 & $51^{\circ} 17^{\prime} \mathrm{N}$ & $167^{\circ} 27^{\prime} \mathrm{E}$ & 2323 \\
\hline RNDB24GGC & Unfrozen & 0.2 & N.W. Pacific & 0.828 & 23.80 & 11.00 & $51^{\circ} 17^{\prime} \mathrm{N}$ & $167^{\circ} 27^{\prime} \mathrm{E}$ & 2323 \\
\hline $\mathrm{BC} 207$ & Frozen & 0.5 & N.E. Pacific & 0.537 & 14.97 & 16.00 & $35^{\circ} 40^{\prime} \mathrm{N}$ & $121^{\circ} 37^{\prime} \mathrm{W}$ & 795 \\
\hline BC207 & Unfrozen & 0.5 & N.E. Pacific & 0.565 & 15.82 & 16.00 & $35^{\circ} 40^{\prime} \mathrm{N}$ & $121^{\circ} 37^{\prime} \mathrm{W}$ & 795 \\
\hline BC238 & Frozen & 0.5 & N.E. Pacific & 0.691 & 19.64 & 16.00 & $35^{\circ} 57^{\prime} \mathrm{N}$ & $122^{\circ} 59^{\prime} \mathrm{W}$ & 3590 \\
\hline BC238 & Unfrozen & 0.5 & N.E. Pacific & 0.635 & 17.95 & 16.00 & $35^{\circ} 57^{\prime} \mathrm{N}$ & $122^{\circ} 59^{\prime} \mathrm{W}$ & 3590 \\
\hline $13 B C 55-4$ & Unfrozen & 2.6 & Eq. Atlantic & 0.828 & 23.80 & 28.50 & $02^{\circ} 06^{\prime} \mathrm{S}$ & $23^{\circ} 03^{\prime} \mathrm{W}$ & 5065 \\
\hline 12PC51 & Unfrozen & 2.3 & Eq. Atlantic & 0.954 & 27.50 & 28.50 & $00^{\circ} 00^{\prime} \mathrm{N}$ & $23^{\circ} 00^{\prime} \mathrm{W}$ & 3875 \\
\hline O173-4-G & Unfrozen & 2.1 & N. Atlantic & 0.915 & 26.42 & 26.00 & $31^{\circ} 54^{\prime} \mathrm{N}$ & $64^{\circ} 08^{\prime} \mathrm{W}$ & 4469 \\
\hline
\end{tabular}




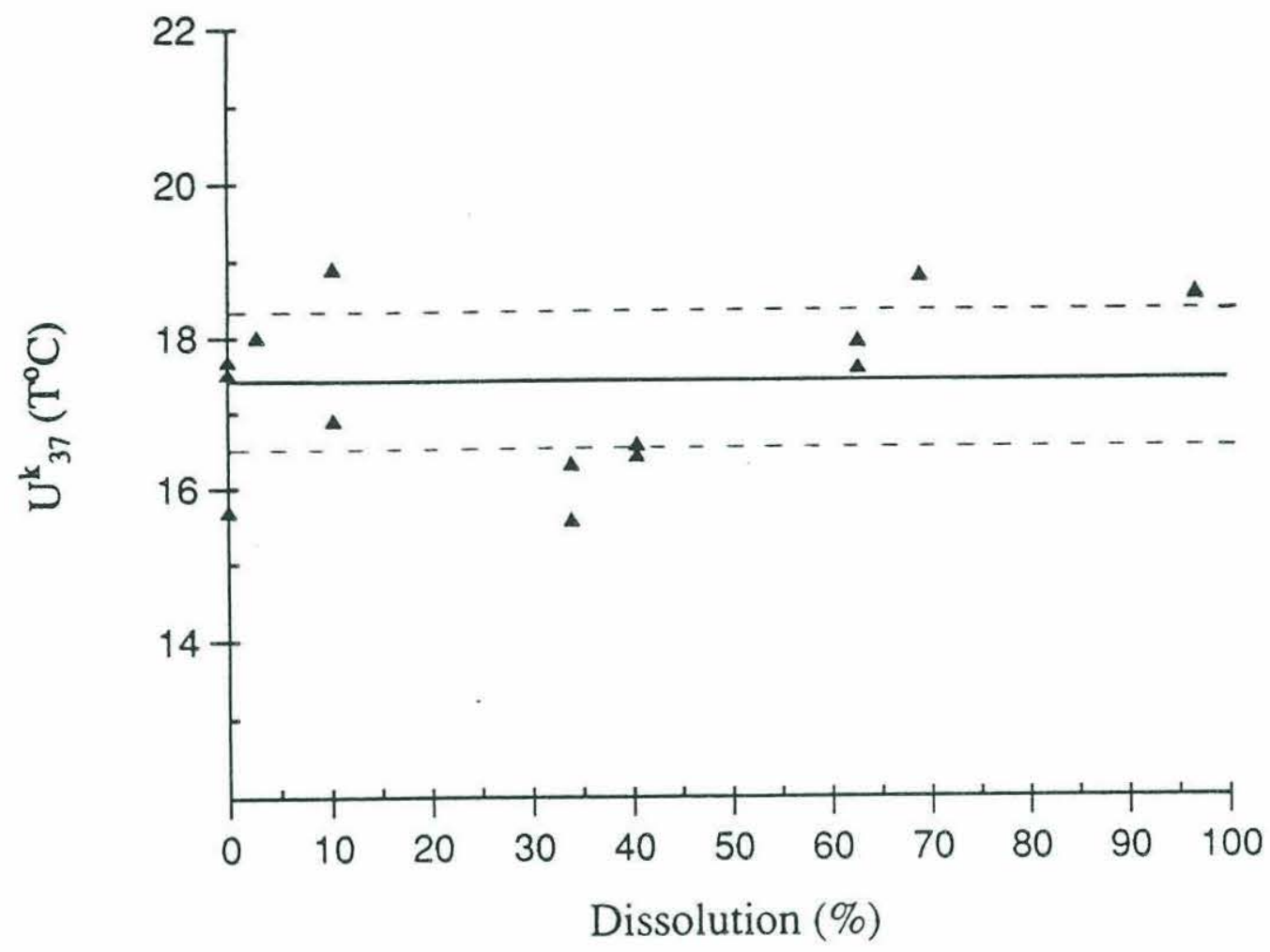

Figure 2-4: $\quad \mathrm{U}_{37}^{k}$ values of Walvis Bay sediments for varying amounts of carbonate dissolution in laboratory experiments. Solid line is average temperature value $\left(17.42^{\circ} \mathrm{C}\right)$. Dotted lines are the $1 \sigma$ $\left(0.90^{\circ} \mathrm{C}\right)$ error bars on the estimate.

concentrations in the sediments, indicating that the alkenones were not released or mobilized into the overlying water by the dissolution of the $\mathrm{CaCO}_{3}$ (Table 2-2). Thus, results of this experiment indicate that the effects of carbonate dissolution do not significantly effect $\mathrm{U}_{37}^{k}$ temperature estimates.

Because these laboratory conditions are so different from those encountered on the ocean floor a pair of core-top samples from the Equatorial Atlantic was analysed (Table 2-1) from above the lysocline (core $12 \mathrm{PC} 51,88 \% \mathrm{CaCO}_{3} ; 3870 \mathrm{~m}$ ) and below (soutar box core 13BC55-4, 14\% $\left.\mathrm{CaCO}_{3} ; 5065 \mathrm{~m}\right)$. These locations are separated by only $2^{\circ}$ latitude in waters that are presently approximately $28^{\circ} \mathrm{C}$, and should have very similar initial sedimentary inputs if the principle mode of deposition is settling through the water column. In this region this assumption appears to be sound (Curry and Lohmann, 1986). These samples have $\mathrm{U}_{37}^{k}$ temperatures of $27.5^{\circ} \mathrm{C}$ and 


\begin{tabular}{ccccc}
\hline $\begin{array}{c}\text { Dissolution } \\
\%\end{array}$ & $\begin{array}{c}{[37: 3]} \\
\mathrm{ng} / \mathrm{g}\end{array}$ & $\begin{array}{c}{[37: 2]} \\
\mathrm{ng} / \mathrm{g}\end{array}$ & $\mathrm{U}_{37}^{k}$ & $\begin{array}{c}\mathrm{U}_{37}^{k} \text { temperature } \\
\left({ }^{\circ} \mathrm{C}\right)\end{array}$ \\
\hline \hline 0 & 4801 & 8101 & .627 & 17.69 \\
0 & 4836 & 7914 & .621 & 17.52 \\
0 & 4634 & 5921 & .560 & 15.70 \\
2.8 & 3753 & 6592 & .637 & 18.01 \\
10.25 & 3506 & 7021 & .667 & 18.90 \\
10.25 & 3522 & 5298 & .601 & 16.90 \\
34.0 & 3545 & 4921 & .581 & 16.31 \\
34.0 & 3858 & 4842 & .557 & 15.57 \\
40.25 & 3917 & 5518 & .585 & 16.57 \\
40.25 & 4679 & 7022 & .600 & 16.42 \\
63.0 & 3873 & 6740 & .635 & 17.94 \\
63.0 & 4215 & 6983 & .624 & 17.59 \\
69.1 & 4285 & 8438 & .663 & 18.79 \\
97.0 & 4423 & 8405 & .655 & 18.55 \\
97.0 & 4625 & 8804 & .656 & 18.57 \\
& & & & \\
\hline
\end{tabular}

Table 2-2: Concentrations of the di- and tri-unsaturated ketones in the dissolution samples after acid treatment and decanting of the supernatent.

$23.8^{\circ} \mathrm{C}$ respectively, despite having been deposited under the same surface waters. There are several possible explanations for this discrepancy: First, the SST overlying the two cores could be truly different, due to positioning of the equatorial upwelling zone. Equatorial upwelling can be as narrowly confined as $1^{\circ}$ latitude (Wyrtki, 1981), however, this is considered unlikely because the colder estimate is about $4^{\circ} \mathrm{C}$ colder than surface waters in that location today (Fuglister, 1960; Levitus, 1982). Second, carbonate dissolution in the deeper core might have lowered the sedimentation rate and may have allowed bioturbation to incorporate pre-Holocene sediment into the $1 \mathrm{~cm}$ deep sample at the top of this core. Holocene sedimentation rates above the lysocline in this region are $1.5-2 \mathrm{~cm} / \mathrm{ky}$ and carbonate accumulation rates are 2-3 times that of non-carbonates in the Holocene (Curry and Lohmann, 1986). Had most of the carbonate been dissolved, the rate of non-carbonate accumulation could allow bioturbation to incorporate glacial age sediments into the surface layer (glacial age samples from the shallower core, below $\sim 15 \mathrm{~cm}$, show similar $\mathrm{U}_{37}^{k}$ levels to this core-top value; see Chapter 3), also lateral transport of fine $\mathrm{CaCO}_{3}$ and/or alkenones into this site cannot be discounted. Third, dissolution may have 
affected $U_{37}^{k}$ values, however this is inconsistent with laboratory studies. Further investigation of dissolution pairs such as these will be necessary to help resolve this issue.

An independent check on the effects of dissolution under natural conditions can be made by examining core-top $\mathrm{U}_{37}^{k}$ temperatures with respect to core depth. $\mathrm{CaCO}_{3}$ dissolution increases with increasing depth in the ocean, due to increasing unsaturation of $\mathrm{CaCO}_{3}$ caused by increased pressure and decreased temperatures at depth (van Andel et al., 1975), as well as being due to the corrosiveness of the deep water present in a given location. Calcareous nannofossils begin to show evidence of dissolution above $300 \mathrm{~m}$ in the Atlantic Ocean, but dissolve more slowly than foraminifera, and so have a deeper lysocline (Honjo and Erez, 1978). Because the increase in dissolution of calcium carbonate tests progressively increases with increasing depth, some assessment of the effect of dissolution on $\mathrm{U}_{37}^{k}$ can be gained by looking for a correlation between deviation from expected values of $U_{37}^{k}$ and the water depth of core samples in Table 21. Figure $2-5$ is a plot of the difference between $\mathrm{U}_{37}^{k}$ temperature and overlying SST $\left(\mathrm{T}\left(\mathrm{U}_{37}^{k}\right)\right.$ - $\mathrm{T}_{w}$ ) versus core depth. The difference between actual SST and the temperature recorded by $\mathrm{U}_{37}^{k}$ does not vary with depth. Linear regression of the data provides a line of slope -0.00011 ${ }^{\circ} \mathrm{C} / \mathrm{m}$ (or $-0.011{ }^{\circ} \mathrm{C} / \mathrm{km}$ ) $\mathrm{r}=-0.053$, and the average difference between $\mathrm{U}_{37}^{k}$ and overlying water temperatures is $+0.61^{\circ} \mathrm{C}$.

\subsubsection{Core Top Calibration of $U_{37}^{k}$}

In order to use $\mathrm{U}_{37}^{k}$ as a "thermometer" it must be thoroughly calibrated. As an initial test, $\mathrm{U}_{37}^{k}$ temperatures were measured from a world-wide selection of core-top sediment samples spanning a wide range of open ocean temperatures $\left(11-29^{\circ} \mathrm{C}\right.$; Figure 2-2, Table 2-1) and compared to overlying SST for the assumed season of coccolith bloom, using both frozen and unfrozen samples (Solid circles, Figure 2-6). One very important assumption made here, especially in the higher latitude samples, is the season of coccolith bloom. It has been assumed for this study that coccolith blooms occur in warm seasons, and the CLIMAP modern SST data set has been used for most study sites (Table 2-1). These results show excellent correlation with estimated temperature, with the exception of the same out-lying sample present in the storage artifacts data set ( $\mathrm{r}=.968$, total variance $\left(\sigma^{2}\right)$ is $0.003 \mathrm{U}_{37}^{k}$ units or $\sim 0.08^{\circ} \mathrm{C}, \sigma=1.4^{\circ} \mathrm{C}$ ). The slope of the regression line agrees, within the errors of the method, with the culture and water column 


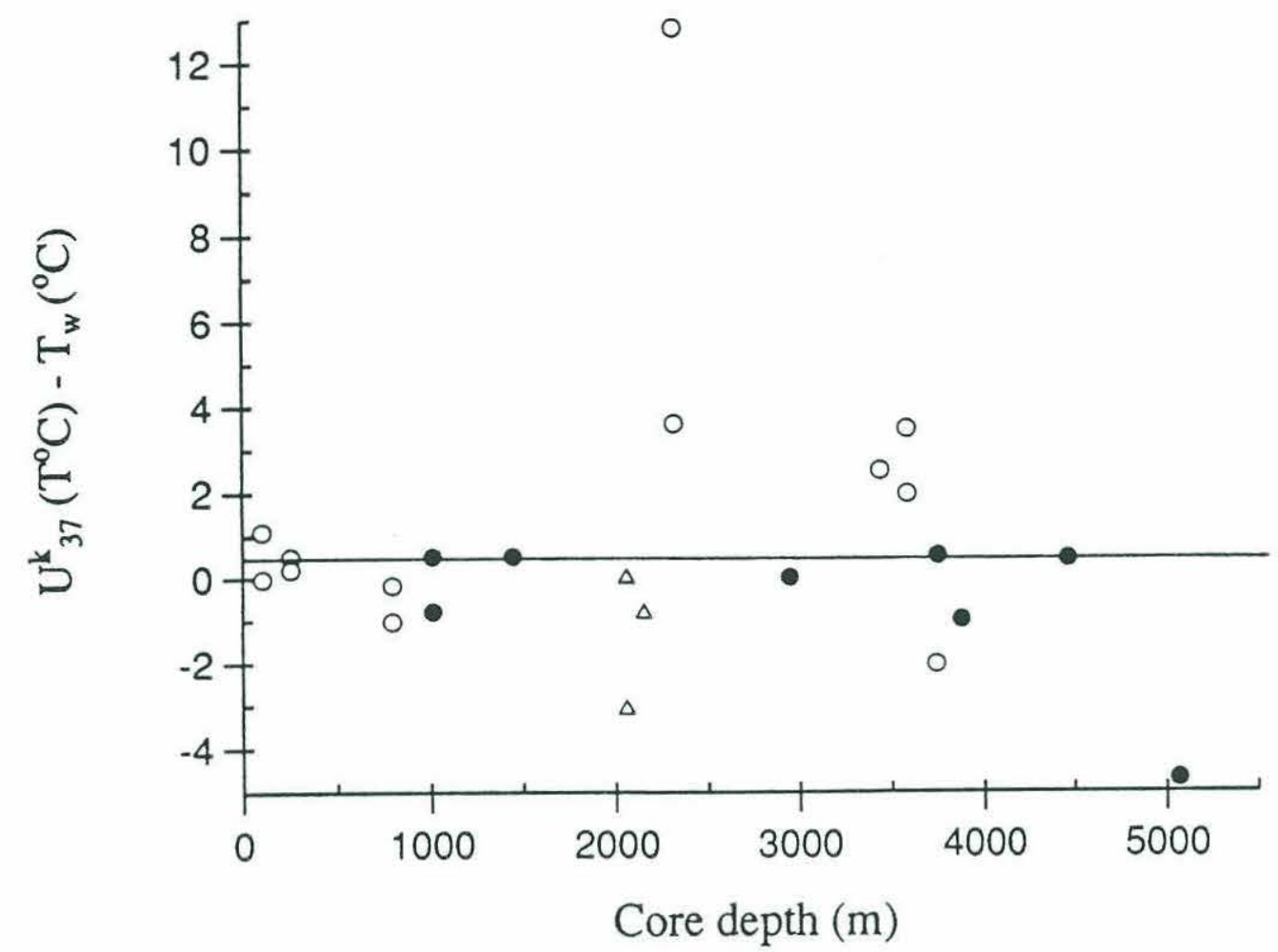

Figure 2-5: Plot of the difference between $\mathrm{U}_{37}^{k}$ temperature and overlying SST $\left(\mathrm{TU}_{37}^{k}\left({ }^{\circ} \mathrm{C}\right)-\mathrm{T}_{w}\left({ }^{\circ} \mathrm{C}\right)\right.$ ) versus core depth. Closed circles are Atlantic Ocean samples, open circles are Pacific Ocean samples, and open triangles are Black Sea samples. The difference between actual SST and the temperature recorded by $\mathrm{U}_{37}^{k}$ does not vary with depth. Linear regression of the data provides a line of slope $-0.0001{ }^{\circ} \mathrm{C} / \mathrm{m}$ (or $-0.011^{\circ} \mathrm{C} / \mathrm{km}$ ) and $\mathrm{r}=-0.053$, indicating essentially no correlation with depth.

regression of Prahl and Wakeham (1987; open circles Figure 2-6). The regression equation for the sediment results is $U_{37}^{k}=0.031 \mathrm{~T}+0.082$ ) which compares favorably with that of Prahl and Wakeham (1987; their equation is $\left.\mathrm{U}_{37}^{k}=0.033 \mathrm{~T}+0.043\right)$ the difference in slopes introduces a maximum temperature difference between the two regressions of $0.5 \mathrm{U}_{37}^{k}$ units $\left(1.25^{\circ} \mathrm{C}\right)$, at the coldest temperatures $\left(0^{\circ} \mathrm{C}\right)$. This offset is in the same sense as that seen in the sample storage aspect of this study. Because a good portion of the data base is the same, this offset is likely to be due to the same storage effects. The magnitude of the offset however, is within the errors of the method $\left( \pm 1.4^{\circ} \mathrm{C}\right)$. These results imply that degradation during sedimentation and residence on the sea-floor do not significantly affect $U_{37}^{k}$ values, and that the empirical formula for converting $\mathrm{U}_{37}^{k^{\prime}}$ values to water temperature developed by Prahl and Wakeham (1987) is 


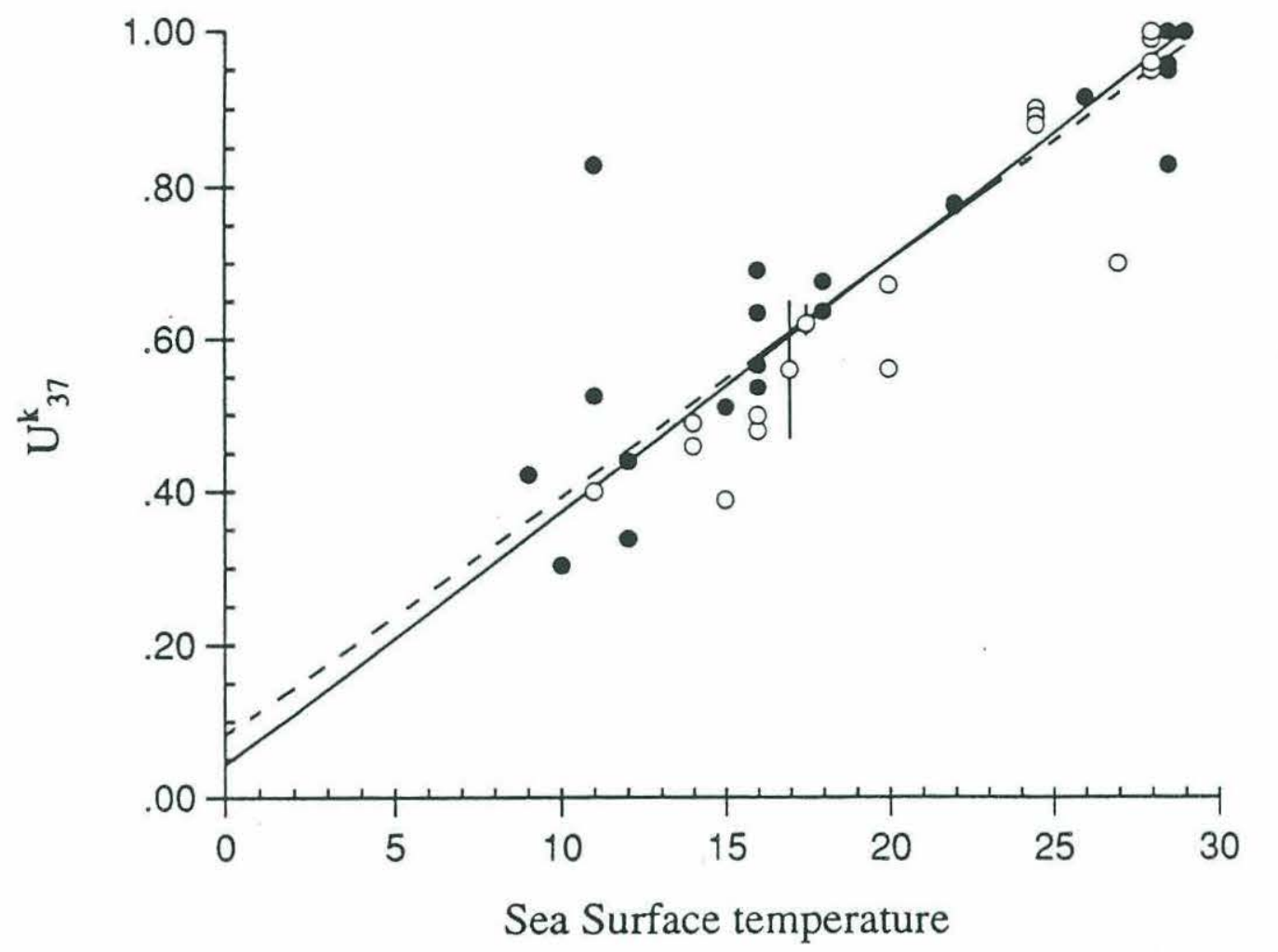

Figure 2-6: Solid circles are $U_{37}^{k}$ values for core top sediments plotted versus summer SST estimates of the overlying waters, open circles are the particulate organic matter results from Prahl and Wakeham (1987). Solid line is the regression line for the culture results of Prahl and Wakeham (1987; individual points used to derive this line are not shown). Dotted line is the regression of the sediment data of the present study, ignoring the outlier. For the entire sediment data set $\mathrm{r}=0.910$, and the equation for the line is $\mathrm{U}_{37}^{k}=0.029 \mathrm{~T}+0.155$; total variance $\left(\sigma^{2}\right)=0.009\left(0.25^{\circ} \mathrm{C}\right) \sigma=2.49^{\circ} \mathrm{C}$. If the outlier is ignored this is changed to: $\mathrm{U}_{37}^{k}=0.031 \mathrm{~T}+0.082, \mathrm{r}=0.968$, total variance $\left(\sigma^{2}\right)=0.03\left(0.08^{\circ} \mathrm{C}\right) \sigma=1.4^{\circ} \mathrm{C}$.

suitable for use in converting $\mathrm{U}_{37}^{k}$ values in sediments to overlying SST.

The $\mathrm{C}_{37}$ alkenones are known to be synthesized by Prymnesiophyceae other than E. huxleyi, and there is some indication these other phytoplankton show a different response to temperature in their unsaturation ratios (Marlowe et al., 1984). However, these algae are only known to occur naturally in coastal and fresh water environments (Marlowe, 1984). The excellent agreement of the core-top SST calibration analyses with the previously published $U_{37}^{k}$ field data and culture results of Prahl and Wakeham (1987) provide additional evidence from numerous regions of the ocean for the suitability of the $\mathrm{C}_{37}$ alkenones as paleotemperature indicators.

There is need for a paleo-SST indicator that is not affected by salinity changes. Of special 
note are the samples from the Black Sea (K134BC 53 and K134BC 34, frozen and unfrozen; Table 2-1). Although no work has been done to estimate the effects of salinity on the unsaturation ratios of the $\mathrm{C}_{37}$ alkenones, it is assumed, based on work on polyunsaturated fatty acids that salinity effects would be slight (J. Volkman, pers. comm., 1989). However, these compounds are used for different biochemical functions and the extraploation of the effects of salinity is at best, tenuous. The only direct evidence then, on the relationship of $U_{37}^{k}$ to salinity, are these samples from the Black sea. The Black Sea has surface salinities of $18-22 \%$, whereas the SST recorded by the alkenones is accurate (Table 2-1). Although based on only three samples, these results are an indication that salinity does not markedly affect $\mathrm{U}_{37}^{k}$.

Because growth conditions are known to affect other coccolith signals (such as the $\delta^{18} \mathrm{O}$ of the tests; Dudley and Goodney, 1979), it is conceivable that factors that affect productivity of the Prymnesiophytes may affect the temperature recorded by $\mathrm{U}_{37}^{k}$. Growth of E. huxleyi cultures in media with different nutrient levels does not affect the relative concentrations of $\mathrm{C}_{37}$ alkenones (Marlowe, 1984), but no field work has addressed the question of productivity effects on $\mathrm{U}_{37}^{k}$. Although concentration of organics in sediments is not a perfect measure of productivity (Emerson, 1985) it is a first approximation. Figure 2-7 is a plot of the difference between the temperature recorded by $\mathrm{U}_{37}^{k}$ and water temperature versus the total abundance of sedimentary $\mathrm{C}_{37}$ alkenones. There is no apparent effect of "productivity" on the accuracy of $\mathrm{U}_{37}^{k}$, based on these available data.

Also of note are the several locations where there were insufficient concentrations of the alkenones (relative to other lipids in the sample) to obtain a reliable $\mathrm{U}_{37}^{k}$ result. In this study, two core-tops contained insufficient concentrations of $\mathrm{C}_{37}$ alkenones, one from the Pacific, core Par87A-08 ( $\left.54^{\circ} 12.84^{\prime} \mathrm{N}, 148^{\circ} 49.32^{\prime} \mathrm{W}, 3446 \mathrm{~m}\right)$ and one from the Fram Strait in the Norweigan Sea, core PS21295-4 ( $\left.77^{\circ} 59.52^{\prime} \mathrm{N}, 2^{\circ} 25.23^{\prime} \mathrm{E}, 3112 \mathrm{~m}\right)$. Both these cores are from high latitudes, and other cores from the North Atlantic have been found to be barren as well (F. Prahl, pers. comm., 1989). Also barren were glacial level samples from core RNDB- 24GGC, in the Pacific, although surface sediments did contain ample ketones to obtain reliable $\mathrm{U}_{37}^{k}$ values (Table 2-1). It is assumed that the very low levels of alkenones in these locations are due to two factors. In high latitudes, short growing seasons result in the deposition of only small amounts of alkenones to the sediments. This combined with the typical slow sedimentation 


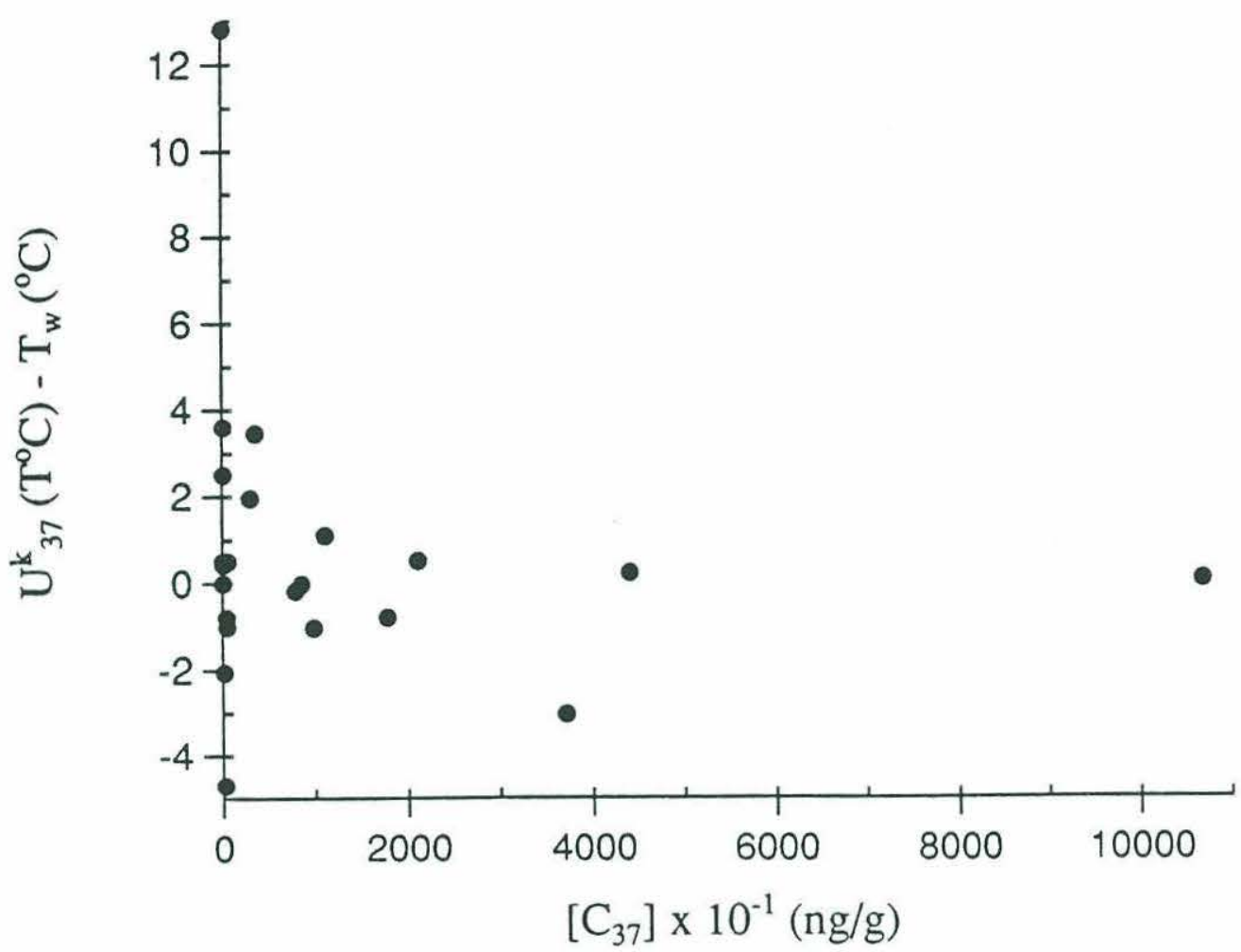

Figure 2-7: Plot of the difference between $\mathrm{U}_{37}^{k}$ temperature and overlying SST $\left(\mathrm{TU}_{37}^{k}\left({ }^{\circ} \mathrm{C}\right)-\mathrm{T}_{w}\left({ }^{\circ} \mathrm{C}\right)\right.$ ) versus abundance of $\mathrm{C}_{37}$ alkenones $(\mathrm{ng} / \mathrm{g})$. The difference between actual SST and the temperature recorded by $\mathrm{U}_{37}^{k}$ does not vary with "productivity". Linear regression of the data provides a line of slope $-0.00011^{\circ} \mathrm{C} / \mathrm{m}$ ( or $-0.011^{\circ} \mathrm{C} / \mathrm{km}$ ) and $\mathrm{r}=-0.053$, indicating essentially no correlation with depth.

rates of the open ocean may allow sufficient aerobic degradation of organic matter upon burial that an insufficient quantity of $\mathrm{C}_{37}$ alkenones is left to reliably produce a temperature signal. Although alkenones were detectable in trace amounts (less than $20 \mathrm{ng} / \mathrm{g}$ of either $37: 2$ or $37: 3$ ) in some of these samples, the signal was not sufficiently above baseline noise, or too small relative to other compounds in the extract, to provide meaningful results. In samples rich in other lipids that elute in the same fraction as the alkenones under column chromatography, this is especially a problem, because these samples cannot be concentrated sufficiently for the dection of the $\mathrm{C}_{37}$ alkenones. Although in high northern latitudes $E$. huxleyi is the dominant coccolithophore (Okada and McIntyre, 1979), these results indicate that there are locations where Prymnesiopyhceae do grow, where $\mathrm{U}_{37}^{k}$ may not be usable. 


\subsection{Conclusions}

This study to refine $\mathrm{U}_{37}^{k}$ for quantitative sedimentary applications confirms the usefulness of the method as a paleotemperature estimator. Specifically:

- There is no appreciable difference in $\mathrm{U}_{37}^{k}$ between most samples collected and stored frozen and those stored at room temperature for up to 4 years. Results do indicate storage at room temperature may cause a resolvable shift to warmer temperatures in samples from surface waters of less than $8^{\circ} \mathrm{C}$, but this is not definitive. Thus, no special handling appears to be required for $\mathrm{U}_{37}^{k}$ analyses and the many sediment cores presently available may be suitable for this organic geochemical technique.

- Laboratory dissolution experiments indicate that the $\mathrm{C}_{37: 2}$ or $\mathrm{C}_{37: 3}$ ketones are unaffected by the conditions that destroy carbonates in this setting, a result which encourages the use of the $\mathrm{U}_{37}^{k}$ technique in sediments where the total or partial dissolution of $\mathrm{CaCO}_{3}$ renders foram-based techniques unusable or unreliable. Comparison of the accuracy of $\mathrm{U}_{37}^{k}$ in recording overlying SST versus core depth indicates dissolution under more natural conditions does not significantly alter the ablilty of $U_{37}^{k}$ to record accurately SST. However, further field research on core samples from across the lysocline is needed before possible dissolution effects are fully understood.

- Calibration of the $\mathrm{U}_{37}^{k}$ method with SST in surface sediments for samples from varied oceanic regions yields a regression line that is at most $1.25^{\circ} \mathrm{C}$ warmer than the regression line of the culture and water column results of Prahl and Wakeham (1987). The difference between the two regressions is less than the error limits of the two data sets. Agreement of these two data sets indicates that Prahl and Wakeham's equation for converting $U_{37}^{k}$ values to water temperatures is suitable for use in sediments.

- Lowered salinities do not appear to affect $\mathrm{U}_{37}^{k}$ temperature estimates in the limited number of samples available at this time. However, in lower salinity coastal environments, the importance of $\mathrm{C}_{37}$ alkenone producing Prymnesiophytes other than E. huxleyi needs to be investigated. 
- An examination of $\mathrm{C}_{37}$ concentrations in sediments as a proxy for productivity indicates that different growth conditions do not affect the accuracy of temperatures recorded by $\mathrm{U}_{37}^{k}$.

- Concentrations of $\mathrm{C}_{37}$ alkenones were found to be too low in some sediments to produce a reliable $\mathrm{U}_{37}^{k}$ temperature estimate. Such low concentrations may make $\mathrm{U}_{37}^{k}$ unusable in some locations, particularly in high latitudes. 


\section{Chapter 3}

\section{Past sea surface temperatures of the Equatorial Atlantic}

\subsection{Introduction}

Modern sea surface temperature variations in the tropical Atlantic are controlled seasonally by winds (Hastenrath, 1977). In the northern hemispheric summer, the strong southern trade winds extend into the northern hemisphere (Riehl, 1979), minimum SST occurs due to upwelling, and part of the South Equatorial Current is diverted to the north, up the coast of Brazil. At this time, both wind and currents transport southern hemispheric heat out of the equatorial zone into the northern hemisphere (Hastenrath, 1977; 1980). In the northern hemispheric winter these winds and the South Equatorial Current weaken, transport across the equator is relaxed, and SST is at a maximum. This causes seasonal variations of about $2^{\circ} \mathrm{C}$ (Reynolds, 1982).

At the last glacial maximum Equatorial Atlantic SST appears to have been lower by $2^{\circ} \mathrm{C}$ (Prell et al., 1976; Gardner and Hays, 1976; CLIMAP, 1981; Mix et al., 1986; McIntyre et al., 1989). Generally, these lower temperatures are assumed to have been caused by increased wind velocity during that time (Parkin and Shackleton, 1973; Parkin, 1974, Parkin and Padgham, 1975; Gardner and Hays, 1976; Sarnthein et al., 1981) via mechanisms similar to those that cause the seasonal cooling seen in the Equatorial Atlantic today (McIntyre et al., 1989).

Although these glacial SST estimates for the Equatorial Atlantic are about $2{ }^{\circ} \mathrm{C}$ cooler 
than modern values, they are not as low as temperature estimates for the adjacent African continent based on snowline depression (Omaston, 1965) and pollen studies (Flenley, 1979; Livingstone, 1980; Hamilton, 1982; see Rind and Peteet, 1985 for a review of the literature). Studies there indicate terrestrial temperatures were as much as $5-6^{\circ} \mathrm{C}$ cooler in the last glacial maximum (Hansen et al., 1984; Rind and Peteet, 1985 and references therein) whereas studies of lake levels (Street and Grove, 1976, 1979) and dune formation (Sarnthein, 1978) indicate that climate there was drier at the same time. Although some modeling results suggest that Atlantic SST estimates are compatible with temperature estimates for the African continent (Manabe and Hahn, 1977; Manabe and Broccoli, 1985), one cause of the discrepancy between land and marine estimates may be the fact that all of these SST studies rely on foraminiferabased estimates.

Foraminiferal assemblage SST estimates have embedded in them the environmental effects of individual species' habitats. Foraminifera live in and across the thermocline, the effects which are not unequivocally separable from actual SST (Fairbanks and Weibe, 1980; Fairbanks et al., 1980, Fairbanks et al., 1982). In upwelling zones for example, the relationship of foraminiferal size to the $\delta^{18} \mathrm{O}$ signal recorded in the test is reversed for species such as Globigerina bulloides and Neogloboquadrina duterei (which are considered divergence species; Prell and Curry, 1981; McIntyre et al., 1989) due to changes in habit influenced by the coastal upwelling conditions (Dunbar, 1983; Wefer et al., 1983). Indeed, $N$. dutertrei which dwell at intermediate depths in subtropical waters, are found much more frequently in surface waters in upwelling areas (Wefer et al., 1983). Furthermore, $\delta^{18} \mathrm{O}$ estimates have ice volume and salinity effects of at least $1.3^{\circ} \%$ (Fairbanks, 1989), much greater than the SST changes in this area $\left(\mathrm{a} 2{ }^{\circ} \mathrm{C}\right.$ change causes an isotope effect of $0.44^{\circ} \%$ ).

McIntyre et al. (1989) suggest two possible mechanisms for lowering SST in the last glacial maximum (Figure 3-1). Compared to the modern situation (a), one model for glacial conditions (b) suggests cooler assemblages were primarily caused by shallowing of the thermocline resulting from increased divergence due to stronger trade winds, without a large decrease in actual surface mixed layer temperatures. An alternative model (c) suggests that lower SST estimates were due to the combination of both advection of cooler water (and the accompanying foraminifera) from high latitudes and shallowing of the thermocline. SST in this situation would be lower than that 


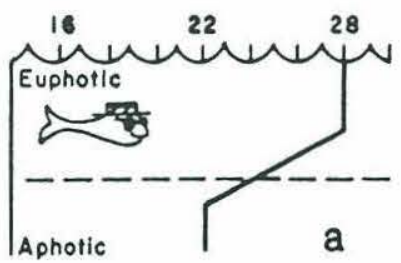

Tropical > Divergence > Transitional > Subpolor

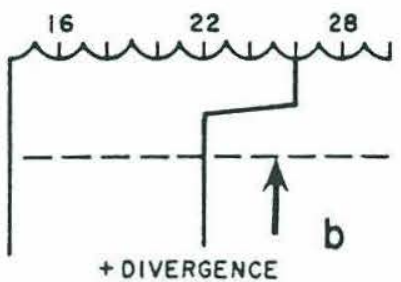

Tropical $\simeq$ Divergence $>$ Transitional $>$ Subpolar

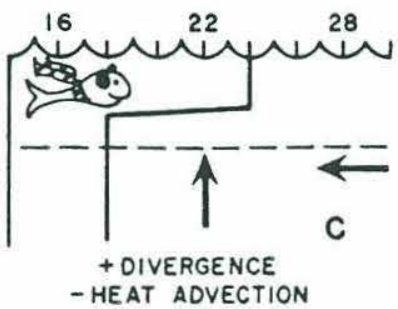

Tropical $\simeq$ Tronsitionol $\geq$ Divergence $>$ Subpolor

Figure 3-1: After McIntyre et al. (1989). These sketches represent relative dominance of the foraminiferal assemblages in the equatoral Atlantic for three possible oceanographic configurations. a.) modern, b.) increased divergence and thermocline shallowing due to increased trade wind forcing, c.) increased cool water advection with increased divergence.

caused by divergence alone. Foraminiferal assemblages cannot distinguish between these two situations. Both models (b) \& (c) are oversimplfied, reducing the complicated upwelling process (as discussed by Prell and Curry, 1981) to changes in thermocline depth in order to explain assemblages that have no modern analogues; the actual conditions are certainly more complex. It is also important to note that no firm depths can be ascribed to the thermocline or photic level in these models. Because assemblages similar to equatorial glacial assemblages do not exist today, there is no way to accurately establish their associated temperatures. Consequently, just how much the assemblage changes are due to cool surface waters, or to shallowing of the thermocline and other factors is uncertain (Mix et al., 1986).

The $\mathrm{U}_{37}^{k}$ technique of SST estimation is based on alkenones synthesized by phytoplankton 
(primarily the coccolith Emiliania huxleyi in the open ocean). Phytoplankton are restricted to the shallow depths of the photic zone ( $\leq 200 \mathrm{~m}$; Okada and Honjo, 1973; Honjo and Okada, 1974 ) and studies indicate that even in tropical locations most primary productivity occurs in the upper layers of that zone (see Chapter 1 for a full discussion). A temperature estimator based on phytoplankton can potentially provide a surface mixed layer temperature estimate that is less influenced by near-surface oceanographic changes than faunally-based techniques. As organically-synthesized molecules, the alkenones should not be greatly influenced by salinity changes (J. Volkman, pers. comm.) brought about by ice volume changes, evaporation precipitation differences, or local freshwater run-off which influence oxygen isotope signals. The fact that $U_{37}^{k}$ is apparantly not influenced by such factors can provide valuable information about both the SST history of the Equatorial Atlantic, and about the other methods which previously have been used to examine paleo-SST.

The Equatorial Atlantic has been studied extensively, and as such, it is an excellent location to apply $U_{37}^{k}$ as a test of models (b) and (c) for SST change during the last glaciation (Figure 3-1). This chapter attempts to address the ambiguities of SST estimates in the Equatorial Atlantic, including the discrepancies between $\delta^{18} \mathrm{O}$ and foraminiferal assemblages temperature estimates at several sites in the tropical Atlantic (Mix and Ruddiman, 1985) and discrepancies between land and marine records. In order to do this, $\mathrm{U}_{37}^{k}$ results are compared to SST estimates from oxygen isotopes and foraminiferal assemblages for the same sediment depths from core 86 Gyre-14 12PC51, from the central Equatorial Atlantic. This piston core was recovered from a location very near to cores V30-40, and V30-41 (Figure 3-2).

\subsection{Methods}

\subsubsection{Geochemical Techniques}

\section{a) stable isotopes}

In this study isotope analyses were conducted following the laboratory procedures described by Keigwin (1979), and Curry and Lohmann (1985, 1986), with minor modifications. Sediment samples of 5-10 g dry weight were washed on a $63 \mu \mathrm{m}$ sieve under running tap water, after drying at $50^{\circ} \mathrm{C}$, specimens of the planktonic foraminifera Globigerinoides sacculifer were picked from 


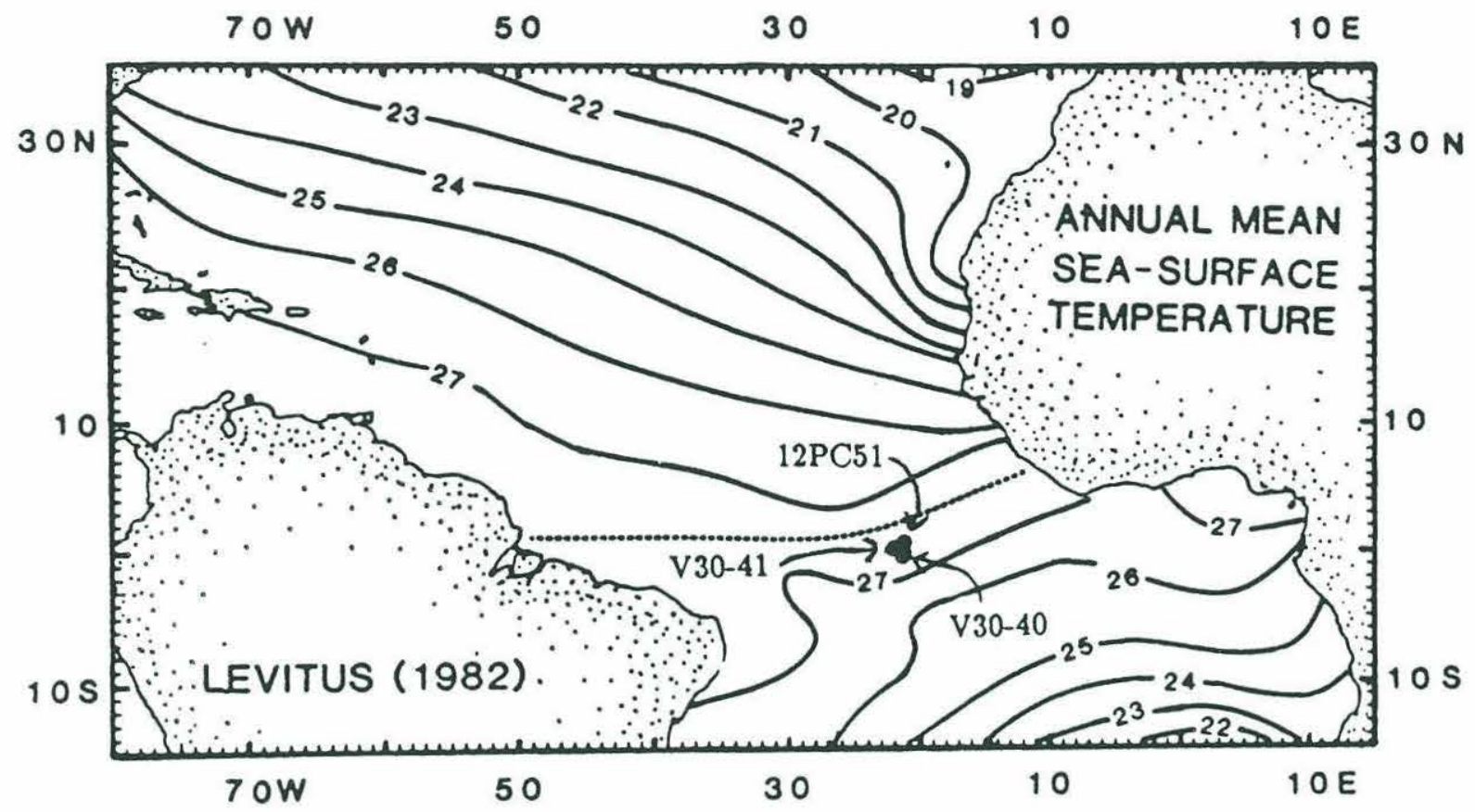

Figure 3-2: Solid circle is location of cores: $12 \mathrm{PC} 51 ; 0^{\circ} 0.25^{\prime} \mathrm{N}, 22^{\circ} 59.89^{\prime} \mathrm{W}, 3870 \mathrm{~m}, \mathrm{~V} 30-400^{\circ} 12^{\prime} \mathrm{S}$, $23^{\circ} 09^{\prime} \mathrm{W}$, and $\mathrm{V} 30-410^{\circ} 13^{\prime} \mathrm{N}, 23^{\circ} 04^{\prime} \mathrm{W}$ ). Map taken from Mix et al. (1986).

the $300-350 \mu \mathrm{m}$ fraction. The 8-10 individuals used per analysis were cleaned ultrasonically in $\mathrm{MeOH}$, crushed in $\mathrm{MeOH}$, and roasted under vacuum for one hour at $370^{\circ} \mathrm{C}$ before being reacted in $\mathrm{H}_{3} \mathrm{PO}_{4}$ at $50^{\circ} \mathrm{C}$. The evolved gas was distilled three times using frozen isopropanol and liquid nitrogen and the purified $\mathrm{CO}_{2}$ was then analysed on a VG Micromass $602 \mathrm{E}$ mass spectrometer. All results are reported as permil (parts per thousand; $\%$ ) deviations from the PDB standard using NBS-20 as a laboratory standard. Analytical precision is better than $0.10 \%( \pm 1 \sigma)$ based on NBS-20 replicates. Replicate analyses on a given sample are $\pm 0.2 \%$ ( 13 duplicates were run on different days for this core).

b) other geochemical techniques

Samples for $\mathrm{U}_{37}^{k}$ and $\mathrm{CaCO}_{3}$ analyses were taken at the same core levels as those for stable isotopes and faunal studies. Alkenones were recovered from the sediment and analyzed by the methods described in Chapter 2. These methods are also described in Farrington et al. (1988). The calcium carbonate content of sediments was determined by the technique described in 
Chapter 2, which is based on the method of Jones and Kaiteras (1983).

\subsubsection{Foraminiferal Assemblage Temperature Estimates}

The same samples used for $\delta^{18} \mathrm{O}$ analyses, after washing and drying, were sieved to $\geq 150 \mu \mathrm{m}$ and successively split until 300-500 whole planktonic foraminifera were obtained. For faunal analyses the 29 species and morphotypes used by the CLIMAP group $(1976,1981)$ were counted. SST estimates were then obtained using the modern analogue technique (Hutson, 1980; Prentice, 1980; Overpeck et al., 1985; Prell, 1985; Anderson et al., 1989). The modern analogue technique matches a downcore assemblage with modern core-top samples which have similar faunas, using a dissimilarity coefficient (Prell, 1985; Anderson et al., 1989). The 10 best fit core-tops are chosen and the average of their associated temperatures is the temperature estimate for the sample. The modern SST data base used is the same as that used by CLIMAP, and estimates produced by the modern analogue technique provide estimates that are comparable in value and precision to the CLIMAP transfer functions (Prell, 1985). However, analogue estimates correlate equally or better to observed SST and have lower standard errors than CLIMAP type estimates (Prell, 1985).

The analogue method was chosen for faunal SST estimates in this study because it has the advantage over transfer function estimates of providing a dissimilarity coefficient for each sample. The dissimilarity coefficient allows for sample by sample determination of how well each sample fits the analogue picks, which is in effect, a measure of the reliability of the estimate and is considered an advantage in situations where the communality of the samples is poor (dissimilarity coeficients of less than 0.2 are considered acceptable matches, Anderson et al., 1989). In certain situations analogues may be more reliable than other faunal methods such as factor analysis or factor temperature regression because analogue estimates do not depend on the entire modern data set. All SST estimates for this study produced from the raw faunal counts were provided by Dr. Warren L. Prell at Brown University. 


\subsection{Results}

\subsubsection{Stratigraphy}

Piston core 12PC51 has the typical coloration of an Atlantic Quaternary core (G. A. Jones, pers. comm., 1987). The top $3 \mathrm{~cm}$ are tan-grey; 4-7 cm light tan (Holocene), 7-12 $\mathrm{cm}$ dark tan with mottled brown, grading to brown (Holocene-glacial transition); $12-13 \mathrm{~cm}$ are light grey grading to medium grey at $13 \mathrm{~cm}$ (glacial), and below $13 \mathrm{~cm}$ it remains uniformly medium grey to the bottom of the core at $284 \mathrm{~cm}$. The color of the top $3 \mathrm{~cm}$ is typical of Atlantic core-tops which may indicate no sediment is missing. The $\delta^{18} \mathrm{O}$ and $\mathrm{CaCO}_{3}$ results suggest otherwise.

Estimates of ages down core $12 \mathrm{PC} 51$ are based on $\delta^{18} \mathrm{O}$ and $\% \mathrm{CaCO}_{3}$ stratigraphy with samples taken at $2 \mathrm{~cm}$ intervals down to $100 \mathrm{~cm}$ depth in the core. The $\delta^{18} \mathrm{O}$ results show the oxygen isotope stage 2 maximum at approximately $13 \mathrm{~cm}$ depth, with the $\% \mathrm{CaCO}_{3}$ maximum slightly shallower, at approximately $9 \mathrm{~cm}$. The offset of these maxima is also seen in core V30-40 (Jones and Ruddiman, 1982), which is sampled at the same detailed spacing as 12PC51 (Figure 3-3, Table 3-1 and Appendix A). Comparison of this record with ${ }^{14} \mathrm{C}$ dates for the $\delta^{18} \mathrm{O}$ maximum in the cores $\mathrm{V} 30-40$ and $\mathrm{V} 30-41$, which are from the same geographic location, indicate that this level corresponds to about $15 \mathrm{ky}$ (Mix and Ruddiman 1986). Typical sedimentation rates for this area are $\sim 2 \mathrm{~cm} / \mathrm{ky}$ (Curry and Lohmann, 1986; Mix and Ruddiman, 1986; Curry and Miller, 1989) which indicates that approximately the top $10 \mathrm{~cm}$ (or about $5.0 \mathrm{ky}$ ) of core 12PC51 may be missing. Holocene carbonate values at the top of box core 12BCP49 are the same as 12PC51 (87.4\%) and begin to drop after $17 \mathrm{~cm}$ depth, further confirming the loss of about $10 \mathrm{~cm}$ from the top of 12PC51 (Figure 3-4). Despite the uncertainty of the coretop stratigraphy, the isotopic stage 1-2 boundary (13 ky) is taken at $13 \mathrm{~cm}$ based on the determinations of Shackleton and Opdyke (1973). Based on this stratigraphy and by comparison with isotopic records and ${ }^{14} \mathrm{C}$ dating in core V30-40 (Mix and Ruddiman, 1985) the stage $2-3$ boundary ( $32 \mathrm{ky}$ ) is tentatively assigned to $37 \mathrm{~cm}$ depth. For purposes of comparison in this study, sediment from $0-7 \mathrm{~cm}$ is considered Holocene, and $15-21 \mathrm{~cm}$ is considered glacial "maximum". 


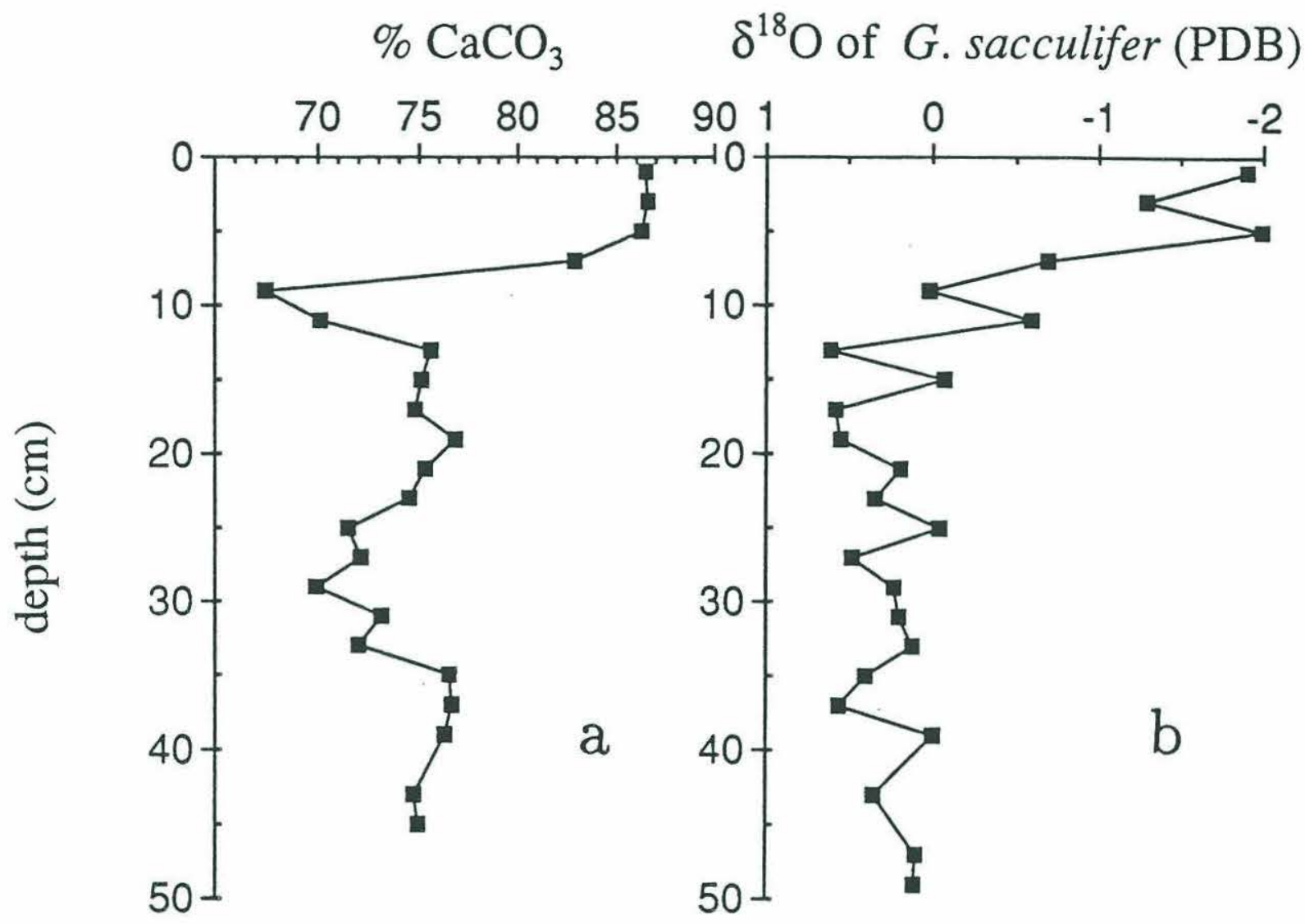

Figure 3-3: Stratigraphic control on core 12PC51. a.) $\mathrm{CaCO}_{3}$ content of the sediments b.) Foraminiferal $\delta^{18} \mathrm{O}$ values for Globigerinoides sacculifer. The point of maximum enrichment of ${ }^{18} \mathrm{O}$ values, at $4 \mathrm{~cm}$ deeper than the $\mathrm{CaCO}_{3}$ minimum, is approximately $13 \mathrm{~cm}$ depth. By comparison with ${ }^{14} \mathrm{C}$ dating on nearby cores V30-40 and V30-41 (Mix and Ruddiman, 1986) this is about $15 \mathrm{ky}$. There is no distinct stage 3 minmum in the $\delta^{18} \mathrm{O}$ in this core, which is similar to the $\delta^{18} \mathrm{O}$ in cores V30-40 and V30-41 cores in this area (Mix and Ruddiman, 1986). 


\begin{tabular}{|c|c|c|c|c|c|c|c|c|}
\hline \multirow[b]{2}{*}{$\begin{array}{l}\text { Depth } \\
(\mathrm{cm}) \\
\end{array}$} & \multirow[b]{2}{*}{$\mathrm{U}_{37}^{k}$} & \multirow[b]{2}{*}{$\begin{array}{c}\mathrm{U}_{37}^{k} \text { temperature } \\
\left({ }^{\circ} \mathrm{C}\right) \\
\end{array}$} & \multicolumn{2}{|c|}{ G. sacculifer } & \multirow[b]{2}{*}{$\begin{array}{r}{[37: 3]} \\
\mathrm{ng} / \mathrm{g} \\
\end{array}$} & \multicolumn{3}{|c|}{ MAT } \\
\hline & & & $\begin{array}{r}\delta^{18} \mathrm{O} \\
(\mathrm{PDB})\end{array}$ & $\begin{array}{r}\delta^{13} \mathrm{C} \\
(\mathrm{PDB})\end{array}$ & & $\begin{array}{r}{[37: 2]} \\
\mathrm{ng} / \mathrm{g}\end{array}$ & $\begin{array}{l}\text { SST } \\
\left({ }^{\circ} \mathrm{C}\right)\end{array}$ & $\begin{array}{c}\mathrm{CaCO}_{3} \\
\%\end{array}$ \\
\hline 1 & 0.952 & 27.50 & -1.90 & 1.48 & 22 & 440 & 26.70 & 88.0 \\
\hline 2 & 0.960 & 27.90 & - & - & 5 & 135 & - & - \\
\hline 3 & 0.940 & 27.20 & -1.42 & 2.14 & 12 & 191 & - & 87.3 \\
\hline 5 & 0.953 & 27.60 & -1.99 & 1.25 & 13 & 265 & 26.57 & 87.1 \\
\hline 7 & 0.926 & 26.80 & -1.04 & 1.30 & 11 & 140 & 26.52 & 82.9 \\
\hline 9 & 0.949 & 27.50 & -0.21 & 1.26 & 8 & 142 & 26.47 & 66.2 \\
\hline 11 & 0.977 & 28.30 & -0.59 & 1.26 & 6 & 240 & 25.14 & 71.2 \\
\hline 13 & 0.895 & 25.80 & 0.61 & 1.46 & 59 & 502 & 25.08 & 75.4 \\
\hline 15 & 0.938 & 27.10 & -0.07 & 1.47 & 100 & 1519 & 23.00 & 76.0 \\
\hline 17 & 0.924 & 26.70 & 0.57 & 1.48 & 171 & 2084 & 23.25 & 74.7 \\
\hline 19 & 0.877 & 25.30 & 0.55 & 1.50 & 269 & 1918 & 22.50 & 76.8 \\
\hline 21 & 0.862 & 24.80 & 0.19 & 1.48 & 319 & 1986 & 22.49 & 75.7 \\
\hline 23 & 0.908 & 26.20 & 0.36 & 1.49 & 197 & 1969 & 22.74 & 74.5 \\
\hline 25 & 0.928 & 26.80 & -0.04 & 1.49 & 103 & 1337 & 22.88 & - \\
\hline 27 & 0.882 & 25.40 & 0.48 & 1.37 & 245 & 1844 & 23.38 & 72.1 \\
\hline 29 & - & - & 0.23 & 1.57 & - & - & 21.53 & 70.5 \\
\hline 31 & 0.878 & 25.30 & 0.20 & 1.66 & 283 & 2041 & 23.23 & 72.6 \\
\hline 33 & - & - & 0.12 & 1.53 & - & - & 23.89 & 72.0 \\
\hline 35 & - & - & 0.41 & 1.48 & - & - & 23.26 & 76.5 \\
\hline 37 & 0.928 & 26.80 & 0.56 & 1.73 & 142 & 1836 & 23.80 & 77.6 \\
\hline 39 & - & - & . $\quad-$ & - & - & - & - & 77.1 \\
\hline 41 & - & - & - & - & - & - & - & 75.7 \\
\hline 43 & 0.887 & 25.60 & 0.35 & 1.56 & 160 & 1248 & 24.02 & 74.7 \\
\hline 45 & - & - & - & - & - & - & - & 74.5 \\
\hline
\end{tabular}

Table 3-1: Primary numerical results for core 12PC51, complete numerical data in Appendix A. 


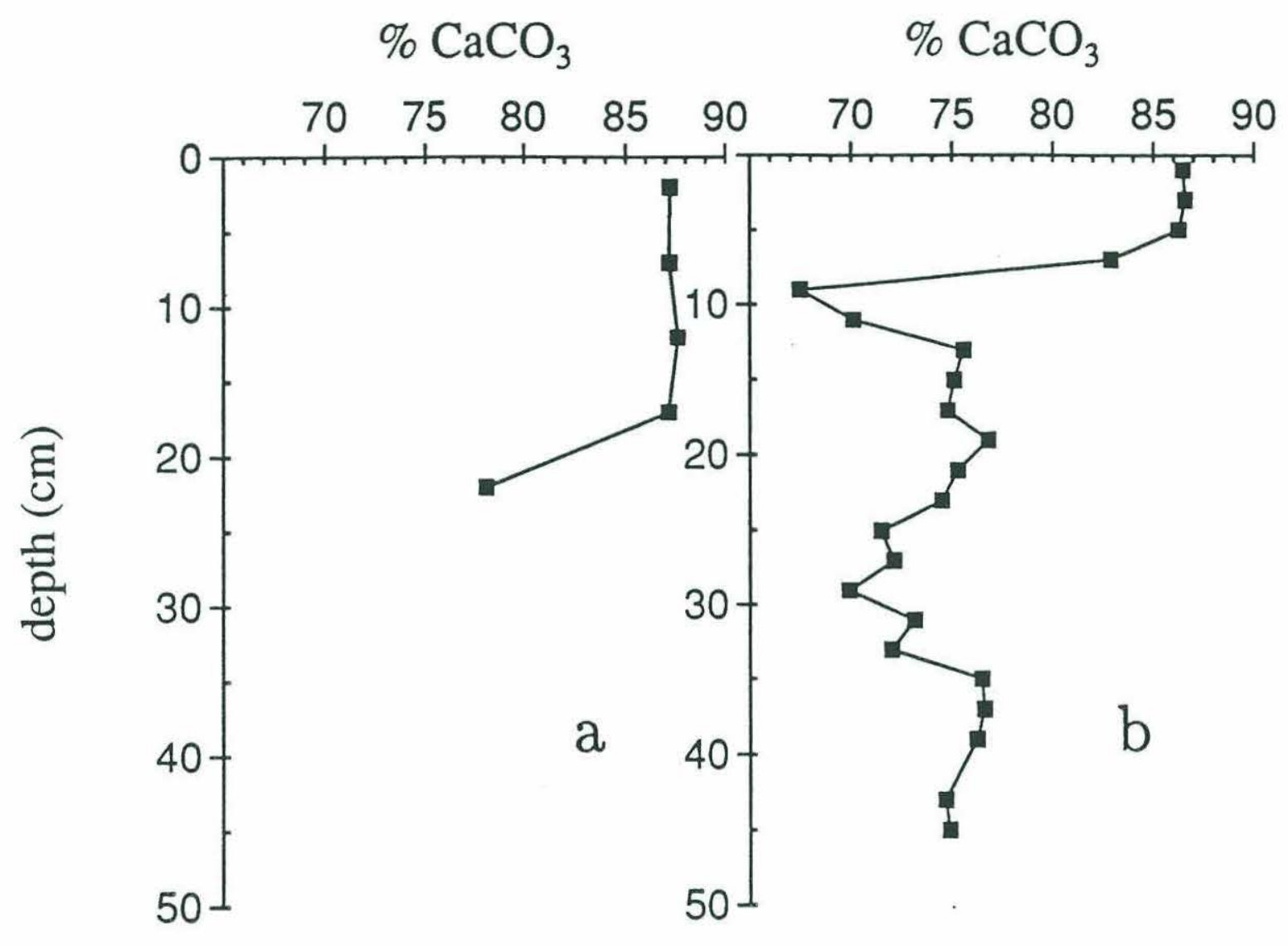

Figure 3-4: a). $\mathrm{CaCO}_{3}$ values for $\left.12 \mathrm{BCP} 49\left(0^{\circ} 0.5^{\prime} \mathrm{N}, 22^{\circ} 59.6^{\prime} \mathrm{W}, 3858 \mathrm{~m}\right) \mathrm{b}\right) . \mathrm{CaCO}_{3}$ results for the top of $12 \mathrm{PC} 51$. Note that decrease in $\mathrm{CaCO}_{3}$ content occurs after $17 \mathrm{~cm}$ in $\mathrm{BCP} 49$, and at $7-9 \mathrm{~cm}$ in PC51, indicating approximately $10 \mathrm{~cm}$ are missing from the top of the piston core that are present in the Soutar box core. 


\subsubsection{Oxygen Isotopes}

In core $12 \mathrm{PC} 51$, oxygen isotopes show a $\sim 2.08^{\circ} \%$ signal amplitude between average Holocene values $\left(\sim-1.77^{\circ} \%\right.$ o $)$ and average glacial values $(\sim 0.31 \%$ \% to interglacial signal amplitude is slightly greater, but comparable to the glacial-interglacial signal from nearby cores V30-40 $\left(\Delta \delta^{18} \mathrm{O} 1.72^{\circ} \%\right.$ ), and V30-41 $\left(\Delta \delta^{18} \mathrm{O} 1.85^{\circ} \%\right.$ ) (Mix and Ruddiman 1986). The maximum two point difference is $2.5 \%$ o between the $5 \mathrm{~cm}$ and $13 \mathrm{~cm}$ samples. This is also larger than the maximum 2 point difference at V30-40 $\left(1.80^{\circ} \%\right.$ ) and V $30-41\left(1.99^{\circ} \%\right.$ o $)$. The 13 duplicate samples for this core have been averaged in this plot.

In order to extract an SST signal from the isotope record, the ice volume effect must be subtracted from the total $2.08^{\circ}$ \% glacial-interglacial signal. This ice volume component is generally accepted to be between $\sim 1.4 \%$ (e.g. Bard et al. 1987) and $1.1 \%$ oo (Imbrie et al., 1973 ) with the most recent (and best) estimate based on Fairbanks's (1989) determination of a $121 \mathrm{~m}$ sea level change, equal to $1.33^{\circ} \%$. When the ice volume effect is taken out of the $\delta^{18} \mathrm{O}$ signal, a temperature and/or salinity signal of $0.75^{\circ} \%$ is left. This converts (at $0.22 \% /{ }^{\circ} \mathrm{C}$; Fairbanks and Mathews, 1978) to a interglacial to glacial temperature drop of $3.40^{\circ} \mathrm{C}\left( \pm 1^{\circ} \mathrm{C}\right)$.

\subsubsection{Foraminiferal Assemblage Temperature Estimates}

The modern analogue technique provides both a warm and a cool season temperature estimate (Figure 3-6, Table 3-1; See Appendix A for complete numerical results and faunal counts). Holocene temperatures $(0-7 \mathrm{~cm})$ agree within error estimates with present warm SST $\left(27.5^{\circ} \mathrm{C}\right)$, and have excellent dissimilarity coefficients of around 0.1 . Below $9 \mathrm{~cm}$ depth both the warm and cool temperature estimates begin to decrease rapidly to glacial maximum values $(15 \mathrm{~cm})$. The warm estimates drop from a Holocene average of $26.6^{\circ} \mathrm{C}$ to a glacial average of $23.0^{\circ} \mathrm{C}$ (at $15-21 \mathrm{~cm}$ ), the cool estimates drop from an average of $24.3^{\circ} \mathrm{C}$ in the Holocene to $15.7^{\circ} \mathrm{C}$ in the glaciation. For the warm estimates this is a $3.75^{\circ} \mathrm{C}$ interglacial-glacial temperature drop and for the cool estimates, an $8.6^{\circ} \mathrm{C}$ decrease. Coldest temperatures occur at $19-25 \mathrm{~cm}$. Below $9 \mathrm{~cm}$ the dissimilarity coefficients jump to $\geq 0.35$, indicating these assemblages have no good modern analogues. The high dissimilarity coefficients are almost twice what is considered acceptable for this method. For these samples, the sites which were chosen as modern analogues for the glacial levels are from high latitudes (generally between $25^{\circ}-45^{\circ}$ ), whereas the Holocene matches are 


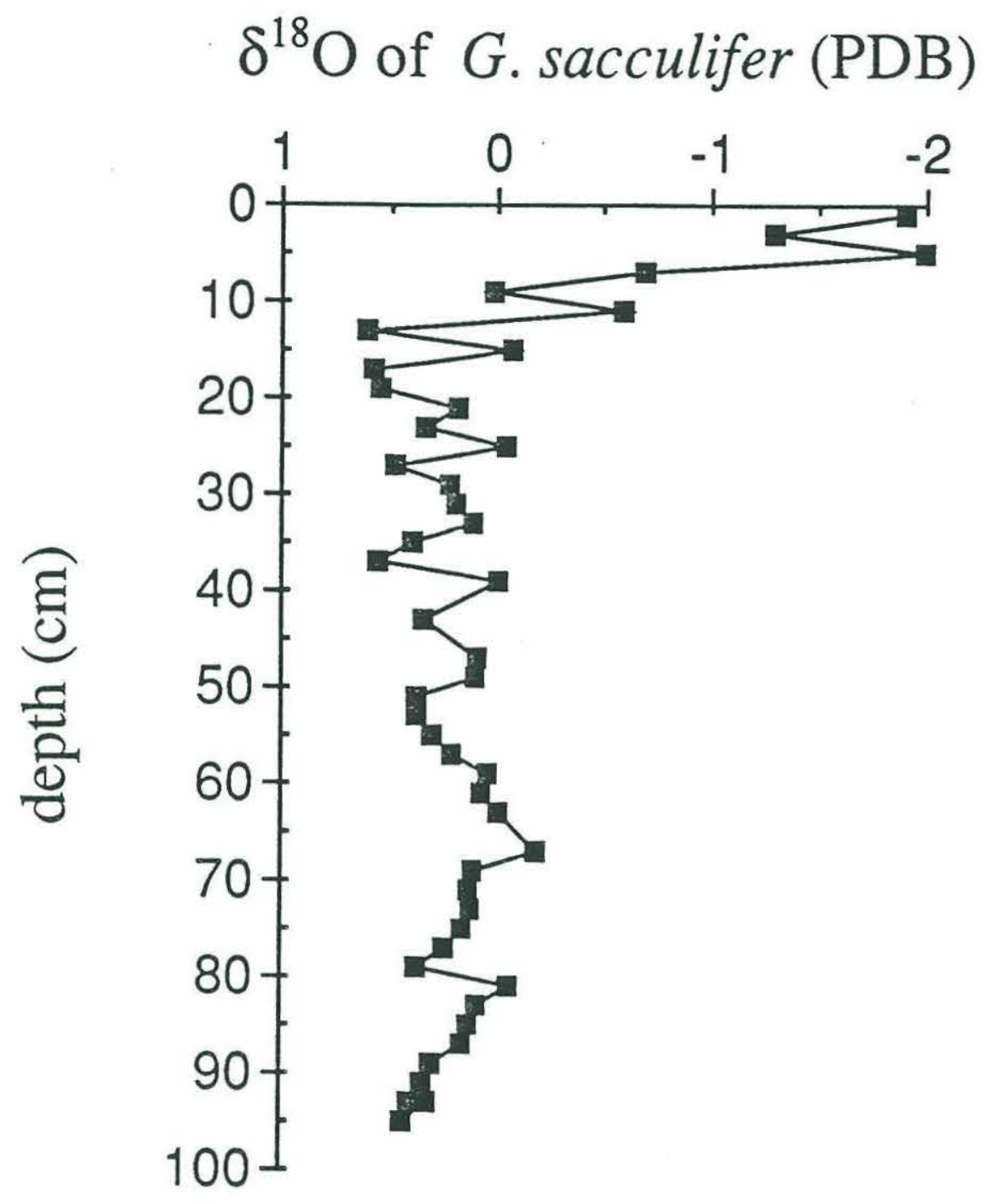

Figure 3-5: $\delta^{18} \mathrm{O}$ of Globigerinoides sacculifer $300-350 \mu \mathrm{m}$. The mean glacial to interglacial signal is $2.08 \%$. The estimated the ice volume component of this signal is $1.33 \%$ which leaves $0.75 \%$ as the temperature portion. This converts (at $0.22^{\circ} \%$ o per ${ }^{\circ} \mathrm{C}$ ) to $\sim 3.40^{\circ} \mathrm{C}$ glacial to interglacial temperature change. 

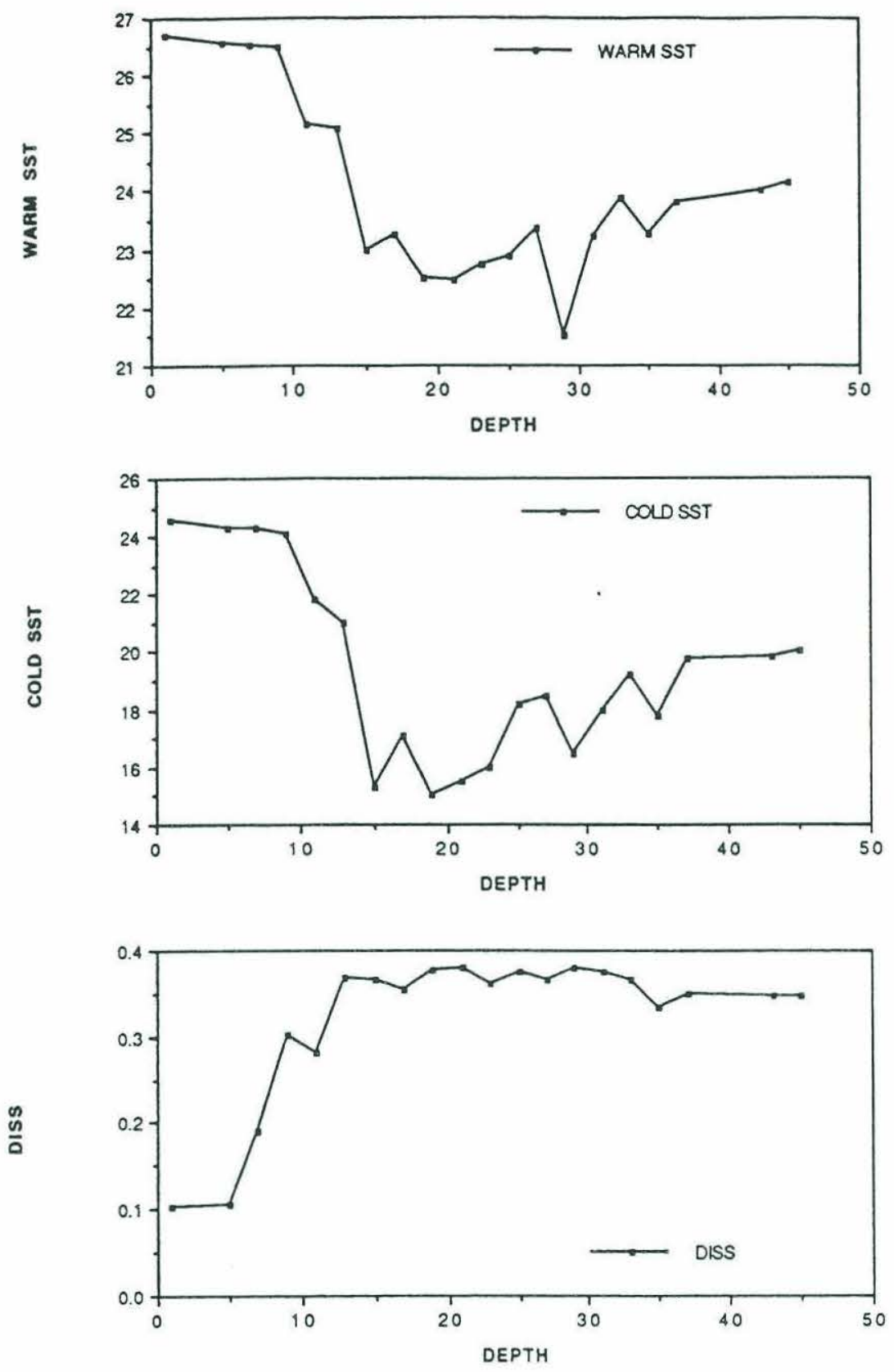

Figure 3-6: Foram assemblage temperature estimates calculated using the modern analogue technique (Prell, 1985). Average glacial to interglacial change is $\sim 3.7^{\circ} \mathrm{C}$ for warm estimates, and $\sim 8.6^{\circ} \mathrm{C}$ for cold estimates. High dissimilarity coeficients $(\geq 0.35)$ are associated with the cooler, glacial level estimates indicating the assemblages at those levels have no good modern analogues. 
from nearby tropical locations.

Transfer function temperature estimates were also run for this core and results are included here in Figure 3-7 for completeness and to allow comparison of the analogue data with other studies. This transfer function program is the one (with some modifications) used to obtain past sea surface temperatures in the Equatorial Atlantic by CLIMAP $(1976,1981)$, Prell et al. (1976), Mix and Ruddiman (1985), Mix et al. (1986), and McIntyre et al. (1989). The two faunal techniques provide estimates that agree within the errors of the methods, with the analogue technique providing slightly cooler estimates (of as much as $2.1^{\circ} \mathrm{C}$ for an individual pair) in stage 2 . Temperature estimates produced from the raw faunal counts were provided by W. Prell, Brown University. Numerical results are provided in Appendix A.

\subsubsection{Alkenone Unsaturation Ratios}

$\mathrm{U}_{37}^{k}$ temperature estimates averaged for the Holocene $(0-7 \mathrm{~cm})$ are $27.5^{\circ} \mathrm{C}$, and the average glacial temperature $(15-21 \mathrm{~cm})$ is $26.0^{\circ} \mathrm{C}$, indicating an average temperature change of $1.56^{\circ} \mathrm{C}$ between the two climatic regimes (Figure 3-8, Table 3-1). $\mathrm{U}_{37}^{k}$ shows an initial cooling at $13 \mathrm{~cm}$ of $1.5-2.0^{\circ} \mathrm{C}$, a warming of $\sim 1^{\circ} \mathrm{C}$ at $15-17 \mathrm{~cm}$, and then coolest temperatures (about $25^{\circ} \mathrm{C}$ ) at $19-21 \mathrm{~cm}$ (or about $4 \mathrm{ky}$ earlier). The two point maximum difference is $3.5^{\circ} \mathrm{C}$, between the $11 \mathrm{~cm}$ sample and the $21 \mathrm{~cm}$ sample.

The abundances of the $\mathrm{C}_{37}$ alkenones increased four fold during the glaciation (Figure 3-9). The increase begins at $13-15 \mathrm{~cm}$, but highest concentrations are at $17-23 \mathrm{~cm}$, and again at 27-37 cm. This increase in $\mathrm{C}_{37}$ alkenone concentrations is coincident with an increase in total organic carbon (TOC) (Figure 3-9, Jahnke et al., 1989). As with the alkenone concentrations, TOC content of the sediments is highest below $15 \mathrm{~cm}$.

\subsection{Discussion}

The ultimate goal of this study is to compare three different temperature indicies to assess better the glacial to interglacial temperature change in the Equatorial Atlantic. Before this can be done, the methods being used for the comparison, the season being compared, and the time slices used, must be assessed. 

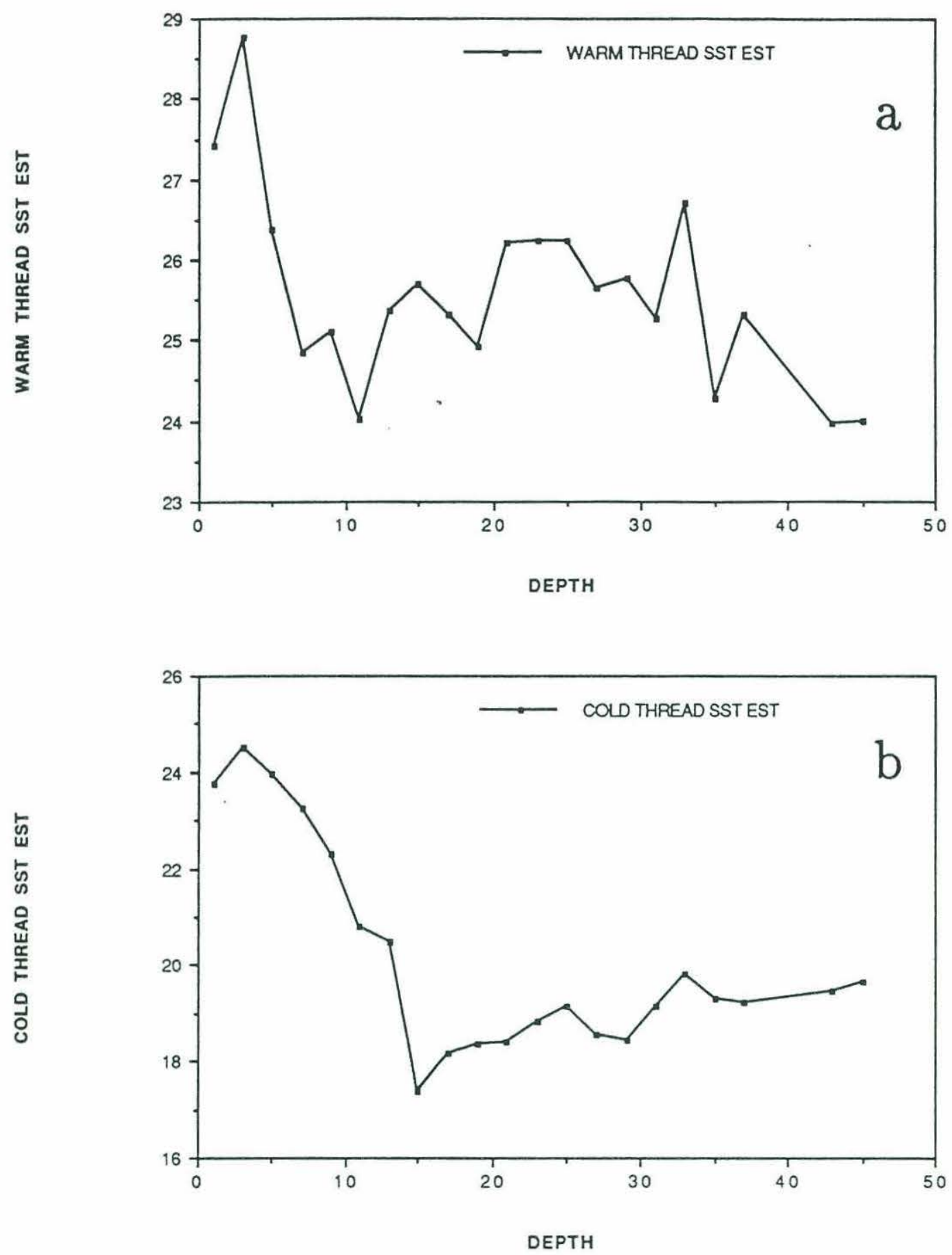

Figure 3-7: Foraminiferal assemblage temperature estimates calculated using transfer functions (thread). a) Warm temperature estimates. b) Cold temperature estimates. 


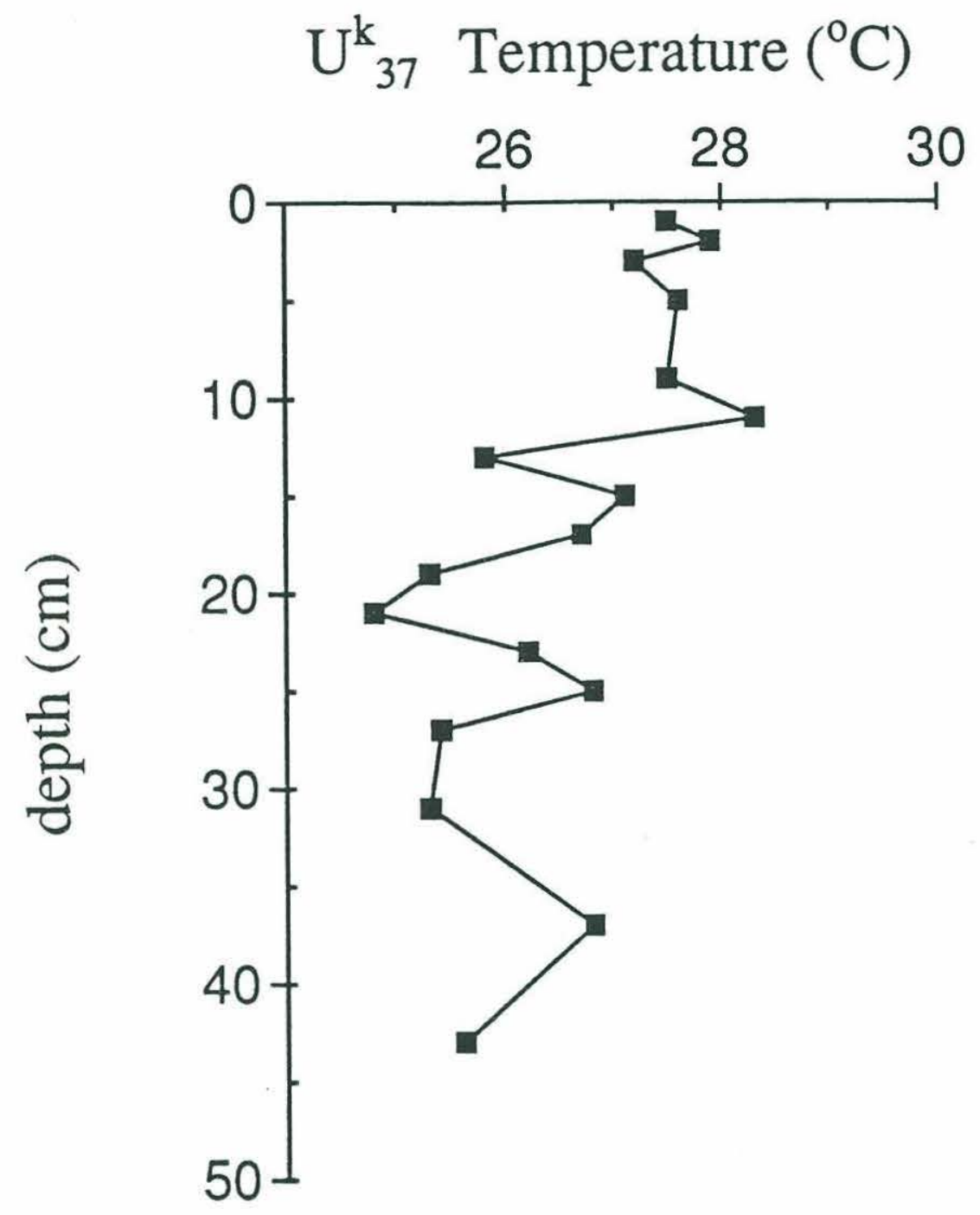

Figure 3-8: $\mathrm{U}_{37}^{k}$ temperature estimates. The data does have some scatter, but the mean temperatures for the two climatic periods have been calculated; interglacial $\sim 27.5^{\circ} \mathrm{C}$ and glacial $\sim 26.0^{\circ} \mathrm{C}$. This gives a glacial to interglacial temperature range of $\sim 1.6^{\circ} \mathrm{C}$. 


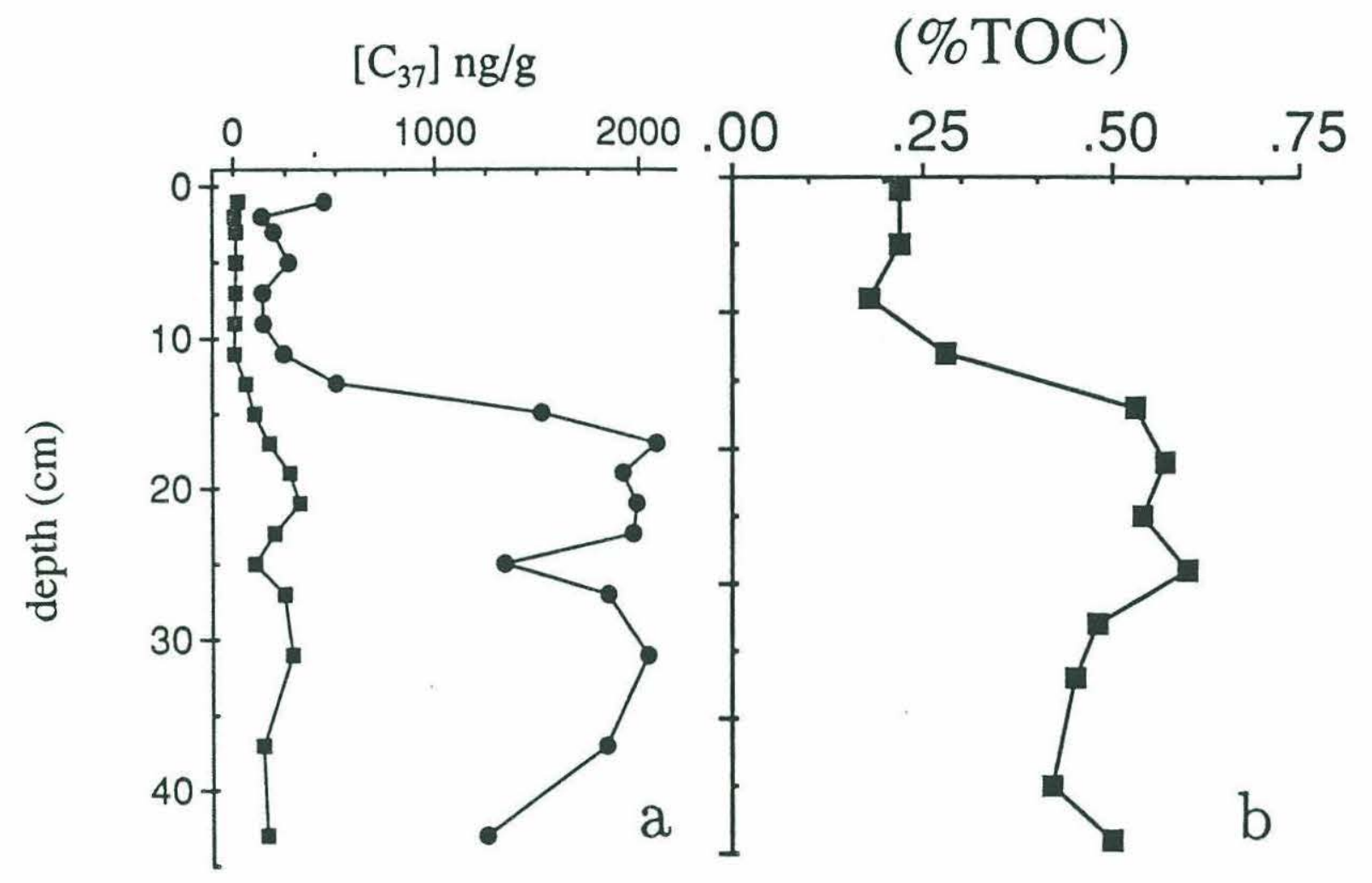

Figure 3-9: a.) Concentration $(\mathrm{ng} / \mathrm{g})$ in the sediments of the $\mathrm{U}_{37}^{k}$ alkenones. $=37: 2, \bullet=37: 3$. Numerical results appear in Appendix A. b.) Total organic carbon content of the sediments (after Jahnke et al., 1989). 
Dissimilarity coefficients of the analogue SST estimates are high in sediments older than Holocene, indicating the communalities are low, and that SST estimates are questionable. As with transfer function SST estimates, the magnitude of the temperature change may be suspect, but the sense should be correct, and useful interpretations can still be made (Mix et al., 1986). Modern analogue warm estimates in this core are in phase with cold season estimates and the oxygen isotope record, whereas warm transfer function estimates are not. This is also true for core V30-40 where temperature estimates are slightly out of phase with both isotopes and cold temperature estimates in that core (McIntyre et al., 1989), for which there is no sufficient explaination. The fact that warm analogue estimates show changes concurrent with the other faunal data in 12PC51 suggests analogue estimates are perhaps better suited for the comparisons in this study.

Stable isotopes were run on $G$. sacculifer, because it is known to be a surface dwelling species (Fairbanks et al., 1980, 1982). However, today the isotope composition of this species is known to be affected more by surface salinity changes caused by precipitation and evaporation changes than by temperature changes in the Equatorial Pacific, because of the large precipitation effects there relative to the small annual temperature changes (Curry et al., 1983). Also, G. sacculifer is not only considered a tropical species, but is also included in the divergence assemblage of McIntyre et al. (1989). Thus G. sacculifer, which inhabits intermediate depths up to 50-100 m (Fairbanks et al., 1980), could be influenced by changes in upwelling conditions (Prell and Curry, 1981). The large glacial to interglacial temperature signal of $G$. sacculifer $\left(3.40^{\circ} \mathrm{C}\right)$ may reflect surface salinity variations and subsurface changes as well as temperature changes. Despite the "divergence" classification of this species, its $\delta^{18} \mathrm{O}$ signal suggests smaller SST changes than the assemblage estimates. Mix et al. (1986) also note that $\delta^{18} \mathrm{O}$ SST estimates from $G$. sacculifer are not as low as transfer function estimates in the last glacial maximum, and attribute the discrepancy to problems with faunal assemblage estimates, as discussed earlier.

A choice had to be made as to which "season" of the analogue results to use for a comparison with $\mathrm{U}_{37}^{k}$ and $\delta^{18} \mathrm{O}$ temperature estimates because boreal winter is the warm season in the Equatorial Atlantic. Also, both $\mathrm{U}_{37}^{k}$ and $\delta^{18} \mathrm{O}$ produce a single number which can only be interpreted as representing the growth season of the organism on which the method is based. Coccoliths are most abundant in fall to winter in the tropical Atlantic (Smayda, 1980), the 
time that SST in this region is warmest. Assuming that in the Equatorial Atlantic most of the biomass of the coccolithophores is produced during this period, the warm season assemblage estimate was chosen for comparison in this study.

When the down-core records of $\delta^{18} \mathrm{O}, \mathrm{U}_{37}^{k}$, and analogue temperatures are compared, differences in signal timing between the different methods can be seen (Figure 3-10). In core 12PC51 the $\mathrm{U}_{37}^{k}$ temperature estimates are slightly out of phase with the faunal records. This may be due to the faunal and floral analyses being conducted on different samples, or to different factores controlling the temperatures recorded by the different organisms. In order to compare results between the three paleotemperature records, Holocene averages were chosen to be the levels $0-7 \mathrm{~cm}$ and glacial averages are those values from the levels $15-21 \mathrm{~cm}$. These levels were chosen to include the minimum and maximum temperature estimates from each method

The floral and faunal methods agree within the errors of the estimates $\left(1^{\circ} \mathrm{C}\right)$ in the Holocene sediments, with $U_{37}^{k}$ always warmer. $U_{37}^{k}$ is more consistent with Levitus (1982) values which are also about $1^{\circ} \mathrm{C}$ warmer than transfer function estimates for this location (Mix et al., 1986). The agreement between analogues and $U_{37}^{k}$ where communalities of the analogues are good, is reasonable assurance that the $\mathrm{U}_{37}^{k}$ is able to quantatively estimate SST downcore. Although both estimates agree within their respective errors, the fact that $\mathrm{U}_{37}^{k}$ is closer to the modern (Levitus) values, may mean that $\mathrm{U}_{37}^{k}$ is a better SST estimator here. Part of the difference between the two estimates may be due to the different depth constraints of the two organisms (see Chapter 1 for a full discussion) and, in part to the different seasonality of the two types of organism on which the methods are based.

Analogue and alkenone paleotemperature estimates are positively correlated (Figure 3-11). A linear regression of these data produces a line of slope 0.45 , and $r=0.653$, which indicates only a weak relationship between the two methods. It should be noted, however, that the three points that fall closest to the line, and indicate best correlation (at the warmest end), are those from Holocene sediments, where the communalities of the analogue estimates are most reliable. Thus, it is maintained that despite the low correlation between the two data sets, $\mathrm{U}_{37}^{k}$ appears to be a reasonable estimator of SST, because where analogues are most reliable, the correlation is very good.

The $1.56^{\circ} \mathrm{C}$ glacial-interglacial change in temperature indicated by the $\mathrm{U}_{37}^{k}$ (Figure 3-8, Fig- 


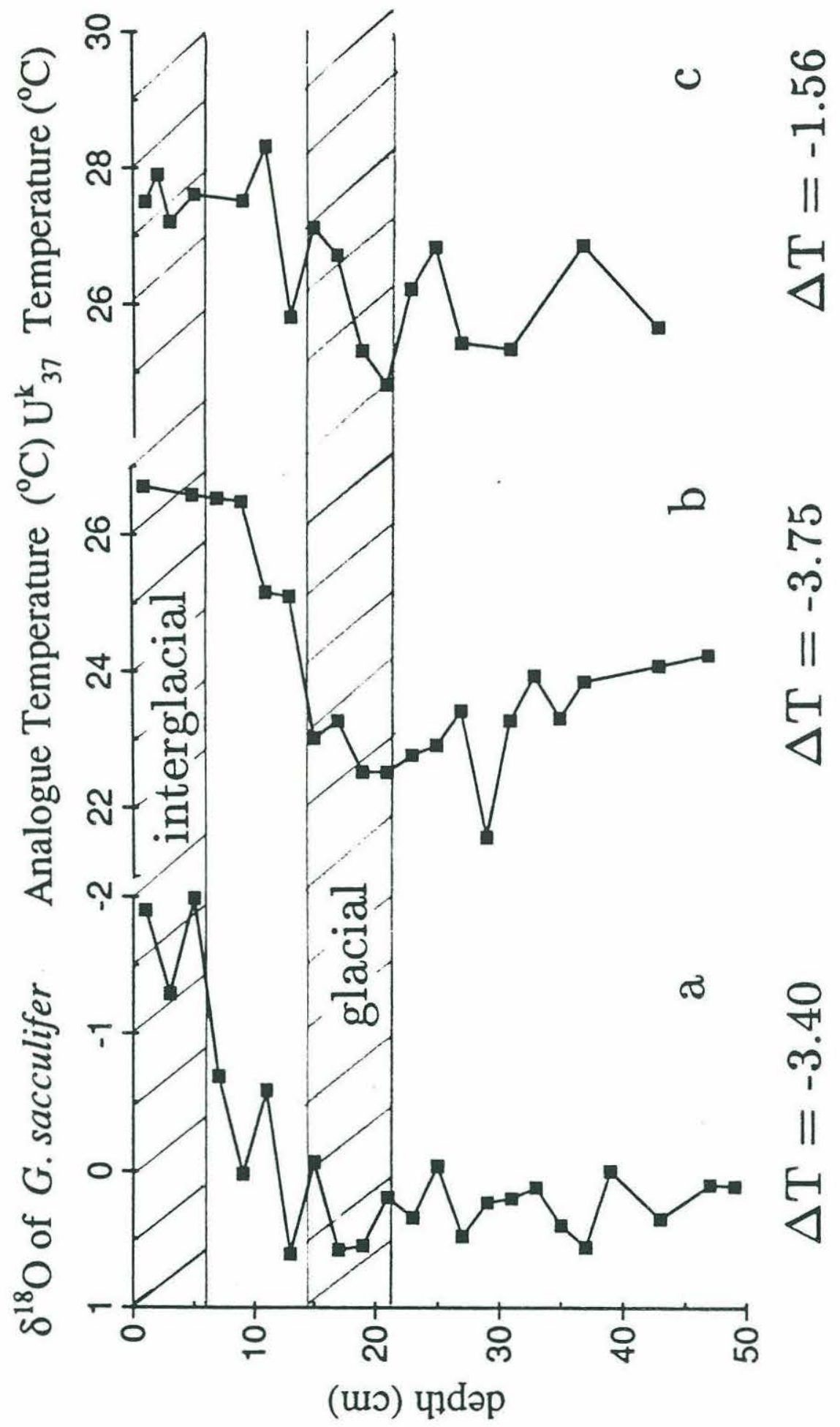

Figure 3-10: Figure 15. The plots of a.) $\delta^{18} \mathrm{O}$ of G. sacculifer, b.) Modern analogue technique temperature estimates and c.) $\mathrm{U}_{37}^{k}$ temperature estimates on the same vertical axis. 


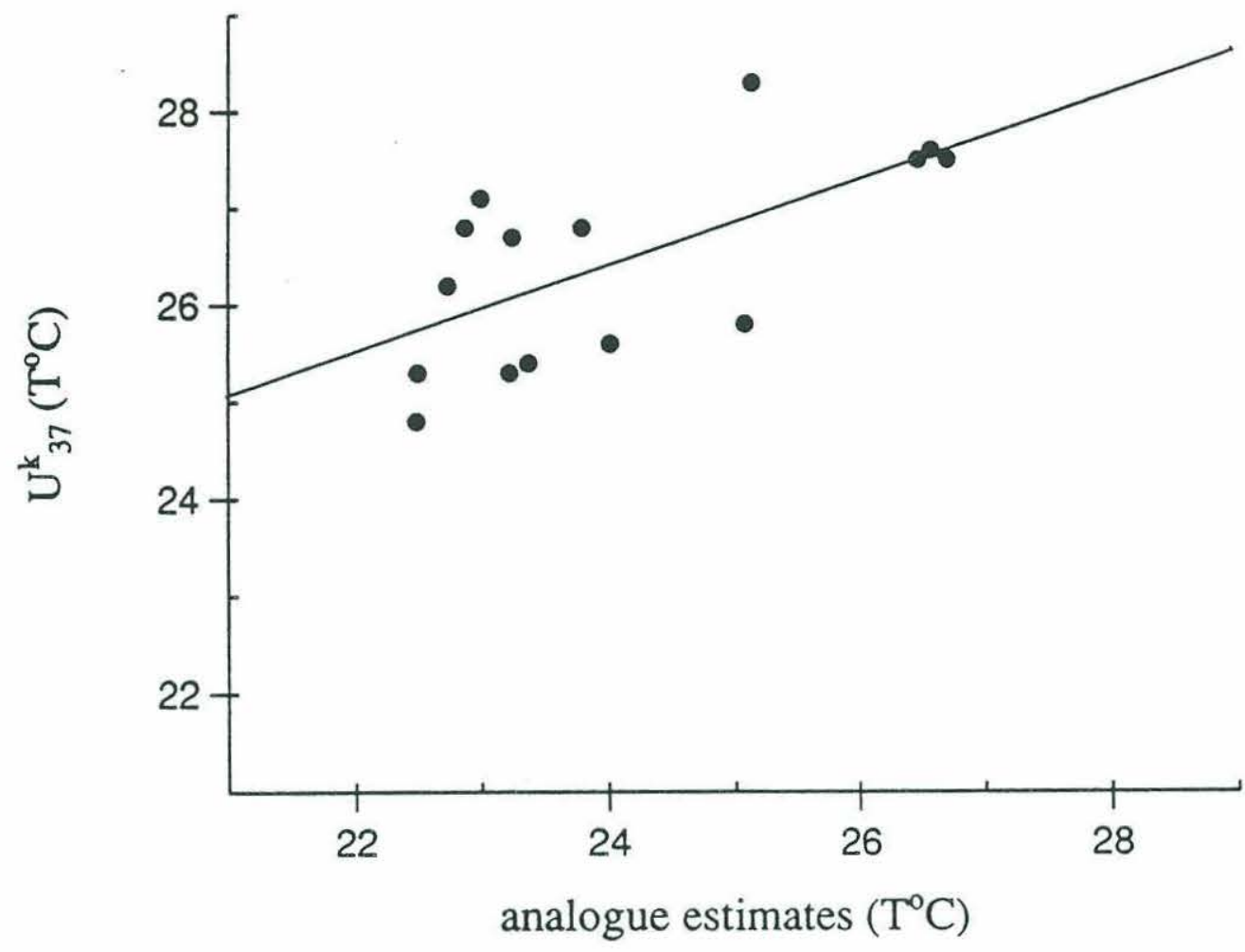

Figure 3-11: $\quad \mathrm{U}_{37}^{k}$ temperature estimates ploted versus analogue temperature estimates for the same sediment depths from core 12PC51. Linear regression for the data produces a line of slope of 0.45 $\left({ }^{\circ} \mathrm{C} /{ }^{\circ} \mathrm{C}\right.$; y-intercept 15.6$)$ and $\mathrm{r}=0.653$, indicating a weak relationship between the two methods. The three points that cluster about the line at the warm end are from Holocene levels in the core, where communalities of faunal estimates are good, indicating a good correlation between the methods where foraminiferal results are most reliable.

ure 3-10) is smaller than the $3.75^{\circ} \mathrm{C}$ change estimated from the warm season analogue estimate and the $3.40^{\circ} \mathrm{C}$ estimate of the $\delta^{18} \mathrm{O}$ record. At glacial and deglacial levels $(9-15 \mathrm{~cm})$ communalities in the faunal assemblages are poor. Because differences between the temperature estimates at glacial levels are $\geq 2^{\circ} \mathrm{C}$, nearly double those seen during the Holocene, and greater than the error estimates, they may reflect real differences in the habitats of the different organisms. The high dissimilarity coefficients of the glacial level analogues are an indication that their temperature estimates may be suspect. It is likely therefore, that the foraminifera may be recording some combination of effects, the most likely of which are both SST and changes in sub-surface oceanographic conditions such as changes in nutrient levels, and thermocline effects (Fairbanks 
and Weibe, 1980; Fairbanks et al., 1980; Fairbanks et al., 1982), and/or advection (McIntyre et al. 1989). If this is true, and assuming that $\mathrm{U}_{37}^{k}$ reflects temperature in the uppermost mixed layer, then the $U_{37}^{k}$ temperatures can be used to begin to sort out the several influences on foraminiferal assemblage SST estimates in this location in the last glaciation. Specifically, it can be used to test the two models (b or c) of McIntyre et al. (1989; see Figure 3-1) (Of course all three estimates could be quite wrong, but it is hoped that this is not true). Although the relative proportions of different faunas in the cold season estimates of McIntyre et al. (1989) in core V30-40 indicate a decrease in the temperature of advected water along with an increase in divergence in the glacial maximum, advection of cool waters along the equator is not supported by nutrient data from the Equatorial Atlantic today (Oudot and Morin, 1987).

Alkenone temperature estimates indicate that warm season temperatures were not as cold as indicated by the assemblages. Therefore, either trade winds and their associated upwelling were not stronger (if model $\mathrm{c}$ is more correct), or advection was not an important component in the glacial maximum signal for the warm season (if model b is more correct). Many studies indicate that winds did increase in the last glacial maximum (Parkin and Shackleton, 1973; Parkin, 1974, Parkin and Padgham, 1975; Manabe and Hahn, 1977; Sarnthein et al., 1981, Manabe and Broccoli, 1985). If the same interhemispheric mechanisms are at work for the cold season as the present day, divergence was primarily responsible for SST reduction in the glacial maximum and advection at the equator was probably not a significant factor. Therefore, the warm SST indicated by the alkenones and cooler foraminiferal temperature estimates supports McIntyre et al.'s model (b), that increased divergence due to stronger winds resulted in a shallower thermocline and an increase in upwelling conditions (similar to those described by Prell and Curry (1981) in the Arabian Sea), without a large decrease in actual SST.

Increased divergence rather than increased advection as the primary cause of SST lowering, is supported by a comparison of mass accumulation rates for two representative intervals for the glacial and interglacial intervals in core 12PC51 (Table 3-2). Sedimentation and carbonate accumulation rates were about the same for both climatic regimes. However, the total planktonic foraminiferal accumulation rate was only half as much in stage 2 as in the Holocene. Despite the decrease in accumulation of "warm" foraminiferal species such as G. sacculifer and Globigerinodes ruber, the accumulation of the divergence and dissolution-resistant species 


\begin{tabular}{lrr}
\hline & $\begin{array}{r}\text { stage } 1 \\
(0-2 \mathrm{~cm})\end{array}$ & $\begin{array}{r}\text { stage 2 } \\
(18-20 \mathrm{~cm})\end{array}$ \\
\hline \hline \% $\mathrm{CaCO}_{3}$ 12PC51 & 86.47 & 76.80 \\
sedimentation rate $\left(\mathrm{cm} \mathrm{ky}^{-1}\right)$ & 1.76 & 1.90 \\
$\mathrm{CaCO}_{3}$ accumulation rate $\left(\mathrm{gm} \mathrm{cm}^{-2} \mathrm{ky}^{-1}\right)$ & 1.31 & 1.16 \\
non-carbonate accumulation rate $\left(\mathrm{gm} \mathrm{cm}^{-2} \mathrm{ky}^{-1}\right)$ & 0.21 & 0.31 \\
total planktonic foram. accumulation rate $\left(\# \mathrm{~cm}^{-2} \mathrm{ky}^{-1}\right)$ & 22,374 & 11,957 \\
$G$. sacculifer accumulation rate $\left(\# \mathrm{~cm}^{-2} \mathrm{ky}^{-1}\right)$ & 4733 & 480 \\
$G$. ruber accumulation rate $\left(\# \mathrm{~cm}^{-2} \mathrm{ky}^{-1}\right)$ & 8825 & 1079 \\
$N$. dutertrei accumulation rate $\left(\# \mathrm{~cm}^{-2} \mathrm{ky}^{-1}\right)$ & 746 & 2392 \\
fragments to planktonic foraminifera ratio & 0.13 & 0.55 \\
& & \\
\hline
\end{tabular}

Table 3-2: Representative rates for stage $1(0-2 \mathrm{~cm})$ and stage $2(18-20 \mathrm{~cm})$ in core 86 Gyre 1412 PC51. Sedimentation rates were based on isotope stages of Shackleton and Opdyke (1973), and comparison to the isotope record of core V30-40 (Mix and Ruddiman (1985). Sedimentation rate for stage 1 was calculated assuming $10 \mathrm{~cm}$ are missing from the top of the core; assuming no sediment is missing from the core top would provide a sedimentation rate of $1 \mathrm{~cm} / \mathrm{ky}$ and a $\mathrm{CaCO}_{3}$ accumulation rate of only $0.75 \mathrm{gm} \mathrm{cm} \mathrm{cm}^{-2} \mathrm{ky}^{-1}$, and all other stage 1 rates would be lowered accordingly. Accumulation rates were calculated using the method of Curry and Lohmann (1986; using their formula for bulk density: $\left.\rho_{d r y}=0.0066\left(\% \mathrm{CaCO}_{3}\right)+0.29\right)$.

Neogloboquadrina dutertrei actually quadrupled, indicating increased foraminiferal production.

Therefore, the decrease in foraminiferal accumulation rates can be attributed to increased dissolution of tests, as evidenced by an increase in the fragment to planktonic ratio in stage 2, due to the presence of more corrosive bottom waters in this location during the last glaciation (Oppo and Fairbanks, 1987). Because $\mathrm{CaCO}_{3}$ accumulation rates remain approximately the same between stages 1 and 2, part of the difference must be made up in the accumulation of other carbonate tests, most probably coccoliths, which indicates that primary productivity was actually higher in the glaciation.

Increased primary productivity is further supported by the greater TOC and alkenone concentrations in glacial sediments. TOC is considered a measure of productivity, and the abundance of alkenones in the sediment are a rough measure of Prymnesiophyte productivity, if other sedmentation factors such as bottom water oxygen concentration, and the organic matter degradation rate constant remain the same (Emerson, 1985; Prahl et al., 1989a). Bottom water oxygen was probably somewhat lower in glacial times at this location (Curry and Lohmann, 1983, 1985; Oppo and Fairbanks, 1987). But TOC is still useful as an approximator of pro- 
ductivity and work by Curry and Lohmann (1983) indicates there may have been an increase in productivity as much as 2-3 times that of present day in the Equatorial Atlantic in the last glaciation, which is attributed to enhanced upwelling. An increase in productivity attributed to upwelling is also seen in the eastern tropical Pacific in glacial times (Pederson, 1983). Although increased divergence (upwelling) is known to enhance productivity, advection of cooler waters would not necessarily be expected to do so (Oudot and Morin, 1987), further supporting the divergence hypothesis.

The $\mathrm{U}_{37}^{k}$ temperature estimates from this study (core 12PC51) have been converted to age and compared to the results of Brassell et al. (1986b), which have been converted to temperature and plotted versus age for this purpose (Figure 3-12). Core M16415 is from the Kane Gap, off Senegal, and sits in the zone of coastal upwelling off Northwest Africa. Brassell et al. (1986b) $\mathrm{U}_{37}^{k}$ results from core M16415 were converted to temperature using the Prahl and Wakeham (1987) relationship and converted to age based on the $\delta^{18} \mathrm{O}$ stratigraphy of Brassell et al. in that core and the isotope stage ages of Shackleton and Opdyke (1973). Presently, SST at the location of core M16415 is cooler than at the site of $12 \mathrm{PC} 51$ today by $2^{\circ} \mathrm{C}$, about $26^{\circ} \mathrm{C}$ (Levitus, 1982; Figure 3-1) and is estimated to be about $22-23^{\circ} \mathrm{C}$ at $18-20 \mathrm{ka}$ (Mix et al., 1985). There is no certified standard reference nor even an ad-hoc working reference material which can be used to intercalibrate $\mathrm{U}_{37}^{k}$ results between laboratories, as with stable isotopes, however, a reasonable comparison can nonetheless be made between the two data sets. Although core $12 \mathrm{PC} 51$ is sampled in much greater detail, both cores clearly show a temperature drop at about $13 \mathrm{ka}$ (the stage 1-2 boundary). The temperature drop at the coastal location is greater (about $3.5^{\circ} \mathrm{C}$ as opposed to $1.6^{\circ} \mathrm{C}$ in the equatorial core), which is reasonable, given the expectation of greater upwelling due to stronger winds during the glaciation (Parkin and Shackleton, 1973; Parkin, 1974, Parkin and Padgham, 1975; Sarnthein et al., 1981), and agrees well with faunal estimates for that location at that time (Mix et al., 1985). Further, with such sparse data points Brassell et al. (1986b) may have hit only the extreme stage 2 values, and by missing the smaller scale fluctuations seen in this study, produced an aliased record thate missed the small scale fluctuations seen in this study. The reason for the better agreement of glacial $\mathrm{U}_{37}^{k}$ temperature estimates from core M16415 with faunal estimates there than those at core 12PC51 may also be due to the presence of faunas with better communalities at the coastal site during 


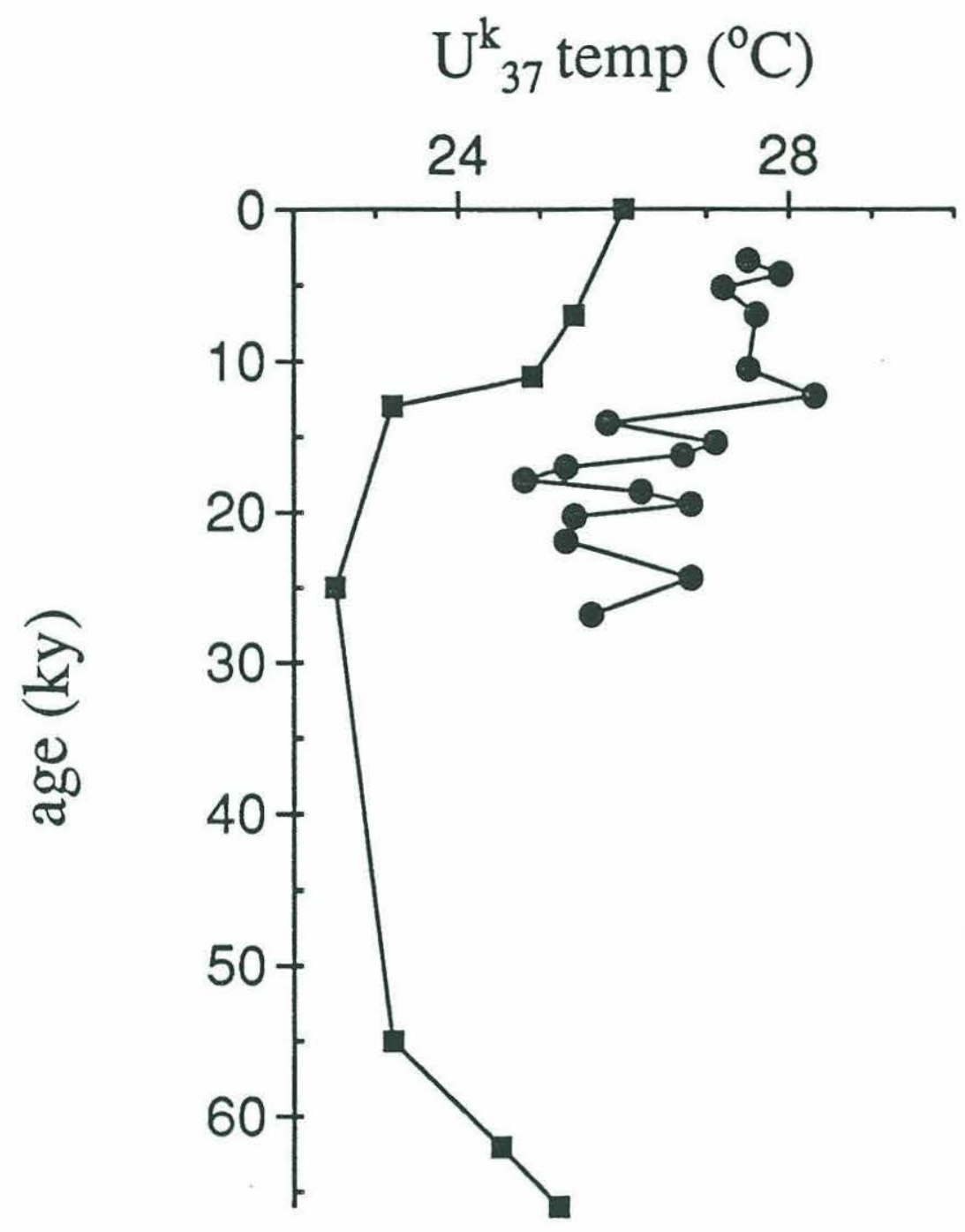

Figure 3-12: Plot of $U_{37}^{k}$ results for core 12PC51 (this study, solid circles) and that of core M16415 (Brassell et al., 1986b); solid squares). Data for core M16415 were converted to temperature, and replotted versus age for this comparison. 
the glaciation. However, this cannot be assessed with data available at this time.

The interglacial to glacial temperature decrease indicated by the alkenones $\left(1.56^{\circ} \mathrm{C}\right)$ is smaller than both $\delta^{18} \mathrm{O}\left(3.40^{\circ} \mathrm{C}\right)$ and assemblage estimates $\left(3.75^{\circ} \mathrm{C}\right)$ and so, the $\mathrm{U}_{37}^{k}$ estimates have an even greater disparity with terrestrial estimates of tropical temperatures during glaciation (5- $6^{\circ} \mathrm{C}$; Hansen et al., 1984; Rind and Peteet, 1985). Part of the difference can be ascribed to the fact that the alkenone temperature estimate must be considered a warm season estimate, while the land estimates are annual averages. Nonetheless, application of the $\mathrm{U}_{37}^{k}$ technique in this instance has not been able to resolve the discrepancy between land and marine estimates of tropical temperatures at the last glacial maximum, and in fact suggests that the disparity was even greater, reinforcing CLIMAP's (1981) conclusion that tropical Atlantic SST's were not much lower than today's. This glacial temperature pattern of greater lowering of surface temperatures over continents fits well with model results indicating that such a temperature gradient would be accompanied by increased trade winds in the tropical Atlantic (Manabe and Hahn, 1977), which in turn supports this sudy's conclusion that increased divergence was the primary cause of SST lowering.

\subsection{Conclusions}

Quantitative application of the $U_{37}^{k}$ paleotemperature technique, when compared with faunal and stable isotope methods in the tropical Atlantic reveals the following:

- Temperature estimates based on $\mathrm{U}_{37}^{k}$ (coccoliths) and the modern analogue technique (foraminiferal assemblages) agree within $1^{\circ} \mathrm{C}$ where foraminiferal assemblages have good communalities in the early Holocene. This is an indication that $\mathrm{U}_{37}^{k}$ is able to accurately, quantitatively record SST in open ocean sediments.

- $\mathrm{U}_{37}^{k}$ temperature estimates indicate about $1.56^{\circ} \mathrm{C}$ cooling of warm season SST at the last glacial maximum in the Equatorial Atlantic, which is about one half the $\sim 3.40^{\circ} \mathrm{C}$ cooling indicated by $\delta^{18} \mathrm{O}$ and the $3.75^{\circ} \mathrm{C}$ cooling indicated by foraminiferal asemblages. Assuming that $\mathrm{U}_{37}^{k}$ is an accurate method based on available data, the discrepancy between $\mathrm{U}_{37}^{k}$ SST estimates and those of faunally based methods during the last glaciation may reflect real oceanographic and climatic effects on $\delta^{18} \mathrm{O}$ and analogue estimates. Indeed, high 
dissimilarity coefficients for the glacial temperature estimates indicate the assemblages living at that time have no good modern analogues, and it is assumed the larger SST changes recorded by faunal techniques may reflect as much as a $2.25^{\circ} \mathrm{C}$ cooling effect due to oceanographic changes associated with enhanced upwelling. The relatively warm $U_{37}^{k}$ temperature estimates support increased divergence instead of advection as the primary cause of SST lowering in the last glaciation.

- $\mathrm{U}_{37}^{k} \mathrm{SST}$ estimates indicate a glacial temperature depression of less than $2^{\circ} \mathrm{Cin}$ the tropical Atlantic, whereas terrestrial indicators (e.g. snowline depression and lake levels) show 5$6^{\circ} \mathrm{C}$ cooling on the African continent. Although part of the discrepancy between these surface temperature estimates may be due to the fact that $\mathrm{U}_{37}^{k}$ produces only a warm season estimate whereas terrestrial estimates are annual averages, $\mathrm{U}_{37}^{k}$ shows an even greater difference with terrestrial estimates than other marine SST estimates for the last glaciation. The $U_{37}^{k}$ temperature estimates reinforce CLIMAP's (1981) conclusion that glacial Tropical Atlantic SST was not much lower than today's. 


\section{Chapter 4}

\section{Sea surface temperature estimates of the Northeast Atlantic for the last half glacial cycle}

\subsection{Introduction}

According to foraminifera-based estimates of sea surface temperature, the northeastern North Atlantic was the area of greatest SST depression during the last glaciation (CLIMAP, 1976; 1981). Glacial summer SST was as much as $10^{\circ} \mathrm{C}$ cooler north of $40^{\circ} \mathrm{N}$ due to southward movement of the polar front from its present position above $65^{\circ} \mathrm{N}$ to approximately $40^{\circ} \mathrm{N}$ (Ruddiman and McIntyre, 1973; CLIMAP, 1976, 1981). The process of change between interglacial and glacial conditions in the North Atlantic is complex because there is strong interaction between oceanic ice cover and temperatures and the extent of ice cover on the northern continents (Ruddiman and McIntyre, 1979, 1981; Bard et al., 1987). Variations in these conditions modifies atmospheric circulation (Manabe and Broccoli, 1985), causing feedbacks that amplify insolation forcing of Milankovitch cycles (Ruddiman and McIntyre, 1981). During deglaciation this interaction is further complicated by meltwater effects (Broecker et al.,1988, 1989; Fairbanks, 1989). Deglacial retreat of polar waters from their maximum extent in the last glaciation to their present configuration was time transgressive, occurring over a period of about 6,000 years 
(Ruddiman and McIntyre, 1973; Duplessy et al., 1986; Bard et al., 1987). During this retreat, the melting of the ice caps produced meltwater plumes in the northern North Atlantic (Jones and Ruddiman, 1982) the extent and locations of which probably varied with time during the deglaciation (Broecker et al., 1988, 1989; Fairbanks, 1989; Keigwin et al., unpublished) also affecting the Gulf of Mexico as well (Leventer et al., 1982).

It is generally accepted that melting and warming began in earnest about 15-14 ka signaled by floral, faunal, lithologic and isotopic changes first described by Ruddiman and McIntyre (1973), with the earliest documented meltwater event occuring at 14.5 ka (Jones and Keigwin, 1988). Subsequent studies showed significant warming or melting events occurred at 12.5 ka (the latter part of termination 1a, 14.5-11.5 ka) and after $9.5 \mathrm{ka}$ (termination $1 \mathrm{~b}$ ), separated by the Younger-Dryas cooling event that was centered on 10.5 ka (Ruddiman and McIntyre, 1973, Duplessy, 1981, 1986; Bard et al., 1987; Broecker et al., 1988; Keigwin and Jones, 1989; Fairbanks, 1989). The sea level curve based on dating of fossil coral reefs in Barbados of Fairbanks (1989) gives compelling evidence for meltwater pulses associated with the termination events at 12.5 and $9.5 \mathrm{ka}$.

The temporal and geographic variability of meltwater discharge to the North Atlantic must have produced produced significant temperature changes as well as changes of the salinity of surface waters. Although recent work by Fairbanks (1989) allows separation of the global ice volume component from other influences on the $\delta^{18} \mathrm{O}$ signal, the local salinity and temperature inputs changed so rapidly in the North Atlantic during the deglaciation that the relative influences of these effects on existing foraminifera-based paleo-temperature indicators are not completely distinguishable. Consequently, the complex history of North Atlantic SST during glacial retreat is not well understood, and is still the subject of much research and debate.

Although the existence and timing of the Younger-Dryas event is well established in the North Atlantic region, its nature and cause is unresolved. At first, based on floral, faunal, and lithologic evidence (Ruddiman and McIntyre, 1973), the Younger-Dryas was thought to be a cooling event associated with a substantial re-advance of polar waters and glacial conditions. Work by Teller (1987) on proglacial lakes and watersheds on the North American continent indicated that meltwater flow to the North Atlantic increased after $12 \mathrm{ky}$ when proglacial lakes began to overflow through the St. Lawrence Valley. Citing both this terrestrial evidence 
and marine evidence, Broecker et al. (1988) proposed that the Younger-Dryas cooling was caused by a diversion of meltwater from the Gulf of Mexico to the North Atlantic from 1011,000 years ago. Broecker et al. (1988) cite in support of their hypothesis the oxygen isotopic and cadimum/calcium evidence of Boyle and Keigwin (1987) indicating that there was also a shutdown of NADW formation during this event. However, there is no published $\delta^{18} \mathrm{O}$ evidence supporting a concurrent meltwater event in the northwest Atlantic. Further, Fairbanks' (1989) sea level curve shows a sea level rise of only a few meters associated with the Younger-Dryas event, and indicates a five fold decrease in the rate of sea level rise. This relatively low rate of sea level rise suggests to Fairbanks (1989), that a large meltwater influence in the North Atlantic might not have caused the Younger-Dryas.

An understanding of deglacial conditions in the North Atlantic can greatly benefit from an SST record that is independent of the competing influences of local salinity, thermocline structure and ice volume. $\mathrm{U}_{37}^{k}$ is a unique new method of SST estimation based on organic compounds, with no apparant salinity effects on its temperature estimates (Chapter 2). Because $\mathrm{U}_{37}^{k}$ is not influenced by salinity or ice volume it may provide a critical, independent test of deglacial SST changes that are based on foraminiferal indicies which may be perturbed by these factors. Therefore, a $\mathrm{U}_{37}^{k}$ SST record for the most recent deglaciation in the area which underwent some of the largest glacial to interglacial temperature oscillations can be used to help separate out the other influences on isotopes and foraminiferal assemblages and thereby help paint a clearer picture of SST change during the deglaciation. Specifically, it can help resolve the question of whether the Younger-Dryas was a cooling event in the ocean or an artifact of low $\delta^{18} \mathrm{O}$ (meltwater) events before and after, as proposed by Fairbanks (1989).

Because foraminifera-based SST estimates show large glacial to interglacial temperature changes in the North Atlantic, this location can also serve as a test for how well the alkenone method reproduces a broad temperature range downcore (which is greater than the errors of the methods). In order to test and apply the $\mathrm{U}_{37}^{k}$ method to investigate SST changes in the North Atlantic, oxygen isotope determinations and foraminiferal assemblage temperature estimates were performed on sediment samples from the same levels from giant gravity core Knr51 29GGC $\left(56^{\circ} 13.1^{\prime} \mathrm{N}, 12^{\circ} 37.7^{\prime} \mathrm{W}, 2626 \mathrm{~m}\right.$ water depth) which was raised from the Feni Drift, an area of high sedimentation rate (approximately $10 \mathrm{~cm} / \mathrm{ky}$; Broecker et al., 1988; Keigwin and Jones, 


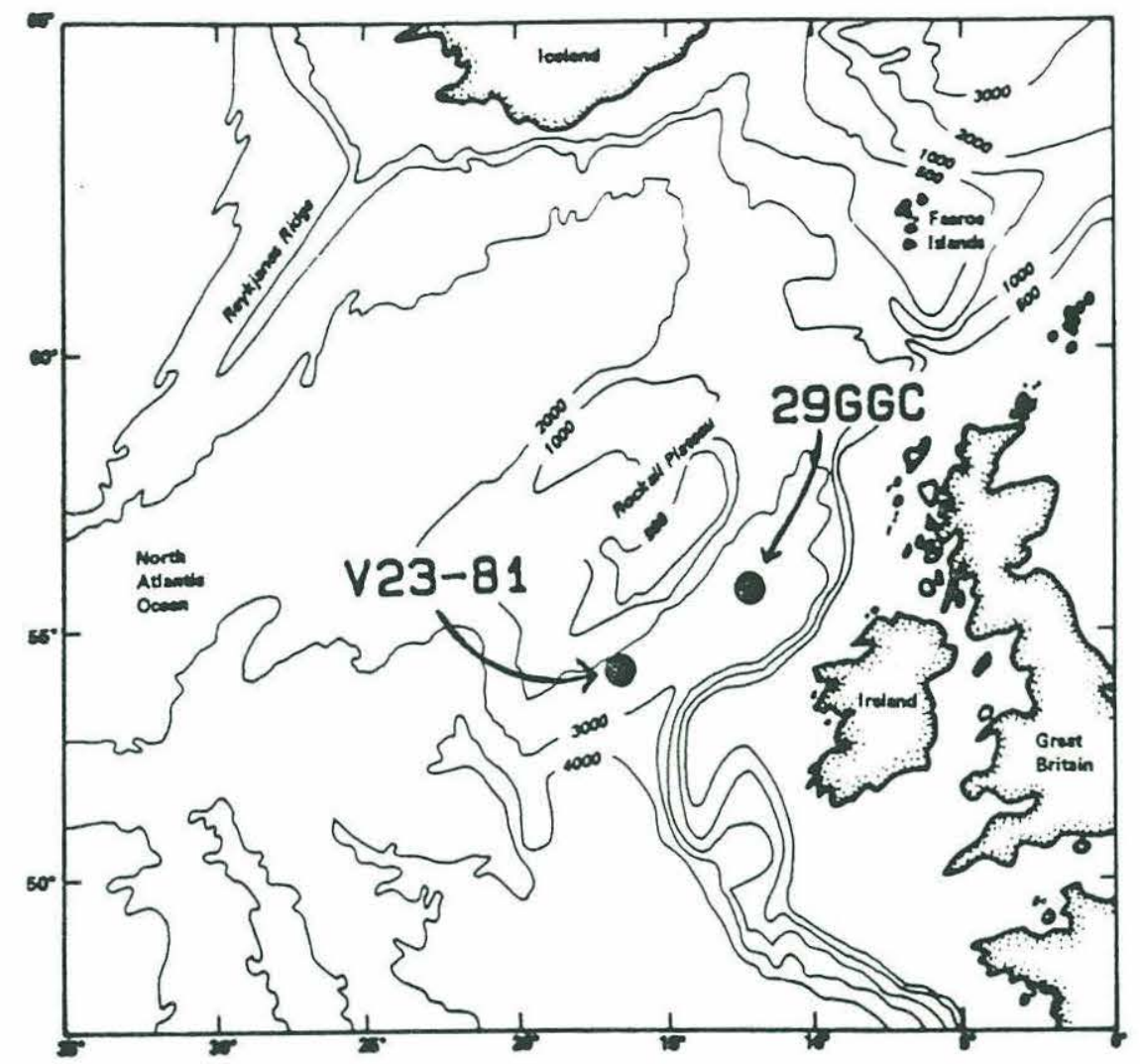

Figure 4-1: Location of cores $29 \mathrm{GGC} 56^{\circ} 13.1^{\prime} \mathrm{N}, 12^{\circ} 37.7^{\prime} \mathrm{W}, 2626 \mathrm{~m}$ and V23-81 $\left(54^{\circ} 15^{\prime} \mathrm{N}, 16^{\circ} 50^{\prime} \mathrm{W}\right.$, $2393 \mathrm{~m}$ depth.

1989). Such a high sedimentation rate is necessary for accurately resolving short-term events like the Younger-Dryas. Core $29 \mathrm{GGC}$ is located very close to core V23-81 $\left(54^{\circ} 15^{\prime} \mathrm{N}, 16^{\circ} 50^{\prime} \mathrm{W}\right.$, $2393 \mathrm{~m}$ depth; Figure 4-1) which is a virtual "type section" for the Younger-Dryas in the North Atlantic. Core V23-81 has been too heavily sampled to be used for $\mathrm{U}_{37}^{k}$ analyses so, core $29 \mathrm{GGC}$ was sampled for the present study, and core V23-81 has been used for stratigraphic correlation. 


\subsection{Methods}

Stable isotope analyses were conducted following the laboratory procedures described in Chapter 3. Analyses for this location were performed on 70-90 individuals of Neogloboquadrina pachyderma from the $150-250 \mu \mathrm{m}$ size fraction of the washed sediment sample (where possible; smallest samples however, were about 40 individuals). Separate analyses were conducted both on the left coiling (sinistral) and the right coiling (dextral) varieties. Temperature estimates based on foraminiferal assemblages were obtained using the modern analogue technique via methods discussed in Chapter 3, and by Anderson et al. (1989). Alkenones were recovered from the sediment and analyzed by the methods described in Chapter 2, and Farrington et al. (1988). It should be noted that $\delta^{18} \mathrm{O}$ and assemblage data come from the same samples, whereas the destructive nature of $\mathrm{U}_{37}^{k}$ analysis on carbonate tests during sonication required separate samples from the same levels.

\subsection{Results}

\subsubsection{Stratigraphy}

Core Knr51-29GGC was originally described by Flood (1978). The upper part of the core shows normal pelagic sedimention, interrupted between $180 \mathrm{~cm}$ and $230 \mathrm{~cm}$ depth by a debris flow. Normal sedimentation appears to occur to the bottom of the core at $263 \mathrm{~cm}$ (Table $3-1$ of Flood, 1978) but this interval is somewhat disturbed and has not been studied. The sediment is light colored (creamy tan) for the top $90 \mathrm{~cm}$ changing to a medium brown over the interval 90-100 $\mathrm{cm}$, and remaining the darker color down to the debris flow.

Estimates of ages downcore are based on the relative abundance of $N$. pachyderma $(s)$ in the total fauna (expressed as a percent, Appendix B) and comparison of these abundances to those of nearby core V23-81, in which individual foraminiferal species have been ${ }^{14} \mathrm{C}$ dated by accelerator mass spectrometer (Broecker et al., 1988; Figure 4-2,). The Younger Dryas event, which is identified as the largest post-glacial peak in N. pachyderma (s) (Ruddiman et al., 1977; Ruddiman and McIntyre, 1981, Broecker et al., 1988) is clearly evident in core 29GGC between 93.5 and $95.5 \mathrm{~cm}$ depth. The level of expression of the Younger-Dryas in core 29GGC, $(50-60 \%$ $N$. pachyderma $(s)$ ) is not as pronounced as at V23-81 (above $80 \% \mathrm{~N}$. pachyderma $(s)$ ) which 


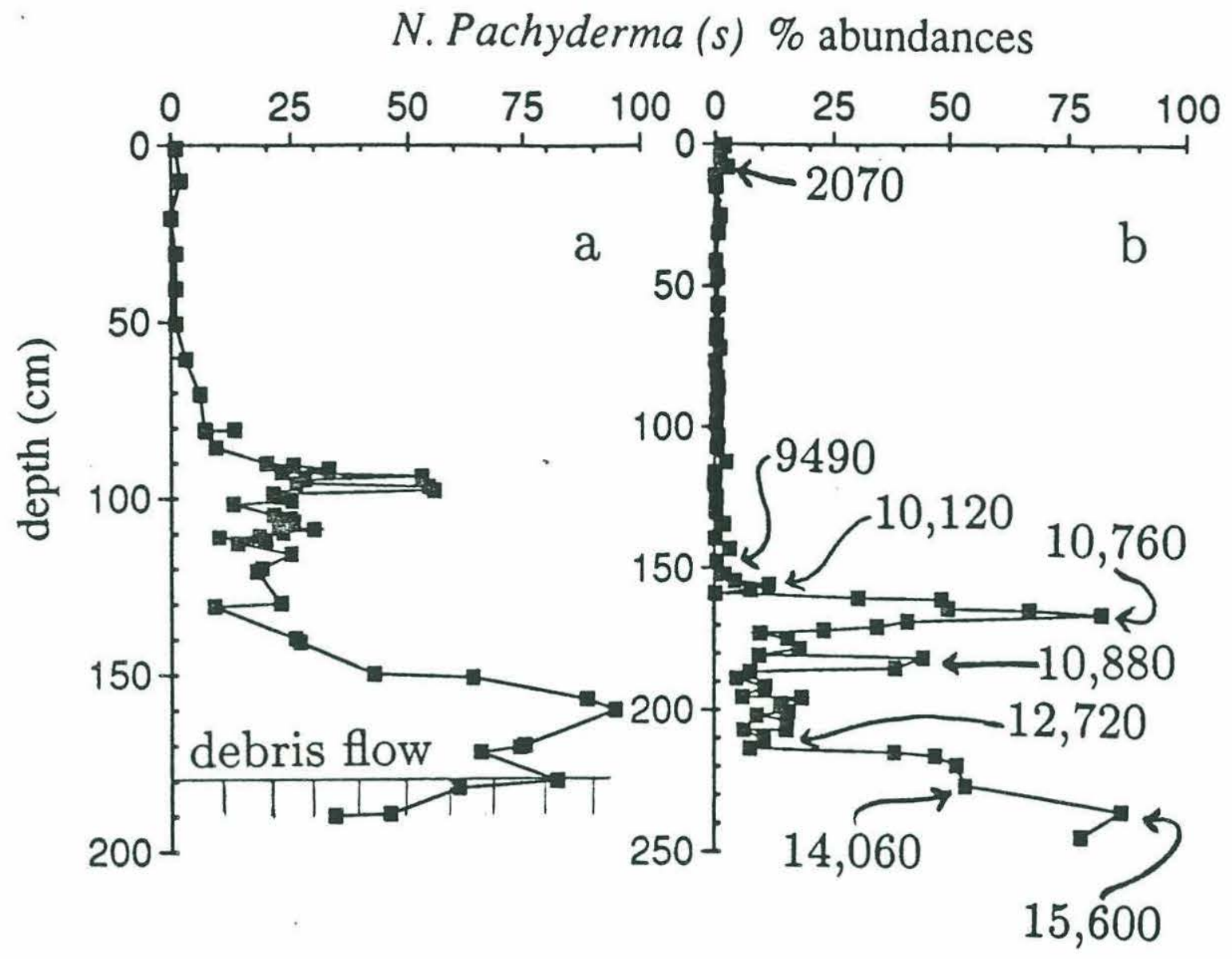

Figure 4-2: a.) N. pachyderma (s) abundances for core 29GGC (this study) and b.) V23-81 (Ruddiman et al., 1977) radiocarbon ages shown are by Broecker et al. (1988).

is most likely due to the lower sedimentation rates in 29GGC. However, peak abundance of about $50 \%$ is typical of other cores in this region (Ruddiman et al., 1977; Keigwin and Jones, 1989). Volcanic shards fitting the description of those from Ash Zone 1, which has been dated at 10,600 yrs BP (Mangerud et al., 1984; and corroborated by dating in deep sea cores by Keigwin and Jones, 1989), were also found at 93-97 cm. Low abundances of $N$. pachyderma (s) above and below the Younger-Dryas in core 29GGC ( 80 and $130 \mathrm{~cm}$ respectively) are assumed to correspond with the levels dated 9.5 and $12.7 \mathrm{ky}$ in V23-81. N. pachyderma (s) abundances of approximately $90 \%$, similar to glacial levels in core V23-81, are reached by $157 \mathrm{~cm}$ in core 29GGC, well above the debris flow noted by Flood (1978) at $180 \mathrm{~cm}$. This level dated at $15.6 \mathrm{ka}$ 
in V23-81, is likewise assumed to correlate. Abundances of $N$. pachyderma ( $s$ ) decrease from over $90 \%$ at $170 \mathrm{~cm}$ down to $40 \%$ at the $190 \mathrm{~cm}$ level. Low abundances at $190 \mathrm{~cm}$ are assumed to reflect material from the debris flow. All analyses from levels below $170 \mathrm{~cm}$ are therefore considered somewhat suspect.

\subsubsection{Stable Isotopes}

Both right and left coiling varieties of $N$. pachyderma were chosen for isotopic analysis because neither was sufficiently abundant throughout the core to provide a continuous, single species record. Previous results from Feni Drift cores showed $N$. pachyderma $(s)$ in Holocene sediments to have $\delta^{18} \mathrm{O}$ values typical of the deglaciation (Duplessy et al., 1981; Keigwin and Jones, 1989), and so are considered to have been bioturbated into these levels. At depths where the right coiling variety is low in abundance, or insufficient individuals were available for isotopic analyses (below $160 \mathrm{~cm}$ ), N. pachyderma (s) samples were run to supplement the record (Figure 4-3, Table 4-1).

The maximum signal amplitude of $1.5^{\circ} \%$ in $N$. pachyderma $(d)$ is not believed to represent the full glacial-interglacial signal because $N$. pachyderma (d) at nearby core Knr51-GGC-11 shows maximum values of $3.75 \%$ and a signal amplitude of $2.75 \%$ (Keigwin and Jones, 1989). In core 29 GGC maximum $\delta^{18} \mathrm{O}$ of $N$. pachyderma (d) occurs at $150 \mathrm{~cm}\left(2.15^{\circ} \%\right.$ o $)$ depth and decreases by $1.2^{\circ} \%$ at $140-130 \mathrm{~cm}$ (to $1.43^{\circ} \%$ ), which is believed to be equivelent to termination 1a (about $12.7 \mathrm{ka}$ ). There is a $0.5^{\circ}$ \% increase in $\delta^{18} \mathrm{O}$ at the Younger-Dryas level (95-105 cm), followed by a shift of $1.2 \%$ o to Holocene values (of about $1.0^{\circ} \%$ oo) at $80-90 \mathrm{~cm}$ which is believed to be termination $1 \mathrm{~b}(9.5 \mathrm{ka})$. The analysis of $N$. pachyderma (s), run only for the lower part of the core (because of the scarcity of this species in Holocene sediments) indicates deglacial values by comparison with GGC-11 (Keigwin and Jones, 1989).

\subsubsection{Foraminiferal Assemblage Temperature Estimates}

The modern analogue technique provides both a warm and a cold season SST estimate, as well as a dissimilarity coefficient for assessing how reliable the estimate is (Figure 4-4, Table 4-1). The dissimilarity coefficients for this site are excellent - with the exception of one point (at $120 \mathrm{~cm}$ ) all values are below 0.1 . Cold SST estimates are about $9^{\circ} \mathrm{C}$ for the Holocene and drop 


\begin{tabular}{|c|c|c|c|c|c|c|c|c|c|}
\hline \multirow[b]{2}{*}{$\begin{array}{c}\text { Depth } \\
(\mathrm{cm}) \\
\end{array}$} & \multirow[b]{2}{*}{$U_{37}^{k}$} & \multirow[b]{2}{*}{$\begin{array}{c}U_{37}^{k} \text { lemperature } \\
\left({ }^{\circ} \mathrm{C}\right)\end{array}$} & \multirow[b]{2}{*}{$\begin{array}{r}{[37: 3]} \\
(\mathrm{ng} / \mathrm{g})\end{array}$} & \multirow[b]{2}{*}{$\begin{array}{r}{[37: 2]} \\
(\mathrm{ng} / \mathrm{g})\end{array}$} & \multicolumn{2}{|c|}{ N. pachyderma (s) } & \multicolumn{2}{|c|}{ N. pachyderma (d) } & \multirow{2}{*}{$\begin{array}{l}\text { MAT } \\
\text { SST } \\
\left({ }^{\circ} \mathrm{C}\right)\end{array}$} \\
\hline & & & & & $\begin{array}{r}\delta^{18} 0 \\
(\mathrm{PDB}) \\
\end{array}$ & $\begin{array}{r}\delta^{13} \mathrm{C} \\
(\mathrm{PDB})\end{array}$ & $\begin{array}{r}\delta^{18} \mathrm{O} \\
(\mathrm{PDB}) \\
\end{array}$ & $\begin{array}{r}\delta^{13} \mathrm{C} \\
(\mathrm{PDB})\end{array}$ & \\
\hline 1 & 0.643 & 18.2 & 26 & 54 & - & - & 0.61 & 0.00 & 12.85 \\
\hline 10 & 0.604 & 17.0 & 12 & 19 & - & - & 0.85 & 0.04 & 12.60 \\
\hline 20.5 & 0.610 & 17.2 & 240 & 376 & - & - & 1.01 & 0.05 & 13.37 \\
\hline 30.5 & 0.756 & 21.6 & 135 & 417 & - & - & 0.92 & 0.09 & 13.41 \\
\hline 40.5 & 0.666 & 18.9 & 165 & 329 & - & - & 0.89 & 0.26 & 12.80 \\
\hline 50.5 & 0.668 & 18.9 & 144 & 301 & - & - & 1.10 & 0.12 & 12.78 \\
\hline 60.5 & 0.614 & 17.4 & 146 & 233 & - & - & 1.23 & 0.43 & 12.87 \\
\hline 70.5 & 0.654 & 18.5 & 101 & 191 & - & - & 1.13 & -0.08 & 12.58 \\
\hline 80.5 & 0.673 & 19.1 & 198 & 445 & - & - & 1.01 & 0.09 & 12.46 \\
\hline 90.5 & 0.768 & 21.9 & 85 & 281 & - & - & 1.73 & -0.17 & 11.61 \\
\hline 93.5 & - & - & - & - & - & - & - & - & 7.58 \\
\hline 94.5 & - & - & - & - & 2.63 & 0.17 & - & - & - \\
\hline 95.5 & 0.504 & 13.9 & - & - & 2.83 & 0.16 & 2.01 & -0.01 & 10.31 \\
\hline 101.5 & 0.510 & 14.2 & 209 & 219 & - & - & 1.90 & -0.43 & 12.04 \\
\hline 105.5 & 0.518 & 14.4 & - & - & 3.04 & -0.10 & 2.10 & -0.17 & - \\
\hline 110.5 & 0.618 & 17.4 & 163 & 295 & 2.72 & 0.00 & 1.40 & -0.11 & 12.49 \\
\hline 120.5 & 0.485 & 13.4 & 307 & 264 & 2.97 & -0.39 & 1.69 & -0.43 & 11.12 \\
\hline 125.0 & 0.512 & 14.2 & - & - & - & - & 1.79 & -0.06 & - \\
\hline 130.5 & 0.553 & 15.4 & 223 & 335 & 2.90 & -0.12 & 0.93 & -0.53 & 12.45 \\
\hline 135.5 & - & - & - & - & 2.85 & -0.11 & 1.43 & -0.06 & - \\
\hline 140.5 & 0.468 & 12.9 & 210 & 185 & 3.02 & -0.07 & 1.92 & -0.71 & 10.01 \\
\hline 150.5 & 0.549 & 15.3 & 42 & 74 & 3.05 & -0.50 & 2.15 & -0.29 & 9.13 \\
\hline 154.5 & - & - & - & - & 2.87 & -0.07 & 2.03 & -0.29 & - \\
\hline 156.5 & - & - & - & - & 2.89 & -0.06 & - & - & - \\
\hline 158.5 & - & - & - & - & 2.75 & -0.03 & 1.85 & 0.12 & - \\
\hline 159.5 & - & - & - & - & 2.38 & -0.28 & - & - & 6.27 \\
\hline 160.5 & 0.318 & 8.3 & 68 & 49 & - & - & - & - & - \\
\hline 161.5 & - & - & - & - & 2.71 & -0.07 & - & - & - \\
\hline 162.5 & - & - & - & - & 2.71 & -0.9 & - & - & - \\
\hline 163.5 & - & - & - & - & 2.68 & -0.07 & - & - & - \\
\hline 166.5 & - & - & - & - & 2.49 & -0.23 & - & - & - \\
\hline 169.5 & - & - & - & - & 2.41 & -0.25 & - & - & - \\
\hline 170.5 & 0.471 & 12.9 & 61 & 40 & - & - & - & - & 7.14 \\
\hline 171.5 & - & - & - & - & 2.41 & -0.16 & - & - & - \\
\hline 173.5 & - & - & - & - & 2.48 & -0.20 & - & - & - \\
\hline 176.5 & - & - & - & - & 2.61 & -0.28 & - & - & - \\
\hline 179.5 & - & - & - & - & 2.87 & -0.31 & - & - & - \\
\hline 181.5 & 0.522 & 14.5 & 118 & 129 & 2.76 & 0.38 & 2.03 & -0.18 & 9.18 \\
\hline 189.5 & 0.554 & 15.5 & 25 & 32 & - & - & 2.05 & -0.07 & 8.60 \\
\hline
\end{tabular}

Table 4-1: Principle numerical results for core 29GGC, see Appendix B for complete numerical results. 


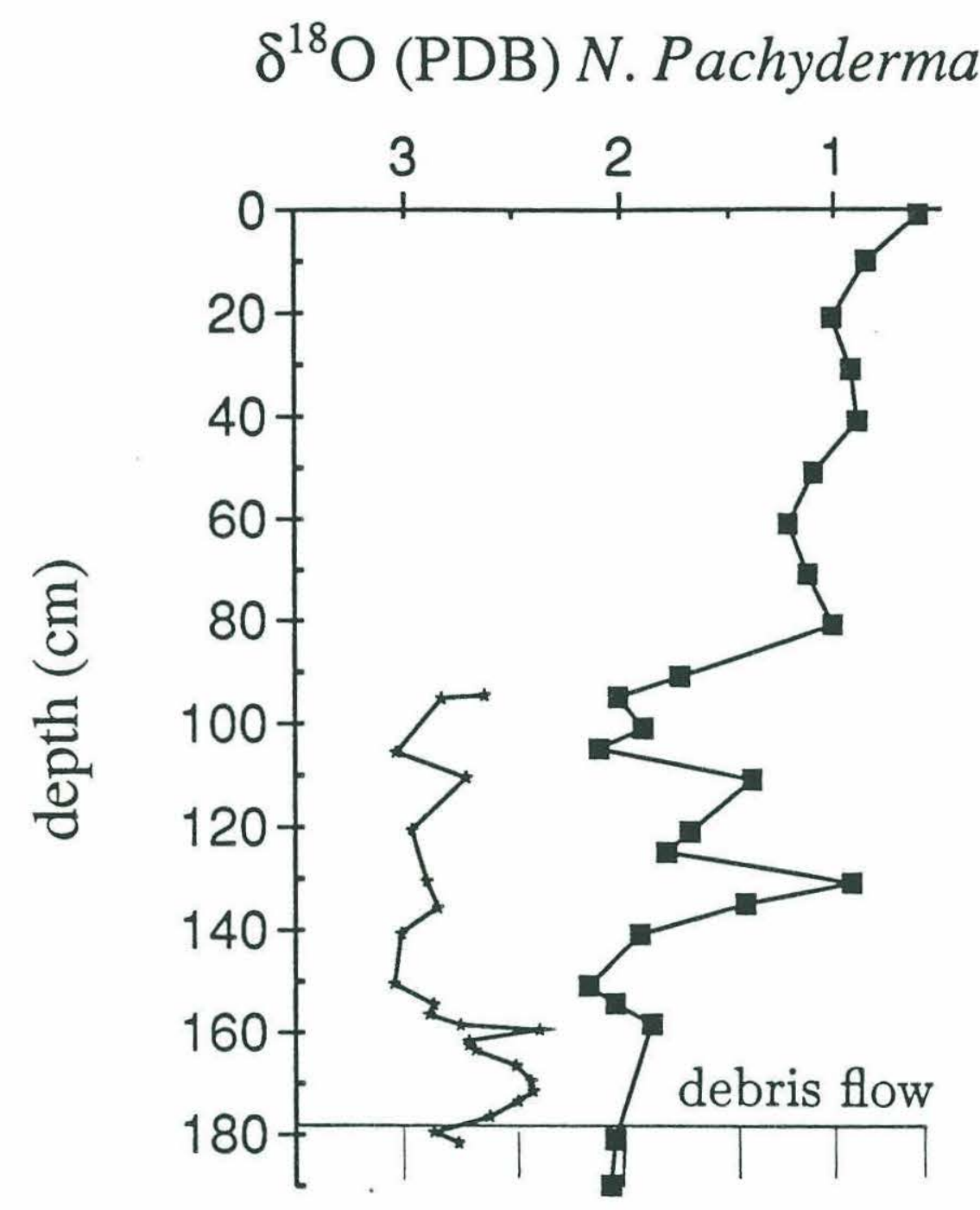

Figure 4-3: $\delta^{18} \mathrm{O}$ results for $N$. pachyderma $(s)\left({ }^{*}\right)$ and $N$. pachyderma (d). 
to $5.5^{\circ} \mathrm{C}$ at $140 \mathrm{~cm}$ (prior to termination $1 \mathrm{a}$ ) and again to $1^{\circ} \mathrm{C}$ at about $160 \mathrm{~cm}$. Warm SST estimates for the Holocene are around $13^{\circ} \mathrm{C}$, dropping to $10^{\circ} \mathrm{C}$ at $140 \mathrm{~cm}$ and to $6^{\circ} \mathrm{C} 30 \mathrm{~cm}$ below. For warm season this is a temperature difference of $7^{\circ} \mathrm{C}$ and for cold $8^{\circ} \mathrm{C}$ between climatic regimes. The Younger-Dryas event at $90-100 \mathrm{~cm}$ is marked by a $6^{\circ} \mathrm{C}$ drop centered at the $93.5 \mathrm{~cm}$ level. A distinct warming of $2-3^{\circ} \mathrm{C}$ is evident at $130 \mathrm{~cm}$ (termination $1 \mathrm{a}$ ).

Total foraminiferal abundances (numbers per gram) are approximately 6,000/g in the Holocene (above $80 \mathrm{~cm}$; Appendix B). These numbers drop by about $1 / 2$ between termination $1 \mathrm{a}$ and $1 \mathrm{~b}(90-130 \mathrm{~cm})$. Below $140 \mathrm{~cm}$ foram abundances are 1-2 orders of magnitude less than Holocene values.

\subsubsection{Alkenone Unsaturation Ratios}

Core-top $\mathrm{U}_{37}^{k}$ temperature estimates are about $18^{\circ} \mathrm{C}$, but at earlier Holocene levels $\mathrm{U}_{37}^{k}$ estimates are as high as $22.0^{\circ} \mathrm{C}$ (at $90 \mathrm{~cm}$ ) and $21.6^{\circ} \mathrm{C}$ (at $30 \mathrm{~cm}$; (Figure 4-5). Temperatures drop abruptly at termination $1 \mathrm{~b}\left(\right.$ at $90 \mathrm{~cm}$ ), then fluctuate between 12.9 and $15.5^{\circ} \mathrm{C}$ down to $150 \mathrm{~cm}$. Coldest SST is $8.3^{\circ} \mathrm{C}$ at $160 \mathrm{~cm}$. The maximum temperature change between average Holocene temperatures and the "late glacial" at $160 \mathrm{~cm}$ is $10^{\circ} \mathrm{C}$. The average difference between the two temperature regimes above and below $90 \mathrm{~cm}$ is $5^{\circ} \mathrm{C}$.

Concentrations of the $\mathrm{C}_{37}$ alkenones in the sediments are reported in ng/g total dry weight of sample. $\mathrm{C}_{37}$ alkenone levels are very low in the top $10 \mathrm{~cm}$, and below $140 \mathrm{~cm}$ but in general the Holocene levels are 3-4 times higher than levels below $140 \mathrm{~cm}$ (Figure 4-6, Table 4-1). Highest levels are at termination $1 \mathrm{a}(130 \mathrm{~cm})$ and termination $1 \mathrm{~b}(80 \mathrm{~cm})$, and at 20-30 $\mathrm{cm}$. Very low concentrations of $\mathrm{C}_{37}$ alkenones at 160-170 cm make these temperature estimates somewhat tenuous.

\subsection{Discussion}

The ultimate intent of this chapter is to compare $\mathrm{U}_{37}^{k}$ to assemblage sea surface temperature estimates in the northeastern North Atlantic in an effort to distinguish between actual SST changes and other influences such as local salinity changes, that may be controlling foraminiferally based SST estimates. In order to do this, first an assessment of the different analyses must 

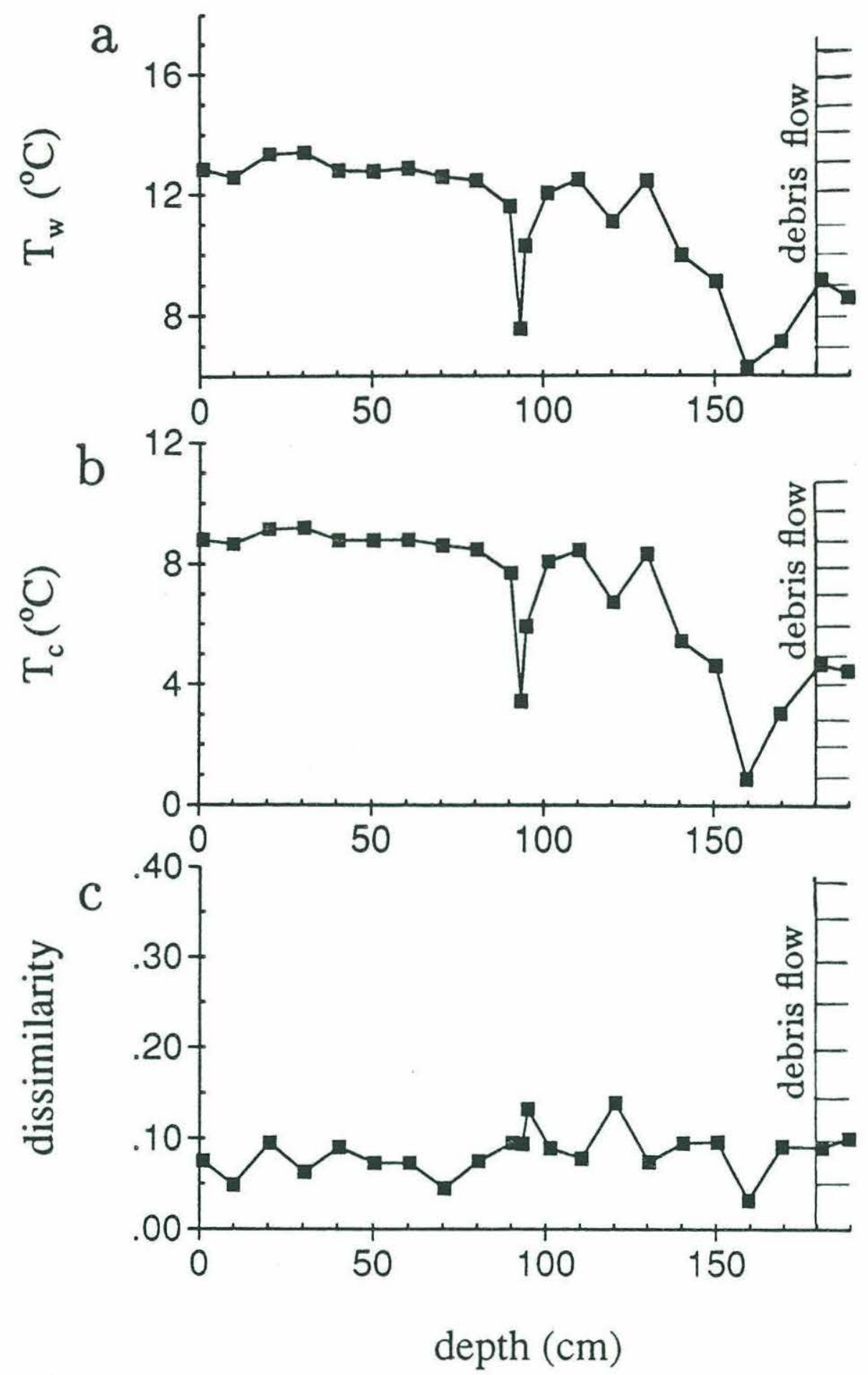

Figure 4-4: Modern analogue technique temperature estimates for core Knr51 29GGC. a.) warm temperatures. b.) cold temperatures. c.) dissimilarity coefficients. 


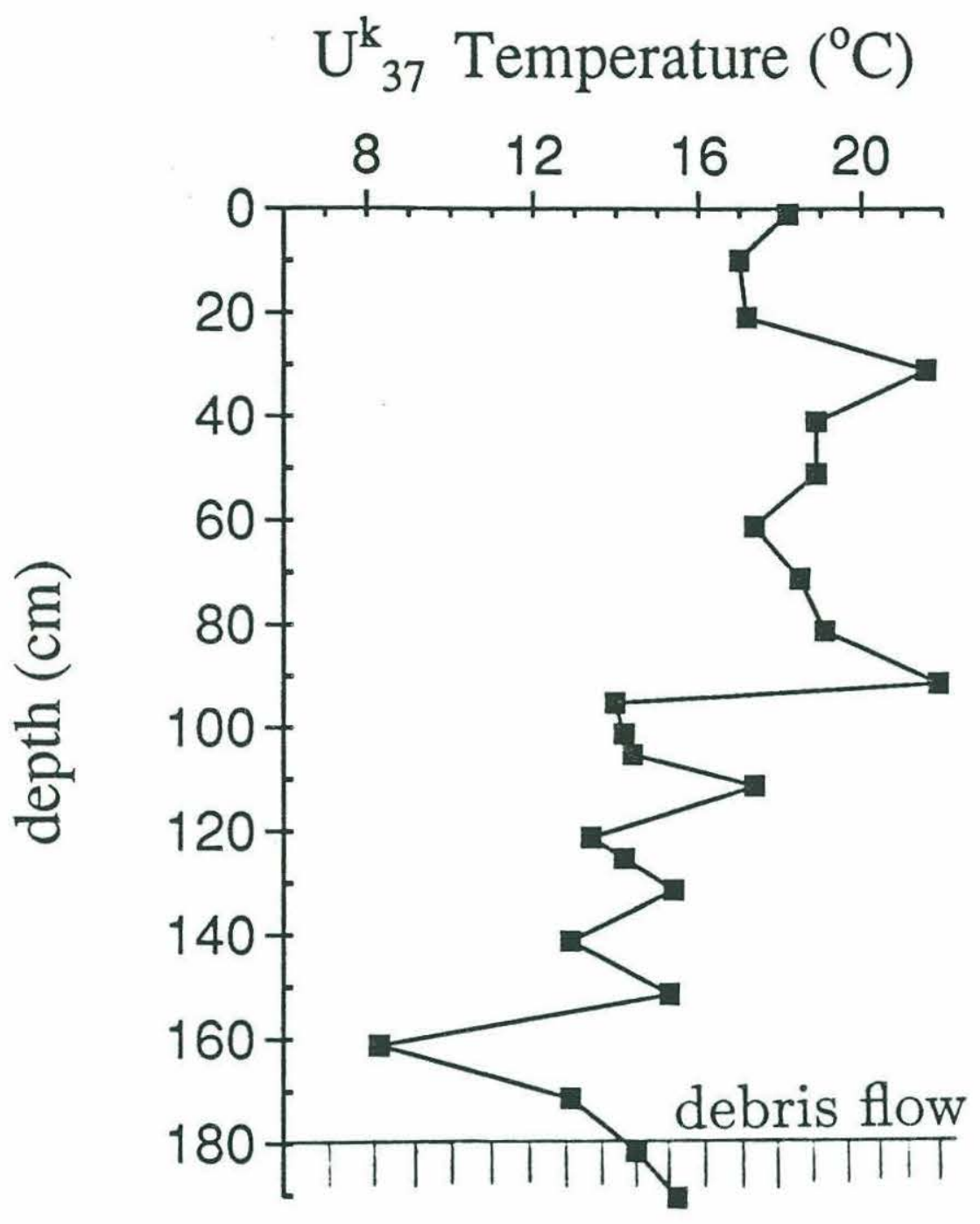

Figure 4-5: $\quad \mathrm{U}_{37}^{k}$ Temperature estimates for core 29GGC. 


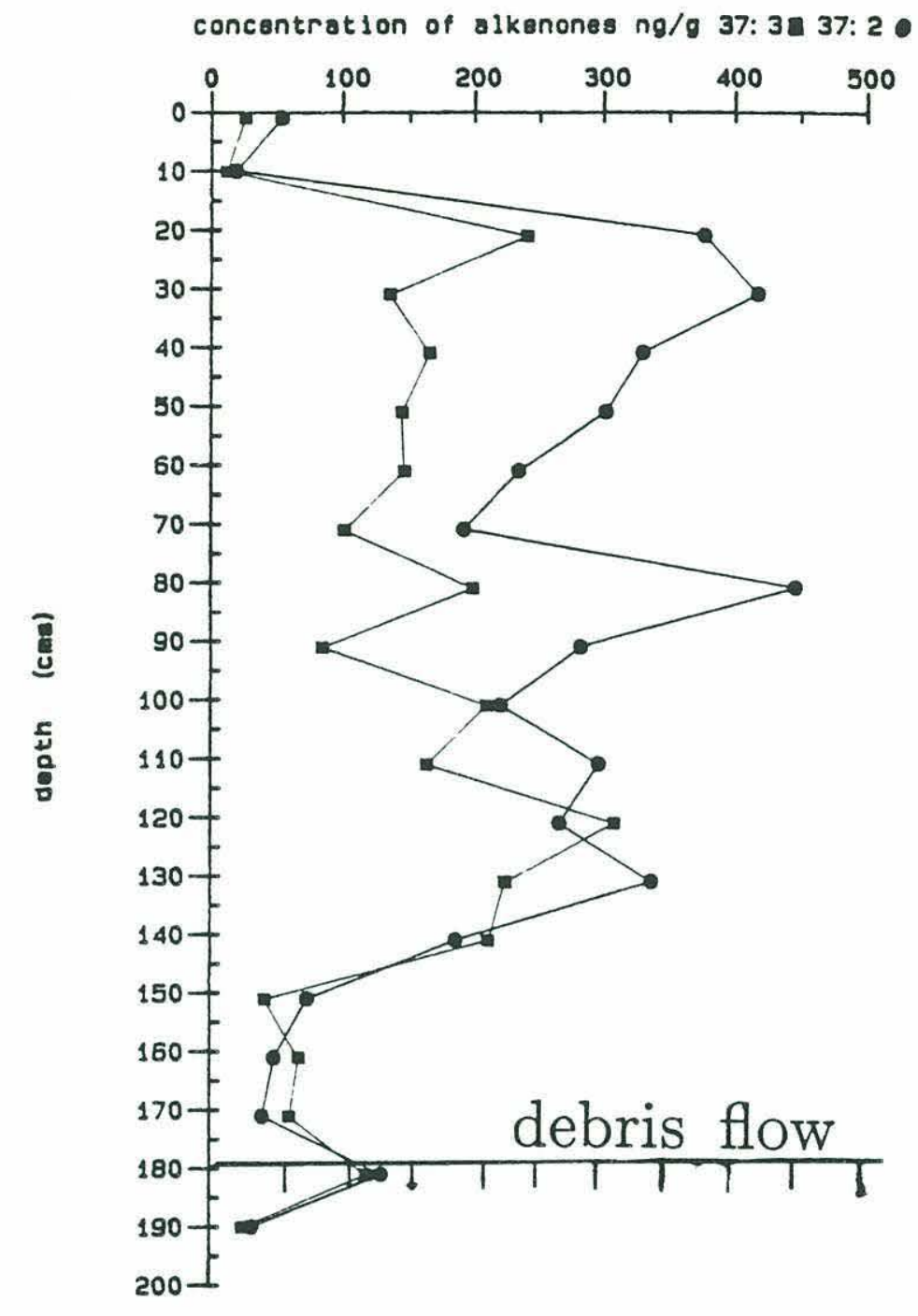

Figure 4-6: Concentration of $\mathrm{C}_{37}$ alkenones in core 29GGC. $37: 3=\mathbf{a}, 37: 2=\bullet$. 
be made.

The $\delta^{18} \mathrm{O}$ of $N$. pachyderma (d) supports the stratigraphy determined by $N$. pachyderma (s) percentages (Figure 4-2) and total foraminiferal abundances for the deglaciation (Appendix B). Typical signals for termination 1a, the Younger-Dryas, and termination $1 \mathrm{~b}$ are seen at 130, 95, and $90 \mathrm{~cm}$ respectively (Ruddiman et al., 1977; Bard etal, 1987; Keigwin and Jones, 1989). The highest $\delta^{18} \mathrm{O}$ values at $150 \mathrm{~cm}$, however, are much lower (by $1.0^{\circ} \%$ ) than expected for glacial levels given the glacial maximum values of about $3.75^{\circ} \%$ at $\mathrm{Knr} 51-\mathrm{GGC}-11^{\circ}$ (Keigwin and Jones, 1989). This indicates that full glacial conditions in core 29GGC predate the debris flow and were lost in this event. However, glacial level abundances of N. pachyderma (s) are present in core $29 \mathrm{GGC}$ above the debris flow, and these levels of $N$. pachyderma $(s)$ are consistent with results from core V23-81 during the deglaciation. In core V23-81 N. pachyderma (s) abundances remain typically glacial until $225 \mathrm{~cm}$ (Broecker et al., 1988) several centimeters higher than glacial $\delta^{18} \mathrm{O}$ values which extend only to $232 \mathrm{~cm}$. (Jansen and Veum, in press; Figure 4-7). This lag of the $N$. pachyderma (s) signal indicates conditions in this area remained cool, in effect, "glacial", even after the initial melting of ice caps began. Cool surface waters in the early deglaciation are plausable if these initial meltwaters helped to keep these waters cool at that time. SST estimates at earliest deglacial (latest glacial) levels in core 29GGC are similar to glacial age SST's in other nearby cores (Ruddiman et al., 1977). Although a lag of the $N$. pachyderma (s) signal behind $\delta^{18} \mathrm{O}$ can in part account for the lack of glacial $\delta^{18} \mathrm{O}$ values in the isotopic signal for core $29 \mathrm{GGC}$, the interval for which glacial faunas are present without glacial $\delta^{18} \mathrm{O}$ is too large for this to be the only cause.

The $\delta^{18} \mathrm{O}$ signal of $N$. pachyderma (d) was compared to the $N$. pachyderma (s) signal in V23-81 (Jansen and Veum, 1990), and considered in developing the age model based on $N$. pachyderma ( $s$ ) abundances in this core to assure a reasonable fit of the data (Figure 4-8). All faunal analyses in core $29 \mathrm{GGC}$ except for $\delta^{18} \mathrm{O}$ of $N$. pachyderma (s), compare favorably to results in nearby cores (Ruddiman et al., 1977; Broecker, 1988; Jansen and Veum, in press) and support the age model based on $N$. pachyderma $(s)$ abundances above $140 \mathrm{~cm}$ depth in the core. The $\delta^{18} \mathrm{O}$ of $N$. pachyderma $(s)$ shows relatively little variation throughout the entire interval for which analyses are available. The reason for this anomalous signal is unknown but, based on the other three faunal parameters which agree well with one another, the age 


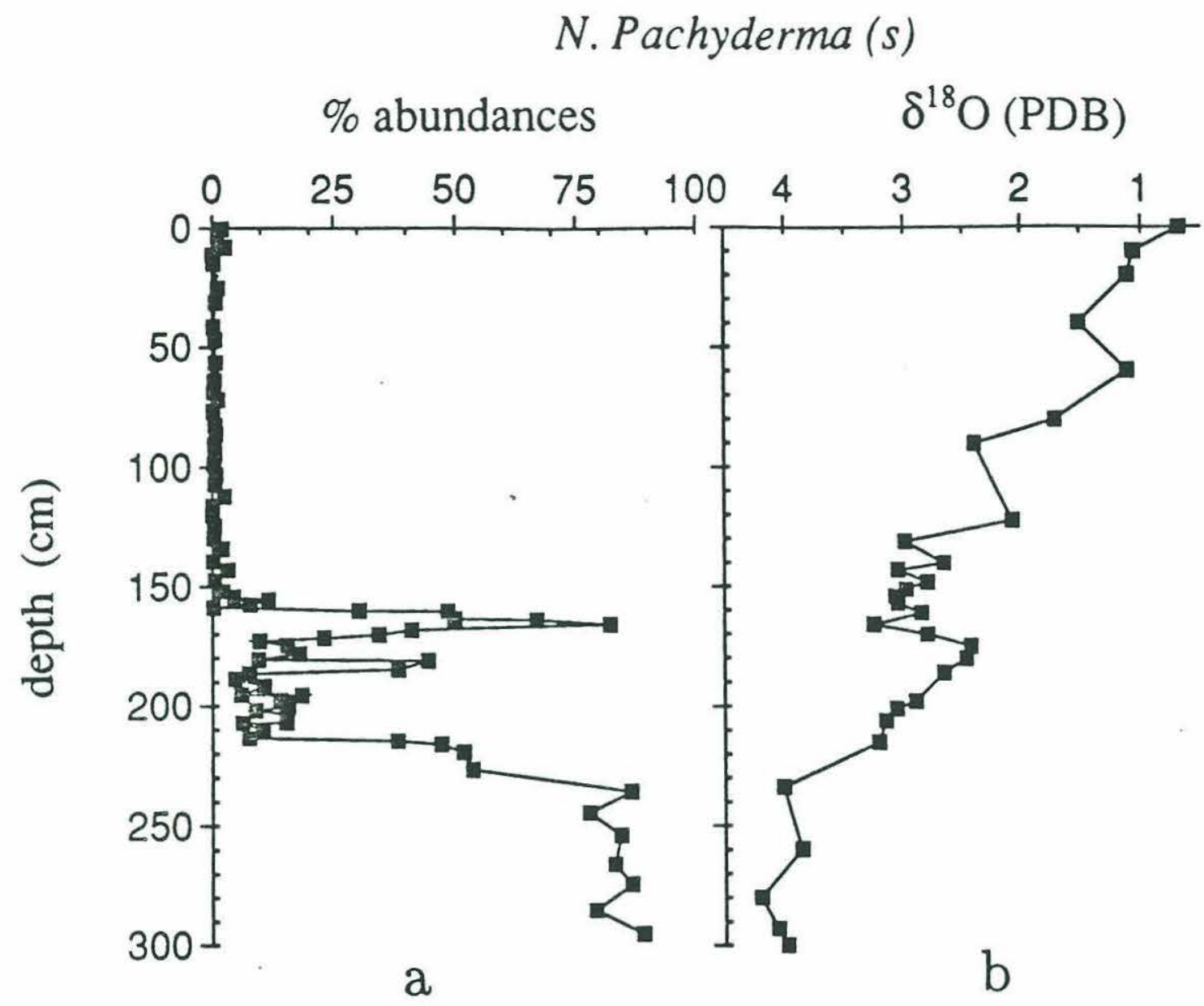

Figure 4-7: a.) N. pachyderma (s) abundances for core V23-81 (after Broecker et al., 1988). b.) $\delta^{18} \mathrm{O}$ for $N$. pachyderma (s) from core V23-81 (after Jansen and Veum, 1990).

model for core $29 \mathrm{GGC}$ is considered valid, particularly above $140 \mathrm{~cm}$ (12.7 ky). Given these stratigraphic considerations, data for core $29 \mathrm{GGC}$ are presented versus age in Figure 4-9 by correlating $N$. pachyderma $(s)$ abundances and $\delta^{18} \mathrm{O}$ values between core 29GGC and V23-81 and using the AMS ${ }^{14} \mathrm{C}$ dates of V23-81. Below $140 \mathrm{~cm}$ ages are somewhat uncertain, because of the disagreement of $N$. pachyderma (d) $\delta^{18} \mathrm{O}$ results with other faunal indicies. However, data below this level ( $\sim 12.7 \mathrm{ky})$ is plotted to age in Figure 4-9 based on N. pachyderma (s) abundances down to $15.6 \mathrm{ky}$ and below that level by extrapolation. The uncertainty of the ages at these levels is emphasized, and the data from these depths are presented in this form only for completeness. 


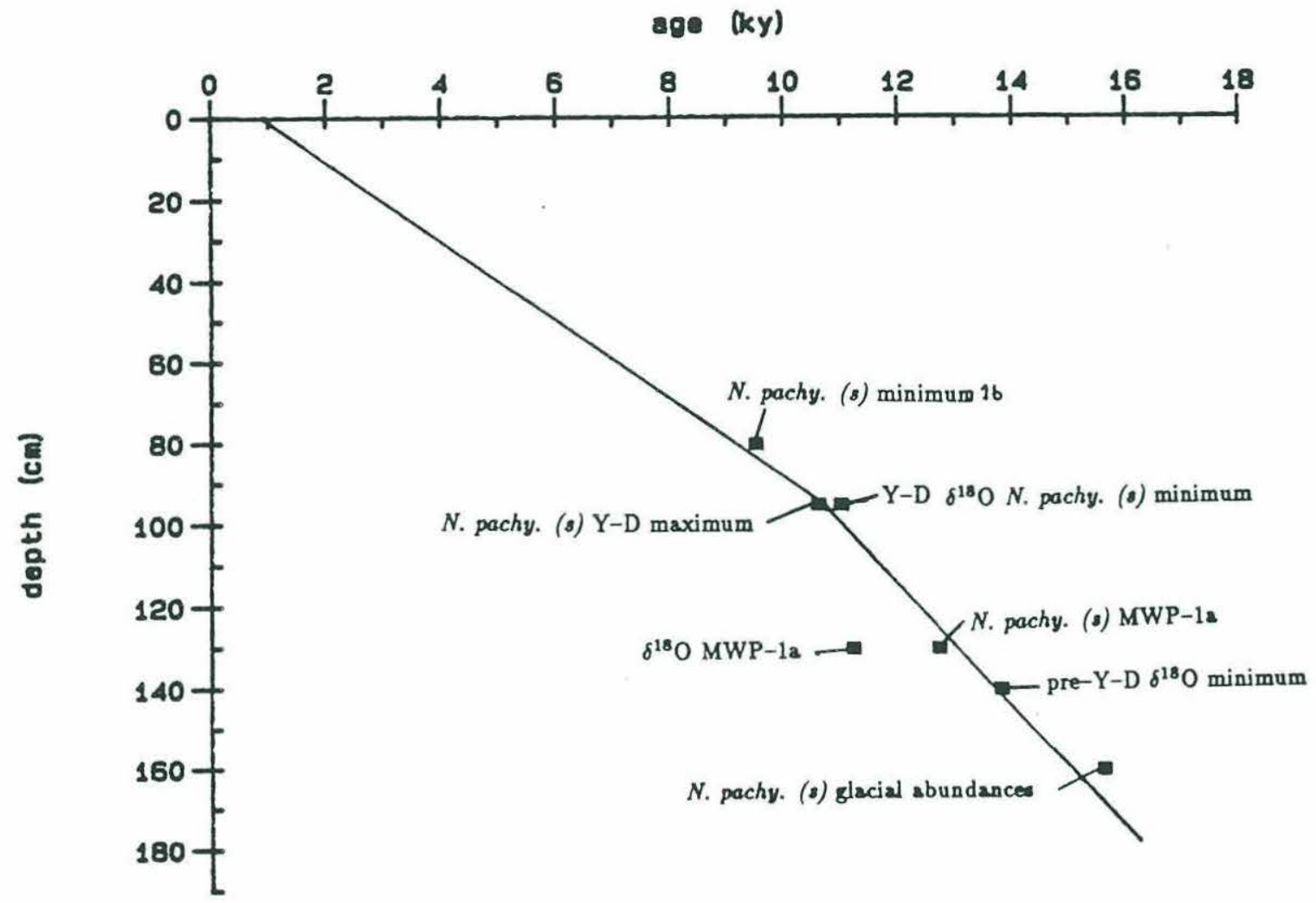

Figure 4-8: Plot of ages (based on ${ }^{14} \mathrm{C}$ AMS dates from core V23-81 (Broecker et al., 1988; Jansen and Veum, 1990). versus depth in core 29GGC of stratigraphic points. Solid line is age model used for this study.

Total faunal abundances at 150-170 cm are 1-2 orders of magnitude less than Holocene and low levels of $\mathrm{C}_{37}$ alkenones are also found at these levels (Appendix B). These low abundances appear to correspond to the "barren zone" of Ruddiman and McIntyre (1981) which they consider to have occured 16-13 ky ago. Lehmann and Jones (submitted) have AMS ${ }^{14} \mathrm{C}$ dated this barren zone by interpolation in the Norwegian Sea providing a more accurate date of about $15 \mathrm{ky}$. Therefore, analyses from $150-170 \mathrm{~cm}$ depth in core 29 GGC appear to be late glacial in age. Because this study is concerned with surface ocean temperatures, not ice volume, and faunal abundances indicate conditions were glacial in nature below $140 \mathrm{~cm}$, these levels are 
considered to represent late glacial values, and will be referred to as such for the purposes of this study, despite the stratigraphic uncertainties.

Modern analogue Holocene estimates agree well with modern transfer function SST estimates for this area $\left(13^{\circ} \mathrm{C}\right.$, Ruddiman et al., 1977 ; CLIMAP, 1981) but are about $1-2^{\circ} \mathrm{C}$ cooler than Levitus (1982) values for this location in the summer. The analogue estimates in this study (Figure 4-4) are virtually the same as the transfer function estimate profile for V23-81 of Ruddiman et al. (1977). Transfer function temperature estimates for V23-81 warm SST are $\sim 13^{\circ} \mathrm{C}$ and cool SST $\sim 9^{\circ} \mathrm{C}$ for the Holocene, showing a $5-6^{\circ} \mathrm{C}$ drop at the Younger-Dryas, and then shift to $9^{\circ} \mathrm{C}$ and $5^{\circ} \mathrm{C}$ respectively below the stage $1 / 2$ boundary. The warm season analogue temperature estimates at this high latitude site were chosen for comparison with $\mathrm{U}_{37}^{k}$ estimates because coccolith blooms occur in the summer in the North Atlantic (Okada and McIntyre, 1979; Milliman, 1980). The standing stock of coccolithophorids in summer is 10-100 times that of fall and winter, and it is assumed that the sediment record reflects this seasonal pattern during glacial times as well as the Holocene (see Chapter 1 for a full discussion).

Holocene $\mathrm{U}_{37}^{k}$ temperature estimates (about $18^{\circ} \mathrm{C}$ ) are somewhat warmer $\left(2-3^{\circ} \mathrm{C}\right)$ than modern SST values (Fuglister, $1960,16^{\circ} \mathrm{C}$; Levitus, $1982,15^{\circ} \mathrm{C}$ ), whereas CLIMAP core-top SST estimates $\left(13^{\circ} \mathrm{C}\right)$ and analogue estimates $\left(13^{\circ} \mathrm{C}\right.$; this core) are slightly cooler $\left(1-2^{\circ} \mathrm{C}\right)$ for this location. This is similar to the differences between the two estimates and modern values seen in the Equatorial Atlantic (see Chapter 3). However, in this case the estimates are further from each other (about $\left.4^{\circ} \mathrm{C}\right)$ and the modern values $\left(2-3^{\circ} \mathrm{C}\right)$. This is most likely due to the greater seasonality of this high latitude location and the fact that the actual SST and annual range in SST can be expected to vary much more widely from year to year than in tropical latitudes. At high latitudes phytoplankton blooms last for periods of as little as 3-4 weeks (Holligan et al., 1983) consequently, their sediment record can represent a very short interval of the summer.

Throughout the Holocene section $U_{37}^{k}$ temperature estimates are consistently warmer than analogues, at some levels by as much as $9^{\circ} \mathrm{C}$ (Figure 4-9). This may be a reflection of the different habitat of the two organisms on which the methods are based. Foraminifera are known to live as deep as $1000 \mathrm{~m}$ (Fairbanks and Weibe 1980, Fairbanks et al., 1980, Fairbanks et al., 1982), and different species reach peak abundances at different times throughout the year. The 


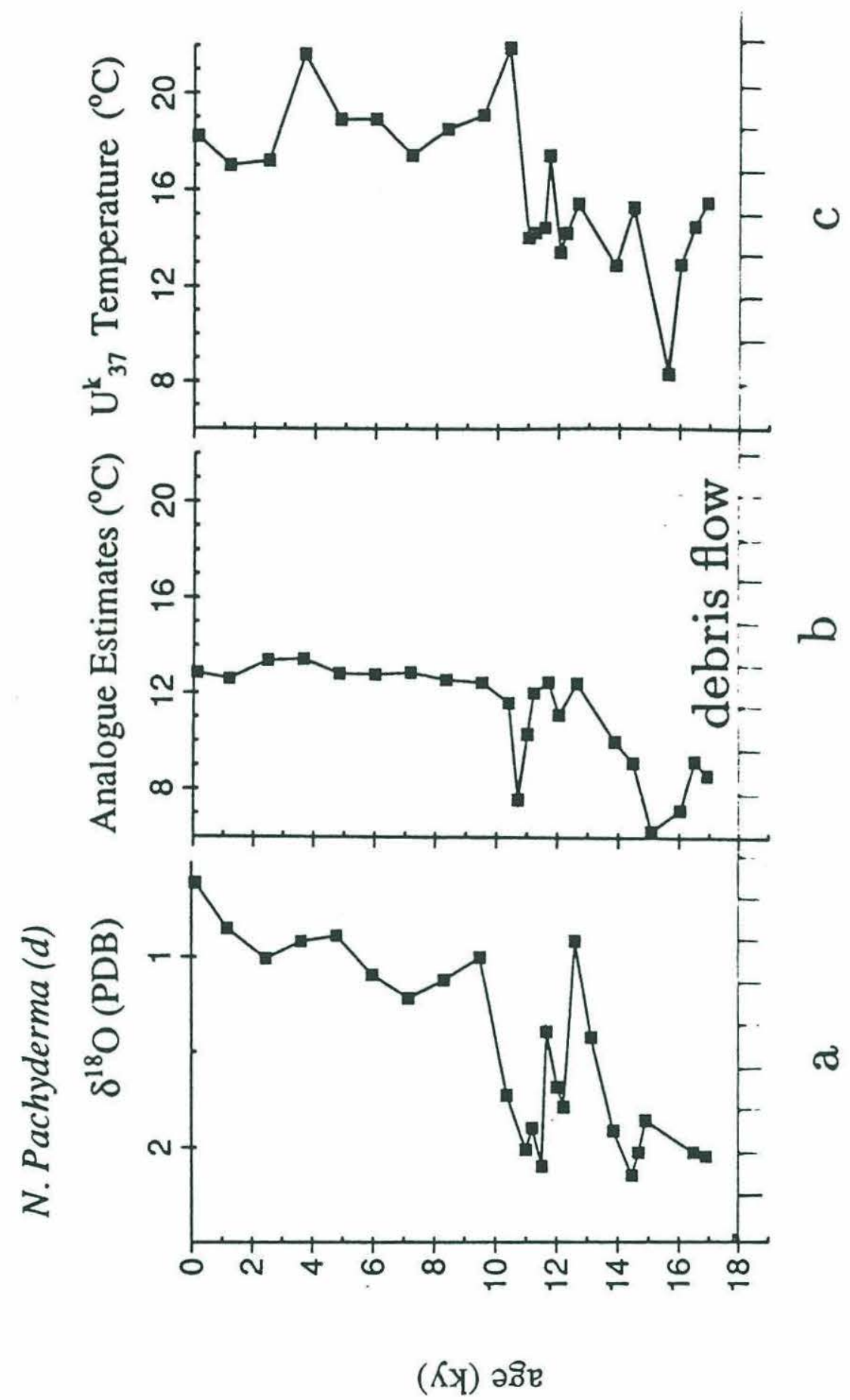

Figure 4-9: Record of a.) $\delta^{18} \mathrm{O}$, b.) analogue, and c.) $\mathrm{U}_{37}^{k}$ temperature estimates, ploted to age. Ages are based on AMS ${ }^{14} \mathrm{C}$ ages in core V23-81, and transposed to $29 \mathrm{GGC}$ by correlation of $N$. pachyderma $(s)$ abundances. Temperature estimates are on the same horizontal scale. 
fauna present at this location is largely composed of species which prefer cold temperatures, and are not by virtue of temperature restricted to surface waters. Coccoliths are necessarily restricted to the photic zone and in high latitudes preferentially choose the top $10 \mathrm{~m}$ of the water column over deeper photic depths extending to $100 \mathrm{~m}$ (Okada and McIntyre, 1979). Standing stock can be as much as $10^{2}$ to $10^{5}$ times higher at the shallower levels (Honjo and Okada, 1974; Okada and McIntyre, 1979) and can be as high as a million cells per liter in surface waters (Berge, 1962; Milliman, 1980; Mitchell-Innes and Winter, 1987) and have been recorded on Rockall Bank at concentrations of over 1 million in the top $1 \mathrm{~m}$ during blooms (Milliman, 1980). It is conceivable therefore, that the coccolith-based marker is recording a shallower, and therefore warmer, part of the surface mixed layer as well as a limited slice of the summer season.

There are several possible sources of error which could cause the $\mathrm{U}_{37}^{k}$ method to return erroneously warm SST values. These include preferential degradation of the more unsaturated $\mathrm{C}_{37}$ alkenones downcore which must be considered more labile due to their larger number of double bonds. However, this is considered unlikely based on the work of Prahl et al. (1989a) which shows no change in $\mathrm{U}_{37}^{k}$ ratios preserved under varying redox conditions. Further, if differential degradation were a problem, it would be expected that the $\mathrm{U}_{37}^{k}$ record would be warmer downcore, and/or that $\mathrm{U}_{37}^{k}$ would record a smaller magnitude signal than the assemblages, when in fact $U_{37}^{k}$ records a larger glacial to interglacial difference. Another explanation for too warm $\mathrm{U}_{37}^{k}$ temperature estimates is that there may be a substantial input in this area from other non-coccolith bearing Prymnesiophyceae whose alkenone unsaturation ratio relationship to temperature is not the same as E. huxleyi. These other algae could be expected to react to changes in SST in the same manner as E. huxleyi, but not with the same relationship as the calibration of Prahl and Wakeham (1987). This is considered possible but not likely because E. huxleyi is such a dominant member of the modern coccolith population in high latitudes (Okada and Honjo, 1973; Honjo and Okada, 1974; Okada and McIntyre, 1979).

The results from the analogue and $U_{37}^{k}$ techniques show a positive but weak correlation between the two data sets (slope $=1.00$, and $r=.592$, Figure 4-10). However, data from Holocene levels (warmest samples) lie tightly clustered about the line, as do colder late glacial level samples (and the Younger-Dryas sample). The "deglaciation" points form a line nearly parallel to, but several degrees below the other clusters and the regression line for the entire data set sug- 


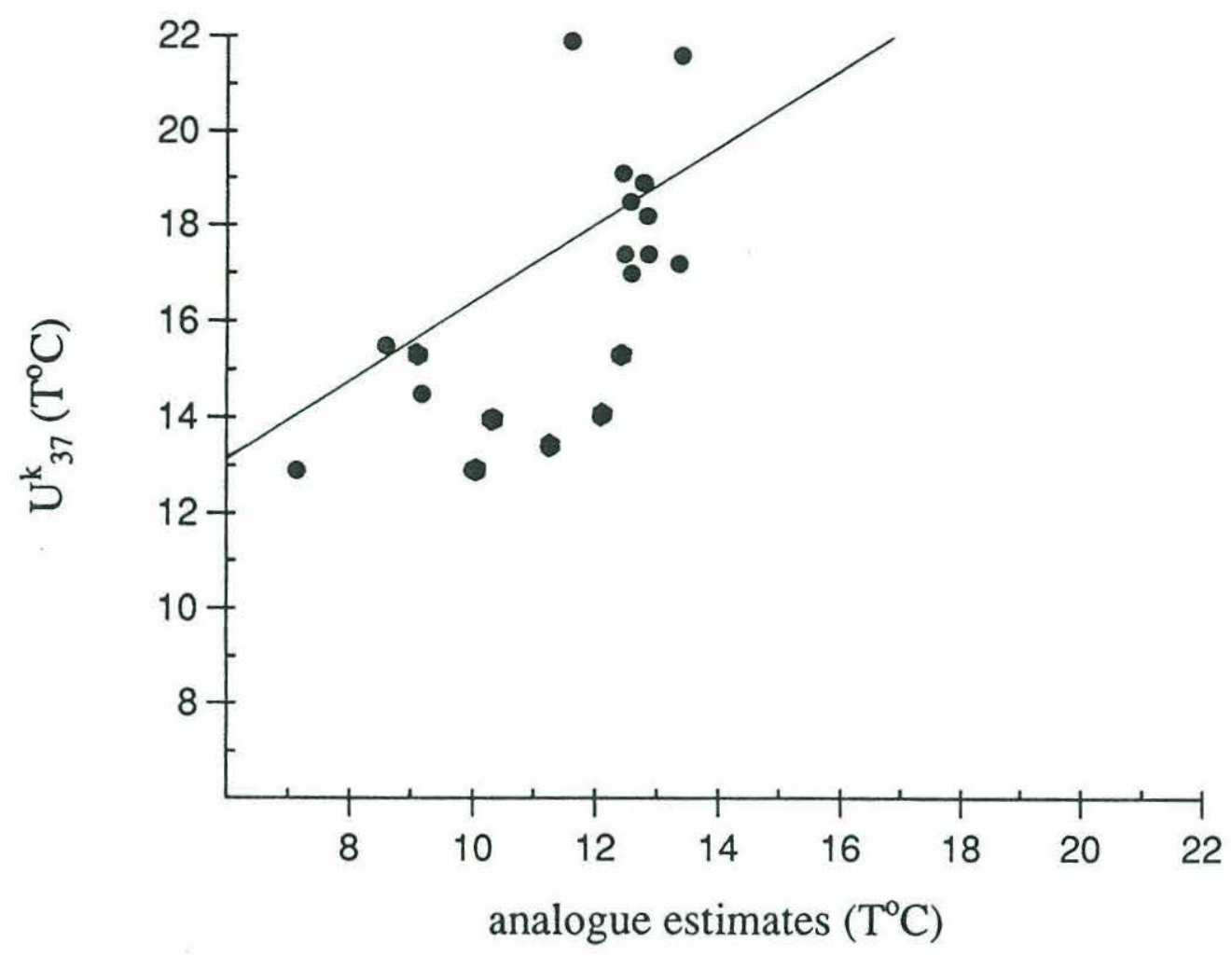

Figure 4-10: $\quad \mathrm{U}_{37}^{k}$ temperature estimates ploted versus analogue temperature estimates for the same sediment depths from core Knr51-29GGC. Linear regression for the data produces a line of slope of 1.00 $\left({ }^{\circ} \mathrm{C} /{ }^{\circ} \mathrm{C}\right.$; y-intercept 5.13) and $\mathrm{r}=0.592$, indicating a weak relationship between the two methods. A change in habitat during the deglaciation of either foraminifera or algae could be partly responsible for the weak relationship between the two methods (see text).

gesting a different relationship between the two temperature estimates during the deglaciation than at other times. A change in habitat during the deglaciation of either foraminifera or algae could be partly responsible for the weak relationship between the two methods.

The overall pattern of the analogue and $U_{37}^{k}$ SST estimates for core 29GGC show similarities (Figure 4-9), which extend in part to the fine details of the curve in the Holocene. Both records show a slight cooling at 1-2 ky, and a warming at $3.5 \mathrm{ky}$. In all cases, the coccolith based $\mathrm{U}_{37}^{k}$ record is spikier than the faunal record (these minor events are not significant in the faunal record, i.e. less than method errors, but the similarities in the two records are still interesting to note). It must be pointed out that detailed differences in the timing between $U_{37}^{k}$ and the faunal records in 29 GGC may be attributable to the fact that different anlayses were performed 
on different sediment samples. These differences may be due to small offsets incurred during re-sampling caused by the poor condition of the core (it is completely dried out and has shrunk considerably). Also, the differences in the timing and expression of the records may be due to different bioturbation effects on the very different substrates on which the methods are based. For example a reduction in production of the alkenones during a short event such as the Younger-Dryas could cause this event to be damped out in the alkenone record. However, alkenone levels (Figure 4-6) show no reduction concurrent with the Younger-Dryas event. So, bioturbation is not considered a likely cause of the discrepancy between the records in this case.

Both temperature records are warm throughout the Holocene, and drop substantially in the late glaciation by $7^{\circ} \mathrm{C}$ for faunal estimates and $10^{\circ} \mathrm{C}$ for $\mathrm{U}_{37}^{k}$ estimates. $\mathrm{U}_{37}^{k}$ shows a cooling of $3^{\circ} \mathrm{C}$ at $10.7 \mathrm{ky}$ within the Younger-Dryas level of $95 \mathrm{~cm}$. The assemblage record indicates a $3^{\circ} \mathrm{C}$ drop at the $95 \mathrm{~cm}$ level, and a total drop for the event of $6^{\circ} \mathrm{C}$ at $93.5 \mathrm{~cm}$. $\mathrm{U}_{37}^{k}$ also shows a $3^{\circ} \mathrm{C}$ drop at the $95 \mathrm{~cm}$ level compared to the data point directly below $(110 \mathrm{~cm})$. But, it must be pointed out this is only a one point peak. If the point at $110 \mathrm{~cm}$ is accurate, then despite the lack of data at $93.5 \mathrm{~cm}$ for $\mathrm{U}_{37}^{k}$, both records show the same cooling at $95 \mathrm{~cm}$, where there is data for both methods. The fact that both temperature estimates indicate lower temperatures at the Younger-Dryas is evidence that this event was accompanied by cooling of surface waters in this location. This interpretation would conflict with the conclusion of Fairbanks (1989) that the Younger-Dryas stands out as an event in the North Atlantic only because of its position between meltwater events before and after. However, Younger-Dryas temperatures indicated by $\mathrm{U}_{37}^{k}$ are not substantially different from SST estimates for the rest of the deglaciation. This indicates that Fairbanks (1989) is substantially correct. Both $\mathrm{U}_{37}^{k}$ and analogues also show a warming of $2-3^{\circ} \mathrm{C}$ coincident with the termination 1a meltwater event.

Despite the obvious difference in the absolute temperatures recorded by the two methods, the similarities in the records are an indication that the $\mathrm{U}_{37}^{k}$ method may provide reliable and useful SST estimates downcore. The $7^{\circ} \mathrm{C}$ interglacial to late glacial temperature drop in this location as estimated by foram assemblages (analogues in this core and by transfer functions, CLIMAP, 1981) is much greater than the errors of the methods, and therefore is considered real. $\mathrm{U}_{37}^{k}$ records this drop as being as much as $3^{\circ} \mathrm{C}$ greater than the foraminifera-based method which is considered an indication of the ability of $U_{37}^{k}$ to record past SST changes, rather thatn 
producing a muted record.

The most significant difference in the overall characters of the records aside from the temperature offset between the two SST records is during the deglaciation (14-9 ky). Throughout the deglaciation, analogues and $U_{37}^{k}$ record the same events, however, while $U_{37}^{k}$ first reach Holocene values $\left(18^{\circ} \mathrm{C}\right)$ at about $10 \mathrm{ka}$, the analogue temperatures first rise to Holocene levels $\left(13^{\circ} \mathrm{C}\right)$ at about $13 \mathrm{ka}$. This causes the actual difference between the two records to be less at this time. At the end of termination 1a (12.7 ka), analogue temperature estimates show a $2^{\circ} \mathrm{C}$ warming, and $\mathrm{U}_{37}^{k}$ a $3^{\circ} \mathrm{C}$ warming, but $\mathrm{U}_{37}^{k}$ estimates return to cooler temperatures (about $14^{\circ} \mathrm{C}$ ) while analogue estimates remain at their warmest levels (about $13^{\circ} \mathrm{C}$ ). $\mathrm{U}_{37}^{k}$ indicates that there is very little trend between 11.5 and $14 \mathrm{ky}$, when $\delta^{18} \mathrm{O}$ and analogue temperature estimates indicate the major deglacial warming. If $U_{37}^{k}$ temperatures are right, this indicates faunal SST estimates may be innacurate during the deglaciation, as suggested by Fairbanks (1989).

The differences between analogue and $U_{37}^{k}$ records in the deglaciation can again best be explained by the differences between the two types of organisms on which they are based. During the deglaciation, and especially at the $12.7 \mathrm{ky}$ meltwater event and 9 ky melting pulse (as evidenced by the $\delta^{18} \mathrm{O}$ record in this core and sea level curves of Fairbanks, 1989) the North Atlantic is believed to have been covered by a low salinity meltwater lid (Broecker et al., 1988; Keigwin et al., unpublished). Phytoplankton must remain in the photic zone, and E. huxleyi is known to thrive quite well in low salinity waters, and its $\mathrm{U}_{37}^{k}$ signal does not appear to be affected by salinities as low as $18 \%$ (as in the Black Sea, see Chapter 2). Therefore, it is assumed that E. huxleyi would have no trouble living in such a low salinity meltwater lid, if sufficient nutrients were available. It is likely a substantial number of the foraminifera were living below this lid; evidence from the Gulf of Mexico during the deglaciation indicates that the meltwater cap there was $50 \mathrm{~m}$ or less in depth (Leventer et al., 1982). At that location the shallow dwelling Globigerinoides ruber showed a large meltwater signal while the deeper dwelling Neogloboquadrina deutertri did not. Foraminifera in the open North Atlantic could easily have recorded different conditions from the phytoplankton. The low salinity meltwater would have resisted mixing because of increased density contrasts, which would have made it more prone to rapid warming or cooling. E. huxleyi blooms in either early or late summer (Okada and 
McIntyre, 1979), which may be due to limitation of nutrients in surface layers which occurs seasonally as stratification sets up in surface waters in the summer. Additional stratification caused by increased density contrasts accompanying a meltwater lid may have further restricted floral blooms to the extreme ends of the summer season. A relatively cooler SST recorded by the flora in the deglaciation, when fauna recorded the same temperatures as Holocene SST may have been caused for example, by rapid cooling in the late summer of the surface layers, while the foraminifers inhabited more saline waters below whose temperatures were similar to those at these depths in the Holocene. If this is so, it is also likely that foraminifera grew throughout the summer causing "warmer" temperatures to be recorded.

SST records from core $29 \mathrm{GGC}$ can be used to assess the local meltwater influence. The 12.7 ky meltwater event caused a $1.2^{\circ} \%$ amplitude signal in the $\delta^{18} \mathrm{O}$ record of $N$. pachyderma (d), which is also observed at a smaller amplitude in the $N$. pachyderma (s) signal from V23-81 $\left(0.75^{\circ} \%\right.$; Jansen and Veum, 1990), as well as other cores from the North Atlantic (Bard et al., 1987; Broecker et al., 1988; Keigwin et al., unpublished). $\delta^{18} \mathrm{O}$ must have been affected substantially by salinity because values are equal to Holocene values at a time when there was still substantial continental ice remaining. Average warming of the two SST records associated with this event was only about $2.5^{\circ} \mathrm{C}$, which can account for only about $0.4^{\circ} \%$ of the isotope signal, leaving about $0.8^{\circ} \%$ o that can be accounted for only by changes in surface salinity. $\delta^{18} \mathrm{O}$ converts (at $1 \%$ salinity to $0.5^{\circ} \% \circ \delta^{18} \mathrm{O}$; Broecker and Peng, 1987) to a drop in salinity of about $1.5 \%$ oo, indicating that meltwaters entrained a substantial amount of ocean water before reaching this site. This meltwater event is not as evident in the $\delta^{18} \mathrm{O}$ of the $N$. pachyderma $(s)$ signal of core 29GGC (Figure 4-3), and is significant but smaller $\left(0.75^{\circ} \%\right.$ ) in the V23-81 record (Figure 4-2), an indication that at 13-12.7 ka this area of the North Atlantic had a significant meltwater influence with only a small warming effect. A thin meltwater lid and relatively small SST change may be the cause of the difference in amplitude between the $N$. pachyderma $(d)$ and N. pachyderma (s) signal at this time. This difference could have been caused by the dextral variety recording the meltwater signal, while the sinistral variety lived in deeper layers below the meltwater, or, the sinistral variety may have lived in the winter when meltwater effects may be presumed to have been much less.

At $11-12 \mathrm{ky}$ in core $29 \mathrm{GGC} N$. pachyderma (d) shows a $0.5-0.75 \%$ lowering, while $\mathrm{U}_{37}^{k}$ 
shows a $3^{\circ} \mathrm{C}$ warming and analogues about $1.5-3^{\circ} \mathrm{C}$ warming. Although most of the magnitude of the warming is within the errors of the two methods and may not be significant, the isotope signal at this event can be completely accounted for by warming of surface waters because sea level rise was relatively slow at this time (Fairbanks, 1989). It is concluded that this preYounger-Dryas warm event is the Allerod, an event observed in numerous other cores from this area (Ruddiman and McIntyre, 1973, 1981; Duplessy et al., 1981; Broecker et al., 1988)

E. huxleyi thrives in brackish waters, as evidenced by its dominant presence in the Black Sea. Although the $\mathrm{C}_{37}$ alkenones are subject to breakdown in sediments (Prahl et al., 1989a), they can be considered as a relative indicator of Prymnesiophyceae productivity, in the same way as TOC can be considered a recorder of productivity if bottom water oxygen and the organic matter degradation rate constant do not change (Emerson, 1985; Prahl et al., 1989a). The high concentrations of $\mathrm{C}_{37}$ alkenones associated with the meltwater events of the two terminations (9.5 and $12.5 \mathrm{ka}$; at 80 and $130 \mathrm{~cm}$, Figure 4-6) indicate that conditions (including lowered salinity) of these terminations were favorable for Prymnesiophyceae growth. These increases in phytoplankton are also reflected in foraminiferal abundance increases. At 13 ka foraminiferal abundances jump to four times late glacial levels, but are not as high as levels at $11 \mathrm{ka}$ which are 1.5 times greater (Appendix B). The change in abundance coincides with the isotopic evidence that termination $1 \mathrm{a}$ in this location was predominantly a meltwater event, if the meltwater did not in restrict foraminiferal growth. Lehmann and Jones (submitted)and Ruddiman and McIntyre (1981) believe a meltwater event at about $15 \mathrm{ky}$ BP originating in the Norwegian Sea is the likely cause of the barren zone in the North Atlantic. Meltwater is believed to have low nutrients which might limit productivity, but if a substantial amount of saltwater was entrained in the meltwater plume in this location at $12.7 \mathrm{ky}$ as discussed above, it is possible for this limiting effect to be absent. The Allerod event (11-12 ky) is believed to be predominantly warming, and the increase in faunal abundances also fits with this hypothesis. $\mathrm{C}_{37}$ abundances do not strictly or as dramatically follow this pattern indicating that foraminifera and/or other phytoplankton may be more influenced by salinities than the Prymnesiophyceae. It is speculated that the reason for this and the low levels of $\mathrm{C}_{37}$ alkenones at $30-40 \mathrm{~cm}$ and at the core-top may be due to varuing dilution by other components, but the exact explanation is unknown.

A direct comparison of $U_{37}^{k}$ temperature estimates from this study with those of Jasper and 
Gagosian (1989) from the Gulf of Mexico, is not meaningful because of the vast difference between the environments of the two cores. However, both core locations are close to continents, and in areas highly influenced by meltwaters during the deglaciation. The $\mathrm{U}_{37}^{k}$ tempertures of Jasper and Gagosian from the Gulf of Mexico indicate SST there was $8^{\circ} \mathrm{C}$ lower during the glaciation, whereas $\delta^{18} \mathrm{O}$ indicates SST could not have been more than $2^{\circ} \mathrm{C}$ lower. In that study $\mathrm{U}_{37}^{k}$ showed a temperature drop $6^{\circ} \mathrm{C}$ greater than $\delta^{18} \mathrm{O}$. The present study indicates a temperature drop $3^{\circ} \mathrm{C}$ larger than faunal estimates in the North Atlantic. Jasper and Gagosian (1989) postulate that a change in the floral community is responsible for the excessive temperature

drop recorded by $\mathrm{U}_{37}^{k}$ in the Gulf of Mexico. If this is true, a similar change in flora may also account for anamolous temperatures in core $29 \mathrm{GGC}$. However, the temperature drop recorded by $\mathrm{U}_{37}^{k}$ in this study is the same as that recorded by faunal methods within the combined errors of the methods. Also, it must be emphasized that the two sites are very different, and the North Atlantic is much more open ocean than the Gulf of Mexico. Further, E. huxleyi is a dominant member of the coccolithophorid population in the High latitude North Atlantic. Sampling frequency in the Gulf of Mexico site is not sufficient to allow for a comparison of deglacial signals between the two sites.

\subsection{Conclusions}

$\mathrm{U}_{37}^{k}$ is a sea surface temperature estimator that apparantly is not directly affected by local salinity or global ice volume changes. This new SST estimator has been compared to foraminiferal records in the northeastern North Atlantic, an area highly influenced by meltwater in the deglaciation. These comparisons reveal the following:

- The similarity of the overall aspects of analogue and $\mathrm{U}_{37}^{k}$ SST estimates indicate that $\mathrm{U}_{37}^{k}$ records warm season SST and SST changes downcore in this high latitude location. Both methods record warmings associated with terminations $1 \mathrm{a}$ and $1 \mathrm{~b}$ at 12.7 and $9.5 \mathrm{ka}$. Differences between the absolute magnitude of the SST estimates are substantial, but can in part be accounted for by differences in the habitats of the two organisms on which the methods are based. $\mathrm{U}_{37}^{k}$ estimates in this location are $2-4^{\circ} \mathrm{C}$ warmer than present SST and other SST estimates, but the ability of $\mathrm{U}_{37}^{k}$ to record similar events as the assemblages 
from this core encourages the use of $U_{37}^{k}$ as a paleotemperature indicator.

- $\mathrm{U}_{37}^{k}$ temperature estimates remained cool throughout the deglaciation, but are always warmer than foraminiferal estimates. Differences between the analogue and $\mathrm{U}_{37}^{k}$ temperature records during the deglaciation indicate that meltwater has a strong influence on the area, and may be decoupling foraminiferal assemblages from the surface-most (melt) waters, by causing them to live below the meltwater lid.

- Temperature estimates indicate that there may have been a $3-6^{\circ} \mathrm{C}$ cooling of surface waters in this area associated with the Younger-Dryas event, but the record of this "cooling" may be exagerated by salinity effects on the fauna. These estimates also reveal surface warming may have been as much $3^{\circ} \mathrm{C}$ associated with the earlier Allerod event.

- SST estimates indicate a significant meltwater influence in this area at 12.5-13 ka causing a salinity effect of $0.8^{\circ} \%$ on the $\delta^{18} \mathrm{O}$ record (about a $1.5^{\circ} \%$ salinity drop), coincident with a $2-3^{\circ} \mathrm{C}$ warming of surface waters.

- High concentrations of $\mathrm{C}_{37}$ alkenones associated with meltwater events at 12.7 and $9.5 \mathrm{ka}$ indicate the alkenone producing Prymnesiophyceae, presumed to be predominantly E. huxleyi, do thrive in those conditions, including lowered salinity, that are present in the deglaciation. 


\section{Chapter 5}

\section{Summary}

When $\mathrm{U}_{37}^{k}$ was first defined in 1986 by Brassell et al., it showed great promise as a paleoclimatic indicator, because it showed trends similar to $\delta^{18} \mathrm{O}$ in downcore records. Subsequent study of the organisms that produce the $\mathrm{C}_{37}$ alkenones, and analyses of surface water samples by Prahl and Wakeham (1987) and Prahl et al. (1988) demonstrated that the $\mathrm{U}_{37}^{k}$ synthesized by E. huxleyi and wild populations of phytoplankton had a linear relationship to growth temperature. The potential of $\mathrm{U}_{37}^{k}$ as a practical paleotemperature indicator rests in its difference from other paleotemperature proxies. It is not based on $\mathrm{CaCO}_{3}$ tests which readily dissolve at depth and have large salinity and ice volume effects. Nor is it based on assemblages which are determined by complex ecological interactions between species, which are known to have changed in some areas of the ocean over glacial-interglacial time scales. The interest in such a novel new SST indicator such as $\mathrm{U}_{37}^{k}$ for estimating past temperatures makes a more definitive asessment of the reliability and quantitative nature of the $U_{37}^{k}$ technique highly desirable. Indeed, interest is so great that several papers have already appeared in the literature tentatively using $\mathrm{U}_{37}^{k}$ to represent past SST (e.g. Ten Haven et al., 1987; Farrington et al., 1988; Jasper and Gagosian, 1989).

The initial objective of this study was to establish the validity of $U_{37}^{k}$ as a temperature estimator in the sediments, and to expand the types of sediments in which $\mathrm{U}_{37}^{k}$ analyses might be reliably conducted. This was accomplished by "calibrating" $U_{37}^{k}$ in core-top sediments and by examining the effects of conditions that cause dissolution of $\mathrm{CaCO}_{3}$ and the effects on $\mathrm{U}_{37}^{k}$ of sample storage at room temperature. The development aspects of this study were positive 
in most respects.

Laboratory experiments on carbonate dissolution showed no change in $U_{37}^{k}$ values with increasing dissolution. Field verification of this in part supports the laboratory experiments, but was less definitive and calls for more study. These results indicate $\mathrm{U}_{37}^{k}$ derived from sediments that have undergone in situ carbonate dissolution will provide valid SST estimates, but more field tests should be conducted before $\mathrm{U}_{37}^{k}$ measurements in such sediments are considered reliable.

Comparison of sediment samples taken and frozen versus those stored at room temperature show no significant difference in $\mathrm{U}_{37}^{k}$ values especially above $8^{\circ} \mathrm{C}$. The results of this study indicate that sediment need not be kept frozen (i.e. preserved) to obtain from it accurate $U_{37}^{k}$ SST estimates. This result will allow greater ease of sample handling in the future. Further, this means that vast numbers of cores previously collected for other analyses may be suitable for $\mathrm{U}_{37}^{k}$ analyses.

Comparison of modern summer SST for the overlying waters with $\mathrm{U}_{37}^{k}$ values from a world wide suite of core-top sediments shows a linear relationship that is not significantly different from that of Prahl and Wakeham (1987), indicating that initial sedimentary diagenesis does not substantially alter the $U_{37}^{k}$ signal synthesized by the phytoplankton. This data set is small however, and needs to be continually added to in the future. It is especially lacking in samples from southern latitudes, and samples representing coldest (high latitude) waters. Several high latitude samples analyzed in this study proved to be "barren", and it is assumed that the short growing season at high latitudes may not, in all cases, input sufficient $\mathrm{C}_{37}$ alkenones to the sediments for reliable $\mathrm{U}_{37}^{k}$ analyses. Thus, $\mathrm{U}_{37}^{k}$ temperature records may be unobtainable in locations (especially at high latitudes) where Prymnesiophyceae biomass is low.

Once the $\mathrm{U}_{37}^{k}$ "paleothermometer" was calibrated in sediments it could be applied quantatively downcore to examine paleo-temperatures. Because core-top calibration cannot answer the question of long term changes in preservation downcore, the $\mathrm{U}_{37}^{k}$ analyses were paired with those of established SST estimators ( $\delta^{18} \mathrm{O}$ and foraminiferal assemblages) to provide a quantative comparison with which to test the accuracy of $U_{37}^{k}$ through the last half glacial cycle. Two sites were chosen for this initial application that would not only serve as a test for $U_{37}^{k}$ but whose SST records from established methods were ambiguous enough that the additional 
information contributed by $\mathrm{U}_{37}^{k}$ might provide insight into past oceanographic conditions in these areas. The locations chosen were the central Equatorial Atlantic and the northeastern North Atlantic.

In both locations downcore comparison of $\mathrm{U}_{37}^{k}$ with temperature estimates based on the modern analogue technique and $\delta^{18} \mathrm{O}$, show good agreement in Holocene sediments, especially in tropical sites, and plausable enough agreement in glacial and deglacial sediments to provide some assurance that $\mathrm{U}_{37}^{k}$ is providing a reliable estimate of past SST. Differences between the methods can in part be ascribed to the differences between the habitats of the two organisms on which the methods are based, but some questions as to the reliability of $U_{37}^{k}$ still remain. Assuming the differences between methods are real, these differences allow the beginning of an understanding of how the surface ocean may have changed as climate changed in the past.

Foraminiferal transfer function estimates of sea surface temperatures in the Equatorial Atlantic dropped by $2^{\circ} \mathrm{C}$ in the warm season during the last glaciation (CLIMAP, 1981; Mix et al., 1986; McIntyre et al., 1989). However, it is known that assemblages present in the Equatorial Atlantic at that time have no modern analogues and the actual temperatures associated with these assemblages are therefore uncertain (Mix et al., 1986; Mix, 1987). It is believed that the temperatures calculated from these assemblages have embedded in them some increased divergence or advection component caused by changes in the surface mixed layer, producing anomalously low temperatures. $\mathrm{U}_{37}^{k}$ results for the glaciation indicate a warm season temperature decrease of only $1.56^{\circ} \mathrm{C}$ as opposed to a $3.75^{\circ} \mathrm{C}$ decrease indicated by modern analogue estimates and a $3.40^{\circ} \mathrm{C}$ decrease indicated by $\delta^{18} \mathrm{O}$, indicating temperature estimates based on foraminifera are exaggerated by as much as $2.25^{\circ} \mathrm{C}$ due to changes in the surface ocean in the last glaciation. Alkenone based temperature estimates support CLIMAP's (1981) conclusion that SST in the Equatorial Atlantic dropped only a small amount in the last glaciation in contrast to terrestrial paleotemperature estimates of $5-6^{\circ} \mathrm{C}$ cooler on the adjacent African continent (Omaston, 1965; Flenley, 1979; Livingstone, 1980; Hamilton, 1982). An increased temperature contrast between land and ocean in this location fits with model results of Manabe and Hahn (1977) which suggest such an increased temperature gradient between the African continent and the Equatorial Atlantic would enhance trade winds.

The northeastern North Atlantic underwent major changes over the last glacial cycle, includ- 
ing a large temperatures decrease and substantial meltwater influence during the deglaciation. Salinity changes are known to affect $\delta^{18} \mathrm{O}$ signals and evidence suggests that meltwater may have affected foraminiferal assemblages as well (Leventer et al., 1982; Fairbanks, 1989). U $\mathrm{U}_{37}^{k}$ should provide an SST record that, unlike foram $\delta^{18} \mathrm{O}$ and faunal SST estimates, is unaffected by salinity for the deglaciation. $U_{37}^{k}$ temperature estimates indicate SST remained cool throughout the deglaciation (though not as cool as late glacial levels), whereas faunal assemblage SST estimates indicate SST rose to Holocene levels at termination 1a (about $12.7 \mathrm{ka}$ ) and remained there. The difference between these estimates may be due to the phytoplankton living in the low salinity meltwater lid, while the foraminifera inhabited the more saline waters below. SST estimates from this study show a cooling of about $3-6^{\circ} \mathrm{C}$ associated with the Younger-Dryas confirming the cooling of northern North Atlantic waters during this event. $\mathrm{U}_{37}^{k}$ provides an independent corroboration of cooling indicated by foraminiferal results at this time which conflicts with Fairbank's (1989) conclusion that cooling did not accompany this event in the North Atlantic. A $2-3^{\circ} \mathrm{C}$ warming is associated with the Allerod event (11-12 ka).

These initial studies show that $U_{37}^{k}$ as a paleotemperature indicator apppears to be of about the same usefulness as established temperature estimators. It has about the same accuracy as other methods (about $\pm 1.5^{\circ} \mathrm{C}$ ), and like faunal assemblages which have non-analogue assemblages in the glacial Equatorial Atlantic, it has anamolous results (e.g. Jasper, 1989; and Holocene temperatures in the North Atlantic, this study) the reasons for which are not completely known. However, the results of this study indicate $\mathrm{U}_{37}^{k}$ not only may be a reliable indicator of paleo-SST, but that the different controls on the growth and habitat of the phytoplankton that produce the alkenones on which it is based, compared to those on which other SST estimators are based, may provide new insight into past oceanographic conditions, which is particularly relevant where results from established estimators are questionable.

Further work can improve the usefulness and effectiveness of this new method. The strength of $\mathrm{U}_{37}^{k}$ as a paleo-thermometer rests on the differences between it and established temperature estimators. The initial tests from this study illustrate that well, but there is much that remains to be done to improve the method, to understand the controls on it better and so, to make it more dependable. The temperature effects on the other $\mathrm{C}_{37}$ alkenone producers such as Isochrysis spp. and Chrysotila lamellosa, should be investigated to help determine their effects 
on the temperature records in coastal areas, especially those affected by fresh water runoff. A better understanding of the physiology and ecology of the alkenone producing Prymnesiophytes is also needed to understand the controls on their alkenone production, including the effects of nutrients and salinity. Temperature estimates need to be obtained from colder waters than those already obtained in culture, water column, and modern sediment samples. Further investigations must be conducted in the field on the effects of dissolution of carbonates on $U_{37}^{k}$ values. A first step would be to obtain further sample pairs from a limited geographical area across the lysocline. This study had only one such pair, a very limited data set.

Much use could be made in the paleoceanographic community by a SST indicator that is independent of foraminifera for very old sediments (the oldest sediments in which the $\mathrm{C}_{37}$ alkenones are found are Cretaceous; Marlowe, 1984; Brassell et al., 1986a). Although $\mathrm{C}_{37}$ alkenones have been found in sediments as old as the Creataceous, their relationship to temperature in sediments older than the first appearance of E. huxleyi (about $250 \mathrm{ka}$ ) is uncertain (Brassell et al., 1986a). If a paleotemperature relationship could be determined, $\mathrm{U}_{37}^{k}$ could be a more powerful paleoceanographic tool. At this time only relative temperatures based on inference from more modern data can be determined for very old sediments and these must be considered very tenuous at best.

The $U_{37}^{k}$ method needs to be applied to other open ocean environments not already investigated, such as the Coral Sea where foraminiferal SST estimates are ambiguous and results are contradictory (Anderson et al., 1989). As in the present study, application of a completely independent SST estimator can help investigators to understand the sea surface temperature history of the area, as well as to begin to understand the controls on foraminiferal temperature estimates. $\mathrm{U}_{37}^{k}$ SST estimates should be verified down-core in a location where foraminiferal based techniques are not questionable. Other areas of the ocean where $\mathrm{U}_{37}^{k}$ should be applied are areas where $\mathrm{CaCO}_{3}$ dissloution has made carbonate based techniques unreliable. Such areas could be upwelling areas where oxidation of organics destroys carbonates. Work has been started by Farrington et al. (1988) off Peru, where the record of El Niño events is probably preserved. Other upwelling areas remain to be studied. Another location with low carbonates but high enough sedimentation rates to provide sufficient resolution of climatic events is the Northwest Pacific, where little is known of the sea surface temperature history. If pursued 
properly $U_{37}^{k}$ can add a valuable piece to the puzzle of the earth's climatic history. 


\section{Bibliography}

[1] Adelseck, C.G. Jr., 1977, Dissolution of deep-sea carbonate: preliminary calibration of preservational and morphologic aspects, Deep Sea Res, 24:1167-1185.

[2] Anderson, D.M., W.L. Prell and N. J. Barrett, 1989, Estimates of sea surface temperature in the Coral Sea at the last glacial maximum. Paleoceano., 4: 615-627.

[3] Bard, M., M. Arnold, P. Maurice, J. Duprat, J. Moyes, and J.-C. Duplessy, 1987, Retreat velocity of the North Atlantic polar front during the last deglaciation determined by ${ }^{14} \mathrm{C}$ accelerator mass spectrometry, Nature, 328:791-794.

[4] Bauerfeind, E., 1987, Primary production and phytoplankton and phytoplankton biomass in the equatorial region of the Atlantic at $22^{\circ}$ West, Proc. Inter. Symp. on Equatorial Verticle Motion, Oceanol. Acta, SP: 113-136.

[5] Berge, G., 1962, Discoloration of the sea due to Coccolithus huxleyi "bloom", Sarsia, 6: $27-40$.

[6] Berger, W.H., and J.S. Killingley, 1977, Glacial - Holocene transition in deep-sea carbonates: Selective dissolution and the stable isotope signal, Science, 197:563-566.

[7] Berner, R.A., 1980, Early Diagenesis, A theoretical Approach, Princeton University Press, Princeton,N.J., 241 pp.

[8] Bonneau, M.C., C. Vergnaud-Grazzini, and W.H. Berger, 1980, Stable isotope fractionation and differential dissolution in recent planktonic foraminifera from Pacific box-cores, Oceanol. Acta, 3:377-382. 
[9] Boyle, E.A., and L.D. Keigwin, 1987, North Atlantic thermohaline circulation during the past 20,000 years linked to high latitude surface temperature, Nature, 330: 35-40.

[10] Brassell, S.C., R.G. Brereton, G. Eglinton, J. Grimalt, G. Liebzeit, I.T. Marlowe, U. Pflaumann, and M. Sarnthein, (1986a), Paleoclimatic signals recognized by chemometric treatment of stratigraphic data, in Advances in Organic Chemistry 1985Org. Geochem., 10: $649-660$.

[11] Brassell, S.C., G. Eglinton, I.T. Marlowe, U. Pflaumann, and M. Sarnthein, 1986b, Molecular stratigraphy: a new tool for climatic assessment, Nature, 320: 129-133.

[12] Broecker, W.S., M. Andree, W. Wolfi, H. Oeschger, G. Bonani, J. Kennett, and D. Peteet, 1988, The chronology of the last deglaciation: Implications to the cause of the Younger-Dryas event, Paleoceano. 3: 1-19.

[13] Broecker, W.S., J.P. Kennett, B.P. Flower, J.T. Teller, S. Trumbore, G. Bonani, and W. Wolfi, 1989, Routing of meltwater from the Laurentide ice sheet during the Younger Dryas cold episode, Nature, 341: 318-321.

[14] Broecker, W.S., and T.-H. Peng, 1987, The oceanic salt pump: does if contribute to the glacial-interglacial difference in atmospheric $\mathrm{CO}_{2}$ ?, Global Biogeochem. Cycles, 1: 251-259.

[15] CLIMAP, 1976, Glacial North Atlantic 18,000 years ago: a CLIMAP reconstruction, Geol. Soc. Am. Memoir 145, pp 43-76.

[16] CLIMAP, 1981, Seasonal reconstructions of the earth's surface at the last glacial maximum,Geol. Soc. Amer. Map and Chart series MC-36:1-18.

[17] Cullen, J.J., and R.W. Epply, 1981, Chlorophyll maximum layers of the Southern California Bight and possible mechanisms of their formations and maintenance, Oceanolo. Acta 4,1: 23-32.

[18] Curry, W.B., and G.P. Lohmann, 1983, Reduced advection into the Atlantic Ocean deep basins during the last glaciation maximum, Nature, 306: 577-580. 
[19] Curry, W.B., and G.P. Lohmann, 1985, Carbon deposition rates and deep water residence time in the Equatorial Atlantic Ocean throughout the last 160,000 years, in Sundquist, E.T. and Broecker, W.S., eds. The Carbon Cycle and Atmospheric $\mathrm{CO}_{2}:$ Natural Variations Archean to Present, Geophysical Monograph no. 32 Amer. Geophys. Union, 285-302.

[20] Curry, W.B., and G.P. Lohmann, 1986, Late Quaternary carbonate sedimentation at the Sierra Leone Rise (eastern Equatorial Atlantic Ocean), Marine Geol. 70: 223-250

[21] Curry, W.B., and K.G. Miller, (1989) Oxygen and carbon isotopic variation in Pliocene Benthic foraminifers of the Equatorial Atlantic, Proc. ODP Sci. Results 108, College Station, TX, 157-166.

[22] Curry, W.B., R.C. Thunnell, and S. Honjo, 1983, Seasonal changes in the isotope composition of planktonic foraminifera collected in Panama Basin sediment traps, Earth Planet. Sci. Lett., 64:33-43.

[23] de Leew, J.W., F.W. van de Meer, W.I.C. Rijpstra, and P.A. Schenk, 1980, On the occurence and structural identification of long chain unsaturated ketones and hydrocarbons in sediments. in Advances in Organic Chemistry, 1979, A.G. Douglas and J.R. Maxwell, eds. Pergammon Press, Oxford, pp 211-217.

[24] Dudley, W.C., and D.E. Goodney, 1979, Oxygen isotope content of coccoliths grown in culture, Deep Sea Res., 26A: 495-503.

[25] Dunbar, R.B., 1983, Stable isotope record of upwelling and climate from Santa Barbara Basin, California, in Coastal Upwelling; Its Sediment Record Part B, Sedimentary Records of Ancient Coastal Upwelling, J. Theide and E. Suess, eds, Plenum Press, NY, pp 217-245.

[26] Duplessy, J.C., M. Arnold, P. Maurice, E. Bard, J. Duprat, and J. Moyes, 1986, Direct dating of the oxygen-isotope record of the last deglaciation by ${ }^{14} \mathrm{C}$ accelerator mass spectrometry, Nature, 320: 350-352.

[27] Duplessy, J.C. G. Delibras, J.L. Turon, C. Pujol, and J. Duprat, 1981, Deglacial warming of the northeastern Atlantic Ocean: Correlation with the paleoclimatic evolution of the European continent, Palaeogeogr. Palaeoclimatol. Palaeoeco. 35: 121-144. 
[28] Emerson, S., 1985, Organic carbon preservation in marine sediments in Sundquist, E.T. and Broecker, W.S., eds. The Carbon Cycle and Atmospheric $\mathrm{CO}_{2}$ : Natural Variations Archean to Present, Geophysical Monograph no. 32 Amer. Geophys. Union, 78-87.

[29] Fairbanks, R.G., 1989, Glacio-eustatic sea level record 0-17,000 years before present: Influence of glacial melting rates on the Younger-Dryas "event" and deep ocean circulation, Nature, 342: 637-642.

[30] Fairbanks, R.G. and R.K. Mathews, 1978, The marine oxygen isotope record in Pleistocene coral, Barbados, West Indies, Quat, Res. 10: 181-196.

[31] Fairbanks, R.G., M. Sverdlove, R. Free, P.H. Wiebe, and A.W.H. Bé, 1982, Vertical distribution and isotopic fractionation of living planktonic foraminifera from the Panama Basin, Nature, 298: 841-844.

[32] Fairbanks, R.G., and P.H. Wiebe, 1980, Foraminifera and chlorophyll maximum: vertical distribution, seasonal succession and paleoceanographic significance, Science, 209: 15241526.

[33] Fairbanks, R.G., P.H. Wiebe, and A.W.H. Bé, 1980, Vertical distribution and isotopic composition of living planktonic foraminifera in the western North Atlantic, Science, 207: 61-63.

[34] Farrington, J.W., A.C. Davis, J. Sulanowski, M.A. McCaffrey, M. Mcarthy, C.H. Clifford, P. Dickinson, and J.K. Volkman, 1988, Biogeochemistry of lipids in surface sediments of the Peru upwelling area at $15^{\circ} \mathrm{S} .$, Advances in Organic Chemistry 1987,Org. Geochem., 13: $607-617$.

[35] Flenley, J.R., 1979, The Equatorial Rain Forest, A Geological History, Butterworths, London.

[36] Flood, R.D., 1978, Studies of deep sea sedimentary microtopography in the North Atlantic Ocean, unpub. Ph.D. thesis, MIT/ WHOI, 392 pp. 
[37] Fuglister, F.C., 1960, Atlantic Ocean Atlas of temperature and Salinity: Profiles and Data from the International Geophysical Year of 1957-1958, WHOI Atlas Series, Woods Hole, MA, 209pp.

[38] Gardner, J.V., and J.D. Hays, 1976, Responses of sea surface temperature and circulation to global climate change during the past 200,00 years in the Eastern Equatorial Atlantic Ocean, Geol. Soc. Am. Memoir 145, pp 221-246.

[39] Hamilton, A.C., 1982, Environmemtal History of East Africa, Academic Press, New York.

[40] Hansen, J., A. Lacis, G. Rind, G. Russell, P. Stone, I. Fung, R. Ruedy, and J. Lerner, 1984, Climate sensitivity: Analysis of feedback mechanisms, in Climate Processes and Climate Sensitivity, Maurice Ewing Series 5, Amer. Geophys. Union, Washington, D.C., $368 \mathrm{pp}$.

[41] Hastenrath, S., 1977, Hemispheric asymmetry of oceanic heat budget in the equatorial Atlantic and eastern Pacific, Tellus, 29: 523-529.

[42] Hastenrath, S., 1980, Heatbudget of Tropical ocean and Atmosphere, Jo. Phys. Oceanogr, 10: $159-170$.

[43] Herbland, A., A. Le Bouteiller, P. Raimbault, 1987, Does the nutrient enrichment of the equatorial upwelling influence the size structure of phytoplankton in the Atlantic ocean?, Proc. Inter. Symp. on Equatorial Verticle Motion, Oceanol. Acta, SP: 115-120.

[44] Herbland, A., and B. Voituriez, 1979, Hydrological structure analysis for estimating the primary production in the tropical Atlantic Ocean, J. Mar. Res., 37: 87-101.

[45] Holligan, P.M., M. Voillier, D.S. Harbour, P. Camus, and M. Champagne-Phillipe, 1983, Satellite and ship studies of coccolothophore production along a continental shelf edge, Nature, 304: 339-342

[46] Honjo, S. and J. Erez, 1978, Dissolution rates of calcium carbonate in the deep ocean; an in-situ experiment in the north Atlantic ocean, Earth Planet. Sci. Let., 40: 287-300.

[47] Honjo, S. and H. Okada, 1974, Community structure of coccolithophores in the photic layer of the mid Pacific, Micropaleo., 20(2): 209-230. 
[48] Hutson, W.H., 1980, The Agulhas Current during the late Pleistocene: analysis of modern faunal analogues, Science, 207: 64-66.

[49] Imbrie, J. and N.G. Kipp, 1971, A new micropaleontological method for quantative paleoclimatology: Application to a late Pleistocene Caribbean core, in Late Cenozoic Glacial Ages K.K. Turekian, ed. Yale Univ. Press, New Haven, CT, pp. 77-81.

·[50] Imbrie, J., J. Van Donk, and N.G. Kipp, 1973, Paleoclimatic investigation of a late Pleistocene Caribbean deep sea core: Comparison of isotope and faunal methods, Quat. Res., 3:10-38.

[51] Jahnke, R.A., S.R. Emerson, C.E. Reimers, J. Schufert, K. Ruttenberg, and D. Archer, 1989, Benthic recycling of biogenic debris in the eastern tropical Atlantic Ocean, Geochim. Cosmochim. Acta, 53: 2947-2960.

[52] Jansen, E. and T. Veum, 1990, Evidence for two-step deglaciation and its impact on North Atlantic deep-water circulation, Nature, 343: 612-616.

[53] Jasper, J.P. and R.B. Gagosian, 1989, Alkenone molecular stratigraphy in an oceanic environment affected by glacial freshwater events, Paleoceano., 4: 603-614.

[54] Jones, G.A. and P. Kaiteris, 1983, A vacuum-gasometric technique for rapid and precise analysis of calcium carbonate in sediments and soils, Research Methods Papers, 1983: 655-660.

[55] Jones, G.A., and L.D. Keigwin, 1988, Evidence from Fram Strait for early deglaciation, Nature, 336: 56-59.

[56] Jones, G.A., and W.F. Ruddiman, 1982, Assessing the global meltwater spike, Quat. Res., 17: $148-172$.

[57] Keigwin, L.D., 1979, Late Cenozoic stable isotope stratigraphy and paleoceanography of DSDP sites from the East Equatorial and Central North Pacific, Earth Planet Sci. Lett., 45: $361-382$. 
[58] Keigwin, L.D., and G. A. Jones, 1989, Glacial-Holocene stratigraphy, chronology, and paleoceanographic observations on some North Atlantic sediment drifts, Deep Sea Res., 36: $845-867$.

[59] Keigwin, L.D., G.A. Jones and S.J. Lehmann, Deglacial meltwater discharge, North Atlantic deep circulation, and abrupt climate change, submitted.

[60] Leventer, A. D. F. Williams, J.P. Kennett, 1982, Dynamics of the Laurentide ice sheet during the last deglaciation: Evidence from the Gulf of Mexico, Earth Planet Sci. Lett., 59: 11-17.

[61] Levitus, S., 1982, Climatological Atlas of the World Ocean, NOAA Prof. Pap., 13, 173 pp.

[62] Livingstone, D.A., Environmental changes in the Nile Headquarters, in M.A.J. Williams and H. Faure, eds. The Sahara and the Nile, pp. 339-359.

[63] Manabe, S. and A.J. Broccoli, 1985, The influence of continental ice sheets on the climate of an ice age, Jour. Geophys. Res. 90, D1: 2167-2190.

[64] Manabe, S. and D.G. Hahn, 1977, Simulation of the tropical climate of an ice age, Jour. Geophys. Res. 82 no. 27: 3889-3911.

[65] Mangerud, J.S., S.E. Lie, H. Furnes, I.L. Kristiansen and L. Lomo, 1984, A Younger Dryas ash bed in western Norway, and its possible correlations with tephra in cores from Norwegian Sea and the North Atlantic, Quat. Res., 3: 3-9.

[66] Marlowe, I.T., 1984, Lipids as paleoclimatic indicators, unpub. Ph.D. thesis, University of Bristol, England, 273 pp.

[67] Marlowe, I.T., S. Brassell, G. Eglinton, and J.C. Green, 1984, Long chain unsaturated Ketones and esters in living algae and marine sediments, Org. Chem., 6: 135-141.

[68] Marlowe, I.T., S. Brassell, G. Eglinton, J.C. Green, and P.A. Course, 1984, Long chain (n$\left.\mathrm{C}_{37}-\mathrm{C}_{39}\right)$ alkenones in the Prymnesiophyceae: Distribution of alkenones and other lipids and their taxonomic significance, British Phycol. J., 19:203-216. 
[69] McIntyre A., W.F. Ruddiman, K. Karlin, and A.C. Mix, 1989, Surface water response of the Equatorial Atlantic to orbital forcing., Paloeceano, 4: 19-55.

[70] Milliman, J.D., 1980, Coccolithophorid production and sedimentation, Rockall Bank, Deep Sea Res., 27A: 959-963.

[71] Mitchell-Innes, B.A., and A. Winter, 1987, Coccolithophores: A major phytoplankton component in mature upwelled waters off the Cape Peninsula, South Africa, in March 1983, Marine Bio., 95: 25-30.

[72] Mix, A.C., 1987, The oxygen isotope record of glaciation, in W.F. Ruddiman ed. North American and Adjacent Oceans During the Last Deglaciation, The Geology of North America vol K-3, Geol. Soc. Amer., pp. 111-136.

[73] Mix, A.C., and W.F. Ruddiman, 1985, Structure and timing of the last deglaciation: Oxygen-isotopic evidence, Quat. Sci. Rev., 4: 59-108.

[74] Mix, A.C. W.F. Ruddiman, and A. McIntyre, 1986, Late Quaternary paleoceanography of the tropical Atlantic, 1: Spatial variability of mean sea-surface temperatures, 0-20,000 years B.P., Paleoceano, 1: 43-66.

[75] Okada, H. and S. Honjo, 1973, The distribution of oceanic coccolithophorids in the Pacific, Deep Sea Res., 20: 355-374.

[76] Okada, H. and A. McIntyre, 1979, Seasonal distribution of modern coccolithophores in the Western North Atlantic Ocean, Marine Bio., 54: 319-328.

[77] Omaston, H.A., 1965, The past and present climate and vegetation of Ruwenzori and its neighborhood. unpub. Ph.D. thesis, Oxford University, England.

[78] Oppo, D.W., and R.G. Fairbanks, 1987, Variability in the deep and intermediate water circulation of the Atlantic Ocean during the past 25,000 years: Northern hemisphere modulation of the Southern Ocean, Earth Planet. Sci. Lett., 86: 1-15.

[79] Oudot, C. and P. Morin, 1987, The distribution of nutrients in the equatorial Atlantic: Relation to physical processes and phytoplankton biomass, Proc. Inter. Symp. on Equatorial Verticle Motion, Oceanol. Acta, SP: 121-130. 
[80] Overpeck, J.T., T. Webb III, and I.C. Prentice, 1985, Quantative interpretation of fossil pollen spectra: Dissimilarity coefficients and the method of modern analogs, Quat. Res. 23: $87-198$.

[81] Parkin, D.W., 1974, Trade-winds during the glacial cycles, Proc. R. Soc. Lond., 337: 73-100.

[82] Parkin, D.W., and R.C. Padgham, 1975, Fruther studies on Trade winds during the glacial cycles, Proc. R. Soc. Lond., 346: 245,260.

[83] Parkin, D.W. and N.J. Shackleton, 1973, Trade wind and temperature correlations down a deep sea core off the Saharan coast, Nature, 245: 455-456.

[84] Pederson, T.F., 1983, Increased productivity in the eastern equatorial Pacific during the last glacial maximum (19,000 to 14,000 yr BP), Geology, 11: 16-19.

[85] Prahl, F.G., G.J. deLange, M. Lyle, and M.A. Sparrow 1989a, Post depositional stability of long chain alkenones under contrasting redox conditions, Nature, 341: 434-437.

[86] Prahl, F.G., L.A. Muehelhausen, and M.W. Lyle, 1989b, An organic geochemical assessment of oceanographic conditions at MANOP Site C over the past 26,000 years, Paleoceano., 4: 495-510.

[87] Prahl F.G., L.A. Muehlhausen and D.L. Zahnle, 1988, A well preserved geochemical record for long-chain, unsaturated ketones, Geochim. Cosmochim. Acta, 52: 2303-2310.

[88] Prahl, F.G. and S.G. Wakeham, 1987, Calibration of unsaturation patterns in long chain ketone compositions for paleotemperature assessment, Nature, 330: 367-369.

[89] Prell, W.L. 1985, The stability of low latitude sea surface temperatures: An evaluation of the CLIMAP reconstruction with emphasis on the positive SST anomalies, Special Rept. U. S. Dept. of Energy, 60 pp.

[90] Prell, W.L. and W.B. Curry, 1981, Faunal and isotopic indices of monsoonal upwelling, Western Arabian Sea, Oceanol. Acta, 4(1): 91-98. 
[91] Prell, W.L., J.V. Gardner, A.W. H. Be, and J.D. Hays, 1976, Equatorial Atlantic and Carribean assemblages, temperatures, and circulation: Interglacial and glacial comparisons Geol. Soc. Am. Memoir 145, pp 247-266.

[92] Raymont, J.E.G., 1980, Plankton and Productivity in the Oceans, $2^{\text {nd }}$ Edition, vol 1: Phytoplankton, Pergamon Press, New York, 490pp.

[93] Rechka, J.A. and J.R. Maxwell, 1987, Characterisation of alkenone temperature indicators in sediments and organisms, in Advances in Organic Chemistry, L. Mattiavelli and L. Novelli, eds., Pergamon, Oxford, Org. Geochem., 13: 727-734.

[94] Reihl, H., 1979, Climate and Weather in the Tropics, Academic Press, San Diego, CA, $611 \mathrm{pp}$.

[95] Reynolds, R.W., 1982, A monthley averaged climatology of sea surface temperature, NOAA Technical Rept. NWS 31, 35 pp.

[96] Rind, D. and D. Peteet, 1985, Terrestrial conditions at the last glacial maximum and CLIMAP sea-surface estimates are they consistent?, Quat. Res., 24: 1-22.

[97] Romankevich, E.A., 1984, Geochemistry of Organic Matter in the Ocean, Springer-Verlag, New York, 334 pp.

[98] Ruddiman, W.F. and A. McIntyre, 1973, Time transgressive deglacial retreat of polar waters from the North Atlantic, Quat. Res., 3: 117-130.

[99] Ruddiman, W.F. and A. McIntyre, 1979, Warmth of the subpolar North Atlantic during northern hemispheric ice sheet growth, Science, 204: 173-175.

[100] Ruddiman, W.F. and A. McIntyre, 1981, Oceanic mechanisms for amplification of the 23,000-year ice-volume cycle, Science, 212: 617-627.

[101] Ruddiman, W.F., S.C. Sancetta and A. McIntyre, 1977, Glacial/interglacial response rate of subpolar North Atlantic waters to climate change: The record in ocean sediments, Phil. Trans. R. Soc. Lond. Ser. B, 280: 119-142. 
[102] Sarnthein, M., 1978, Sand deserts during glacial maximum and climatic optimum, Nature, 272: $43-46$.

[103] Sarnthein, M., G. Tetzlaff, B. Koopmann, K. Wolter, and U. Pflaumann, 1981, Glacial and interglacial wind regimes over the eastern subtropical Atlantic and North-west Africa, Nature, 293: 193-196.

[104] Smayda, T., 1980, Phytoplankton species succession, in I. Morris, ed. The Physiological Ecology of Phytoplankton, University of California Press, Los Angeles, pp. 493-570.

[105] Street, F.A., and A.T. Grove, 1976, Environmental and climatic implications of late Quaternary lake-level fluctuations in Africa, Nature, 261: 385-390.

[106] Street, F.A., and A.T. Grove, 1979, Global maps of lake level fluctuations since 30,000 yr BP, Quat. Res., 12: 83-118.

[107] Teller, J.T., 1987, Proglacial lakes and the southern margin of the Laurentide ice sheet, in Ruddiman, W.F. and Wright, H.E. Jr., eds, North America ans adjacent oceans during the last deglaciation, Geolgical Society of America, Boulder Colorado, vK-3, pp. 39-69.

[108] ten Haven, H.L., M. Baas, M. Kroot, J.W. de Leeuw. P.A. Schenk, and J. Ebbing, 1987, Late Quaternary Mediterranean sapropels III: Assessment of source of input and paleotemperature as derived from biological markers, Geochim. Cosmochim. Acta, 51: 803-810.

[109] Van Andel, Tj. H., G.R. Heath, and T.C. Moore Jr., 1975, Cenozoic Tectonics, Sedimentation, and Paloeceanography of the Central Equatorial Pacific, Geol. Soc. Am. Memoir 143.

[110] Volkman, J.K., G. Eglinton, E.D.S. Corner, and T.E.V. Forsberg, 1980a, Long chain alkenes and alkenones in the marine coccolithophorid Emiliania huxleyi, Phytochemistry, 19: $2619-2622$.

[111] Volkman, J.K., G. Eglinton, E.D.S. Corner, and J.R. Sargent, 1980b, Novel unsaturated straight chain $\mathrm{C}_{37}-\mathrm{C}_{39}$ methyl and ethyl ketones in marine sediments and a coc- 
colithophore Emiliania huxeleyi, Advances in Organic Chemistry, A.G. Douglas and J.R. Maxwell, eds, Pergammon Press, pp. 219-228.

[112] Volkman, J.K., H.R. Burton, D.A. Evritt, and D.I. Allen, 1988, Pigment and lipid composition of algal and bacterial communities in Ace Lake, Vestford Hills, Antarctica, Hydrobiologica, 165: 41-57.

[113] Webster, P. and N. Streten, 1978, Late Quaternary ice age climates of tropical Australasia, interpretation and reconstruction, Quat. Res., 10: 279-309.

[114] Wefer, G. R. Dunbar, and E. Suess, 1983, Stable isotopes of foraminifers off Peru recording high fertility and changes in upwelling history, in Coastal Upwelling; Its Sediment Record Part B, Sedimentary Records of Ancient Coastal Upwelling, J. Theide and E. Suess, eds, Plenum Press, NY, pp 295-307. 


\section{Appendix A}

\section{Supplementary data for Chapter 3}

The following tables are supplementary numerical data that are referred to in the text and are the basis for Figures in Chapter 3. 


\begin{tabular}{ccc}
\hline & \multicolumn{2}{c}{ G. sacculifer } \\
$\begin{array}{c}\text { Depth } \\
\text { (cm) }\end{array}$ & $\delta^{18}$ (PDB) & $\begin{array}{c}\delta^{13} \mathrm{C} \\
\text { (PDB) }\end{array}$ \\
\hline \hline 47 & 0.10 & 1.35 \\
49 & 0.11 & 1.31 \\
51 & 0.38 & 1.46 \\
53 & 0.38 & 1.46 \\
55 & 0.31 & 1.58 \\
57 & 0.22 & 1.40 \\
59 & 0.05 & 1.30 \\
61 & 0.08 & 1.37 \\
63 & 0.00 & 1.46 \\
67 & -0.18 & 1.35 \\
69 & 0.12 & 1.58 \\
71 & 0.14 & 1.54 \\
73 & 0.13 & 1.30 \\
75 & 0.17 & 1.49 \\
77 & 0.25 & 1.50 \\
79 & 0.38 & 1.44 \\
81 & -0.05 & 1.54 \\
83 & 1.10 & 1.69 \\
85 & 0.14 & 1.50 \\
87 & 0.17 & 1.60 \\
89 & 0.31 & 1.62 \\
91 & 0.35 & 1.85 \\
93 & 0.41 & 1.72 \\
95 & 0.44 & 1.69 \\
& & \\
\hline & &
\end{tabular}

Table A-1: Numerical isotopic results for $45-95 \mathrm{~cm}$ in core 86 Gyre $1412 \mathrm{PC} 51$. 


\begin{tabular}{cccccc}
\hline \multicolumn{5}{c}{ M odern Analogue Technique } & \multicolumn{2}{c}{ T ransfer Function } \\
dissimilarity & & \\
Depth & $\mathrm{T}_{\text {warm }}$ & $\mathrm{T}_{\text {cold }}$ & coefficient & $\mathrm{T}$ warm & $\mathrm{T}_{\text {cold }}$ \\
\hline \hline 1 & 26.70 & 24.55 & 0.103 & 27.41 & 23.77 \\
5 & 26.57 & 24.29 & 0.106 & 26.37 & 23.96 \\
7 & 26.52 & 24.27 & 0.191 & 24.83 & 23.24 \\
9 & 26.47 & 24.11 & 0.301 & 25.10 & 22.29 \\
11 & 25.14 & 21.83 & 0.280 & 24.02 & 20.76 \\
13 & 25.08 & 20.98 & 0.368 & 25.37 & 20.47 \\
15 & 23.00 & 15.29 & 0.365 & 25.70 & 17.38 \\
17 & 23.25 & 17.08 & 0.354 & 25.31 & 18.17 \\
19 & 22.50 & 15.00 & 0.377 & 24.91 & 18.38 \\
21 & 22.49 & 15.49 & 0.379 & 26.20 & 18.39 \\
23 & 22.74 & 15.99 & 0.362 & 26.23 & 18.84 \\
25 & 22.88 & 18.15 & 0.376 & 26.23 & 19.14 \\
27 & 23.38 & 18.46 & 0.366 & 25.65 & 18.56 \\
29 & 21.53 & 16.50 & 0.380 & 25.77 & 18.43 \\
31 & 23.23 & 18.00 & 0.374 & 25.27 & 19.14 \\
33 & 23.89 & 19.23 & 0.365 & 26.70 & 19.83 \\
35 & 23.26 & 17.79 & 0.334 & 24.27 & 19.32 \\
37 & 23.80 & 19.75 & 0.350 & 25.31 & 19.24 \\
43 & 24.02 & 19.84 & 0.348 & 23.96 & 19.45 \\
47 & 24.17 & 20.03 & 0.347 & 23.99 & 19.65 \\
& & & & & \\
\hline
\end{tabular}

Table A-2: Faunal Assemblage numerical results for core 86 Gyre 1412 PC51. 


\begin{tabular}{lccccc}
\hline $\begin{array}{l}\text { Depth } \\
(\mathrm{cm})\end{array}$ & $\begin{array}{c}\text { Orbulina } \\
\text { universa }\end{array}$ & coglobatus & $\begin{array}{c}\text { Globogerinoides } \\
\text { ruber } \text { pink }\end{array}$ & ruber white & ruber tot. \\
\hline \hline $0-2$ & 287 & 0 & 813 & 5976 & 6789 \\
$2-4$ & 144 & 36 & 1009 & 6128 & 7138 \\
$4-6$ & 72 & 36 & 1111 & 4730 & 5841 \\
$6-8$ & 284 & 0 & 886 & 5459 & 6345 \\
$8-10$ & 35 & 0 & 491 & 2840 & 3330 \\
$10-12$ & 68 & 17 & 306 & 1615 & 1921 \\
$12-14$ & 0 & 31 & 342 & 932 & 1274 \\
$14-16$ & 22 & 44 & 66 & 640 & 706 \\
$16-18$ & 0 & 0 & 82 & 712 & 794 \\
$18-20$ & 0 & 0 & 0 & 930 & 930 \\
$20-22$ & 30 & 60 & 150 & 690 & 840 \\
$22-24$ & 36 & 0 & 214 & 641 & 855 \\
$24-26$ & 0 & 0 & 19 & 660 & 680 \\
$26-28$ & 77 & 0 & 77 & 842 & 918 \\
$28-30$ & 46 & 0 & 116 & 463 & 579 \\
$30-32$ & 0 & 0 & 141 & 916 & 1057 \\
$32-34$ & 82 & 82 & 0 & 1153 & 1153 \\
$34-36$ & 144 & 29 & 202 & 1239 & 1441 \\
$36-38$ & 76 & 0 & 76 & 1111 & 1187 \\
$42-44$ & 0 & 0 & 106 & 1314 & 1419 \\
$46-48$ & 20 & 39 & 176 & 1581 & 1757 \\
& & & & & \\
\hline
\end{tabular}

Table A-3: Total faunal counts for core 86 Gyre 14 12PC51. All results are in numbers per gram dry weight. 


\begin{tabular}{lccccc}
\hline $\begin{array}{l}\text { Depth } \\
(\mathrm{cm})\end{array}$ & $\begin{array}{c}\text { Globogerinoides } \\
\text { sacculifer }\end{array}$ & $\begin{array}{c}\text { Sphaeroidinella } \\
\text { dehiscens }\end{array}$ & $\begin{array}{c}\text { Globierinella } \\
\text { aequilateralis }\end{array}$ & $\begin{array}{c}\text { Globigerina } \\
\text { bulloides }\end{array}$ & falconensis \\
\hline \hline $0-2$ & 3641 & 0 & 526 & 478 & 287 \\
$2-4$ & 3398 & 72 & 865 & 252 & 577 \\
$4-6$ & 2875 & 0 & 681 & 358 & 72 \\
$6-8$ & 2950 & 0 & 1170 & 425 & 0 \\
$8-10$ & 1617 & 0 & 351 & 280 & 0 \\
$10-12$ & 1280 & 0 & 187 & 340 & 51 \\
$12-14$ & 691 & 0 & 93 & 218 & 31 \\
$14-16$ & 822 & 0 & 22 & 199 & 0 \\
$16-18$ & 639 & 0 & 137 & 137 & 0 \\
$18-20$ & 414 & 0 & 121 & 202 & 0 \\
$20-22$ & 728 & 0 & 240 & 330 & 60 \\
$22-24$ & 760 & 0 & 107 & 178 & 36 \\
$24-26$ & 633 & 0 & 97 & 175 & 19 \\
$26-28$ & 1108 & 0 & 96 & 230 & 38 \\
$28-30$ & 632 & 0 & 93 & 185 & 23 \\
$30-32$ & 1104 & 0 & 35 & 211 & 70 \\
$32-34$ & 890 & 0 & 110 & 220 & 27 \\
$34-36$ & 901 & 0 & 173 & 317 & 29 \\
$36-38$ & 995 & 0 & 126 & 480 & 0 \\
$42-44$ & 1322 & 0 & 212 & 360 & 0 \\
$46-48$ & 1102 & 0 & 98 & 586 & 20 \\
& & & & & \\
\hline
\end{tabular}

Table A-4: Total faunal counts for core 86 Gyre 14 12PC51, continued. 


\begin{tabular}{|c|c|c|c|c|c|}
\hline \multirow{2}{*}{$\begin{array}{l}\text { Depth } \\
(\mathrm{cm})\end{array}$} & \multicolumn{2}{|c|}{ Globigerina } & \multicolumn{3}{|c|}{ Neogloboquadrina } \\
\hline & digitata & rubescens & pachyderma (s) & pachy. (d) & dutertrei \\
\hline $0-2$ & 0 & 287 & 143 & 143 & 574 \\
\hline $2-4$ & 0 & 433 & 0 & 108 & 505 \\
\hline $4-6$ & 0 & 430 & 0 & 394 & 538 \\
\hline $6-8$ & 0 & 744 & 0 & 1949 & 780 \\
\hline $8-10$ & 70 & 175 & 70 & 1788 & 1262 \\
\hline $10-12$ & 0 & 136 & 0 & 1564 & 1173 \\
\hline $12-14$ & 0 & 62 & 0 & 1119 & 1368 \\
\hline $14-16$ & 0 & 22 & 88 & 2008 & 1412 \\
\hline $16-18$ & 0 & 82 & 27 & 1697 & 1205 \\
\hline $18-20$ & 0 & 121 & 0 & 2304 & 2062 \\
\hline $20-22$ & 0 & 270 & 0 & 1829 & 2219 \\
\hline $22-24$ & 0 & 71 & 0 & 1354 & 1995 \\
\hline $24-26$ & 0 & 19 & 19 & 854 & 1165 \\
\hline $26-28$ & 0 & 191 & 38 & 1416 & 1492 \\
\hline $28-30$ & 0 & 139 & 46 & 903 & 1342 \\
\hline $30-32$ & 0 & 106 & 0 & 1445 & 1974 \\
\hline $32-34$ & 0 & 110 & 27 & 384 & 1757 \\
\hline $34-36$ & 0 & 0 & 0 & 1268 & 1498 \\
\hline $36-38$ & 0 & 25 & 0 & 657 & 1490 \\
\hline $42-44$ & 0 & 106 & 0 & 1504 & 1314 \\
\hline $46-48$ & 0 & 39 & 0 & 1249 & 1542 \\
\hline
\end{tabular}

Table A-5: Total faunal counts for core 86 Gyre 14 12PC51, continued. 


\begin{tabular}{lcccccc}
\hline $\begin{array}{l}\text { Depth } \\
(\mathrm{cm})\end{array}$ & $\begin{array}{c}\text { Pulleniatina } \\
\text { obliquiloculata }\end{array}$ & inflata & truncatulinoides $(\mathrm{s})$ & trunc. $($ d) & crassiformis & $\begin{array}{c}\text { N. pachy.-dut. } \\
\text { intergrade }\end{array}$ \\
\hline \hline $0-2$ & 765 & 0 & 48 & 239 & 48 & 0 \\
$2-4$ & 1081 & 0 & 36 & 180 & 108 & 0 \\
$4-6$ & 753 & 72 & 0 & 358 & 36 & 0 \\
$6-8$ & 780 & 35 & 0 & 780 & 177 & 0 \\
$8-10$ & 771 & 210 & 70 & 911 & 386 & 0 \\
$10-12$ & 136 & 391 & 17 & 595 & 272 & 476 \\
$12-14$ & 342 & 466 & 0 & 901 & 280 & 559 \\
$14-16$ & 66 & 706 & 22 & 993 & 287 & 794 \\
$16-18$ & 0 & 986 & 0 & 602 & 329 & 684 \\
$18-20$ & 0 & 970 & 0 & 1051 & 283 & 930 \\
$20-22$ & 0 & 1170 & 0 & 990 & 150 & 660 \\
$22-24$ & 36 & 1460 & 0 & 1211 & 249 & 748 \\
$24-26$ & 19 & 621 & 0 & 815 & 136 & 466 \\
$26-28$ & 0 & 612 & 0 & 689 & 134 & 746 \\
$28-30$ & 0 & 324 & 0 & 509 & 116 & 625 \\
$30-32$ & 0 & 564 & 176 & 423 & 211 & 952 \\
$32-34$ & 0 & 824 & 0 & 988 & 165 & 1373 \\
$34-36$ & 0 & 749 & 0 & 893 & 230 & 1469 \\
$36-38$ & 25 & 657 & 0 & 1010 & 177 & 1364 \\
$42-44$ & 42 & 636 & 0 & 784 & 148 & 911 \\
$46-48$ & 0 & 449 & 0 & 898 & 254 & 1386 \\
& & & & & & \\
\hline
\end{tabular}

Table A-6: Total faunal counts for core 86 Gyre 14 12PC51, continued. 


\begin{tabular}{lcccccc}
\hline $\begin{array}{l}\text { Depth } \\
(\mathrm{cm})\end{array}$ & hirsuta & $\begin{array}{c}\text { Globorotalia } \\
\text { scitula }\end{array}$ & menardii & tumida & $\begin{array}{c}\text { Globigerinita } \\
\text { glutinata }\end{array}$ & $\begin{array}{c}\text { Globigerina } \\
\text { digitata }\end{array}$ \\
\hline \hline $0-2$ & 0 & 0 & 1004 & 191 & 1769 & 0 \\
$2-4$ & 0 & 36 & 793 & 144 & 2740 & 0 \\
$4-6$ & 0 & 0 & 609 & 287 & 1469 & 0 \\
$6-8$ & 0 & 177 & 248 & 284 & 2056 & 0 \\
$8-10$ & 0 & 0 & 35 & 0 & 1507 & 70 \\
$10-12$ & 0 & 34 & 34 & 0 & 629 & 0 \\
$12-14$ & 0 & 62 & 0 & 0 & 559 & 0 \\
$14-16$ & 0 & 22 & 0 & 0 & 485 & 0 \\
$16-18$ & 0 & 27 & 0 & 0 & 520 & 0 \\
$18-20$ & 0 & 40 & 0 & 0 & 889 & 0 \\
$20-22$ & 0 & 0 & 0 & 0 & 720 & 0 \\
$22-24$ & 0 & 36 & 0 & 0 & 1033 & 0 \\
$24-26$ & 0 & 39 & 0 & 0 & 563 & 0 \\
$26-28$ & 0 & 38 & 0 & 0 & 708 & 0 \\
$28-30$ & 0 & 23 & 0 & 0 & 879 & 0 \\
$30-32$ & 0 & 0 & 0 & 0 & 952 & 0 \\
$32-34$ & 27 & 27 & 0 & 0 & 467 & 0 \\
$34-36$ & 29 & 0 & 0 & 0 & 749 & 0 \\
$36-38$ & 0 & 51 & 0 & 0 & 808 & 0 \\
$42-44$ & 21 & 42 & 0 & 0 & 1081 & 0 \\
$46-48$ & 20 & 20 & 0 & 0 & 839 & 0 \\
& & & & & & \\
\hline
\end{tabular}

Table A-7: Total faunal counts for core 86 Gyre 14 12PC51, continued. 


\begin{tabular}{lcccc}
\hline $\begin{array}{l}\text { Depth } \\
(\mathrm{cm})\end{array}$ & $\begin{array}{c}\text { others } \\
\text { (unident.) }\end{array}$ & $\begin{array}{c}\text { Total } \\
\text { planktonics }\end{array}$ & $\begin{array}{c}\text { Total } \\
\text { fragments }\end{array}$ & $\begin{array}{c}\text { frag./plank. } \\
\text { ratio }\end{array}$ \\
\hline \hline $0-2$ & 0 & 17211 & 2390 & .13 \\
$2-4$ & 0 & 18637 & 2307 & .12 \\
$4-6$ & 0 & 14872 & 2903 & .20 \\
$6-8$ & 0 & 19176 & 2907 & .15 \\
$8-10$ & 0 & 12936 & 3085 & .24 \\
$10-12$ & 0 & 9315 & 2720 & .29 \\
$12-14$ & 0 & 8050 & 6278 & .78 \\
$14-16$ & 0 & 8715 & 4258 & .48 \\
$16-18$ & 0 & 7857 & 4298 & .55 \\
$18-20$ & 0 & 10308 & 6670 & .64 \\
$20-22$ & 0 & 10286 & 5998 & .58 \\
$22-24$ & 0 & 10151 & 7124 & .71 \\
$24-26$ & 39 & 6349 & 3495 & .55 \\
$26-28$ & 0 & 8513. & 4591 & .54 \\
$28-30$ & 0 & 6457 & 3356 & .52 \\
$30-32$ & 0 & 9269 & 4934 & .53 \\
$32-34$ & 0 & 8704 & 4393 & .51 \\
$34-36$ & 29 & 9940 & 4898 & .49 \\
$36-38$ & 25 & 9144 & 3915 & .43 \\
$42-44$ & 42 & 9936 & 4025 & .40 \\
$46-48$ & 0 & 10306 & 5075 & .49 \\
& & & & \\
\hline
\end{tabular}

Table A-8: Total faunal counts for core 86 Gyre 14 12PC51, continued. 


\section{Appendix B}

\section{Supplementary data for Chapter 4}

The following tables are supplementary numerical data that are referred to in the text and are the basis for Figures in Chapter 4. 


\begin{tabular}{|c|c|c|c|c|c|}
\hline $\begin{array}{l}\text { Depth } \\
(\mathrm{cm})\end{array}$ & $\begin{array}{c}\text { N. pachyderma }(s) \\
\text { abundances } \\
(\%)\end{array}$ & $\begin{array}{l}\text { total } \\
\text { fauna } \\
(\# / g)\end{array}$ & $\begin{array}{l}\text { Depth } \\
(\mathrm{cm}) \\
\end{array}$ & $\begin{array}{c}N . \text { pachyderma }(s) \\
\text { abundances } \\
(\%)\end{array}$ & $\begin{array}{l}\text { total } \\
\text { fauna } \\
(\# / g)\end{array}$ \\
\hline 1.0 & 1.00 & 5957 & 106.5 & 25.76 & 1886 \\
\hline 10.0 & 2.00 & 5992 & 107.5 & 22.46 & 1063 \\
\hline 20.5 & 0.00 & 6085 & 108.5 & 29.96 & 714 \\
\hline 30.5 & 1.00 & 6953 & 109.5 & 23.48 & 2370 \\
\hline 40.5 & 1.00 & 6324 & 110.5 & 18.56 & 3463 \\
\hline 50.5 & 1.00 & 7208 & 111.0 & 10.00 & 2345 \\
\hline 60.5 & 3.00 & 6571 & 111.5 & 19.87 & 4201 \\
\hline 70.5 & 6.00 & 8137 & 112.5 & 13.95 & 2475 \\
\hline 80.5 & 7.00 & 10869 & 115.5 & 25.15 & 970 \\
\hline 80.5 & 13.29 & 6649 & 119.5 & 19.06 & 2039 \\
\hline 81.0 & 7.23 & 19008 & 120.5 & 18.00 & 1134 \\
\hline 85.5 & 9.33 & 4447 & 129.5 & 23.00 & 678 \\
\hline 90.0 & 20.00 & 4025 & 130.5 & 9.00 & 2122 \\
\hline 90.5 & 25.60 & 2544 & 139.5 & 26.00 & 563 \\
\hline 91.5 & 33.10 & 4496 & 140.5 & 27.00 & 633 \\
\hline 92.5 & 23.21 & 2272 & 149.5 & 42.62 & 124 \\
\hline 93.5 & 52.89 & 2632 & 150.5 & 64.00 & 437 \\
\hline 94.5 & 28.11 & 673 & 156.5 & 88.10 & - \\
\hline 95.5 & 26.19 & 4984 & 159.5 & 94.12 & 89 \\
\hline 96.5 & 54.41 & 5567 & 169.5 & 75.10 & 135 \\
\hline 97.5 & 55.67 & 3585 & 170.0 & 74.00 & 313 \\
\hline 98.5 & 21.35 & 2732 & 171.5 & 65.70 & - \\
\hline 99.5 & 22.82 & 488 & 179.5 & 81.79 & 286 \\
\hline 100.5 & 25.22 & 482 & 181.5 & 61.00 & 230 \\
\hline 101.5 & 13.00 & 1330 & 189.0 & 46.00 & 264 \\
\hline 104.5 & 21.58 & 508 & 189.5 & 34.34 & 69 \\
\hline 105.5 & 25.00 & 1846 & & & \\
\hline
\end{tabular}

Table B-1: N. pachyderma (s) and total faunal abundances for core Knr51 29GGC 


\begin{tabular}{crrl}
\hline & & & $\begin{array}{l}\text { dissimilarity } \\
\text { Depth }\end{array}$ \\
\hline \hline 1 & 12.85 & 8.79 & 0.075 \\
10 & 12.60 & 8.66 & 0.049 \\
20.5 & 13.37 & 9.15 & 0.095 \\
30.5 & 13.41 & 9.19 & 0.063 \\
40.5 & 12.80 & 8.78 & 0.090 \\
50.5 & 12.78 & 8.78 & 0.073 \\
60.5 & 12.87 & 8.80 & 0.073 \\
70.5 & 12.58 & 8.62 & 0.045 \\
80.5 & 12.46 & 8.49 & 0.075 \\
90.5 & 11.61 & 7.72 & 0.095 \\
101.5 & 12.04 & 8.10 & 0.089 \\
110.5 & 12.49 & 8.47 & 0.078 \\
120.5 & 11.12 & 6.75 & 0.139 \\
130.5 & 12.45 & 8.36 & 0.074 \\
140.5 & 10.01 & 5.47 & 0.095 \\
150.5 & 9.13 & 4.66 & 0.096 \\
169.5 & 7.14 & 3.09 & 0.091 \\
181.5 & 9.18 & 4.72 & 0.090 \\
189.5 & 8.60 & 4.50 & 0.100 \\
& & & \\
\hline
\end{tabular}

Table B-2: Modern Analogue Technique numerical results for core Knr51 29GGC 


\begin{tabular}{lccccc}
\hline $\begin{array}{l}\text { Depth } \\
(\mathrm{cm})\end{array}$ & $\begin{array}{c}\text { Orbulina } \\
\text { universa }\end{array}$ & $\begin{array}{c}\text { Globogerinella } \\
\text { aequilateralis }\end{array}$ & $\begin{array}{c}\text { Globigerina } \\
\text { bulloides }\end{array}$ & falconensis & digitata \\
\hline \hline $0-2$ & 17 & 0 & 1192 & 17 & 0 \\
$9-11$ & 0 & 14 & 1254 & 28 & 14 \\
$20-21$ & 15 & 44 & 1287 & 0 & 15 \\
$30-31$ & 70 & 0 & 1421 & 12 & 12 \\
$40-41$ & 66 & 22 & 1048 & 0 & 22 \\
$50-51$ & 16 & 0 & 1650 & 0 & 16 \\
$60-61$ & 36 & 0 & 1567 & 0 & 0 \\
$70-71$ & 0 & 0 & 1844 & 16 & 0 \\
$80-81$ & 0 & 53 & 2512 & 0 & 18 \\
$90-91$ & 0 & 0 & 542 & 0 & 0 \\
$93-94$ & 0 & 0 & 245 & 0 & 0 \\
$94-96$ & 0 & 0 & 421 & 0 & 0 \\
$101-102$ & 0 & 0 & 214 & 0 & 0 \\
$110-111$ & 7 & 0 & 622 & 0 & 0 \\
$120-121$ & 0 & 0 & 293 & 17 & 0 \\
$130-131$ & 0 & 0 & 624 & 4 & 0 \\
$140-141$ & 0 & 0 & 163 & 0 & 0 \\
$150-151$ & 0 & 0 & 41 & 0 & 0 \\
$159-160$ & 0 & 0 & 81 & 0 & 0 \\
$169-170$ & 0 & 0 & 10 & 0 & 10 \\
$181-182$ & 0 & 0 & 27 & 0 & 0 \\
$189-190$ & 0 & 0 & 135 & 0 & 0 \\
& & & & & \\
\hline & & 0 & & & \\
\hline
\end{tabular}

Table B-3: Total faunal counts for core Knr51-29GGC. All results are in numbers per gram dry weight 


\begin{tabular}{lccccc}
\hline $\begin{array}{l}\text { Depth } \\
(\mathrm{cm})\end{array}$ & \multicolumn{2}{c}{ Neoglogoquadrina } & \multicolumn{4}{c}{$\begin{array}{c}\text { Globorotalia } \\
\text { pachyderma }(\mathrm{s})\end{array}$} & pachy. $(\mathrm{d})$ & inflata & truncatulinoides $(s)$ & trunc. $(\mathrm{d})$ \\
\hline \hline $0-2$ & 52 & 2385 & 207 & 0 & 0 \\
$9-11$ & 96 & 1901 & 303 & 0 & 14 \\
$20-21$ & 15 & 2574 & 380 & 0 & 15 \\
$30-31$ & 93 & 2190 & 547 & 0 & 58 \\
$40-41$ & 66 & 2627 & 375 & 0 & 0 \\
$50-51$ & 80 & 1650 & 513 & 16 & 64 \\
$60-61$ & 196 & 2084 & 374 & 0 & 18 \\
$70-71$ & 461 & 2018 & 509 & 0 & 0 \\
$80-81$ & 731 & 2886 & 7944 & 0 & 0 \\
$90-91$ & 497 & 497 & 153 & 0 & 0 \\
$93-94$ & 1438 & 93 & 105 & 0 & 0 \\
$94-96$ & 1265 & 626 & 178 & 0 & 0 \\
$101-102$ & 174 & 297 & 44 & 0 & 0 \\
$110-111$ & 336 & 694 & 265 & 0 & 0 \\
$120-121$ & 205 & 111 & 128 & 2 & 0 \\
$130-131$ & 185 & 275 & 193 & 0 & 0 \\
$140-141$ & 174 & 72 & 29 & 0 & 0 \\
$150-151$ & 278 & 27 & 7 & 0 & 0 \\
$159-160$ & 189 & 0 & 3 & 0 & 0 \\
$169-170$ & 0 & 0 & 100 & 8 & 1 \\
$181-182$ & 139 & 23 & 4 & 0 & 0 \\
$189-190$ & 351 & 78 & 32 & 3 & 1 \\
& & & & & \\
\hline & & & & &
\end{tabular}

Table B-4: Total faunal counts for core Knr51 29GGC continued 


\begin{tabular}{lcccccc}
\hline $\begin{array}{l}\text { Depth } \\
(\mathrm{cm})\end{array}$ & $\begin{array}{c}\text { Globorotalia } \\
\text { crassiformis }\end{array}$ & $\begin{array}{c}\text { N. pachy.-duter. } \\
\text { intergrade }\end{array}$ & hirsuta & Gcitula & glutinata & bradyi \\
\hline \hline $0-2$ & 0 & 1037 & 0 & 17 & 985 & 0 \\
$9-11$ & 0 & 647 & 0 & 69 & 1226 & 0 \\
$20-21$ & 0 & 614 & 0 & 102 & 819 & 29 \\
$30-31$ & 0 & 897 & 0 & 116 & 874 & 47 \\
$40-41$ & 0 & 739 & 0 & 33 & 938 & 0 \\
$50-51$ & 0 & 609 & 32 & 176 & 1185 & 0 \\
$60-61$ & 0 & 623 & 107 & 196 & 837 & 0 \\
$70-71$ & 0 & 842 & 32 & 175 & 1621 & 0 \\
$80-81$ & 0 & 962 & 89 & 214 & 1443 & 0 \\
$90-91$ & 0 & 230 & 0 & 32 & 395 & 0 \\
$93-94$ & 0 & 222 & 0 & 0 & 93 & 0 \\
$94-96$ & 0 & 230 & 0 & 32 & 395 & 0 \\
$101-102$ & 0 & 135 & 12 & 24 & 261 & 0 \\
$110-111$ & 7 & 444 & 50 & 93 & 651 & 0 \\
$120-121$ & 0 & 58 & 2 & 36 & 98 & 0 \\
$130-131$ & 0 & 209 & 8 & 41 & 373 & 0 \\
$140-141$ & 0 & 71 & 0 & 6 & 39 & 0 \\
$150-151$ & 0 & 40 & 2 & 4 & 12 & 0 \\
$159-160$ & 0 & 9 & 0 & 0 & 0 & 0 \\
$169-170$ & 0 & 5 & 0 & 2 & 2 & 0 \\
$181-182$ & 0 & 9 & 0 & 0 & 9 & 0 \\
$189-190$ & 4 & 46 & 3 & 4 & 38 & 0 \\
& & & & & & \\
\hline & & & & & &
\end{tabular}

Table B-5: Total faunal counts for core Knr51 29GGC, continued 


\begin{tabular}{|c|c|c|c|c|c|c|}
\hline \multirow{2}{*}{$\begin{array}{l}\text { Depth } \\
(\mathrm{cm})\end{array}$} & \multicolumn{2}{|c|}{ Globigerina } & \multirow{2}{*}{$\begin{array}{c}\text { other } \\
\text { (unident) }\end{array}$} & \multirow{2}{*}{$\begin{array}{c}\text { Total } \\
\text { planktonics }\end{array}$} & \multirow{2}{*}{$\begin{array}{c}\text { Total } \\
\text { fragments }\end{array}$} & \multirow{2}{*}{$\begin{array}{c}\text { frag./plank. } \\
\text { ratio }\end{array}$} \\
\hline & digata & quinqueloba & & & & \\
\hline $0-2$ & 0 & 69 & 0 & 5979 & 1555 & .26 \\
\hline $9-11$ & 14 & 413 & 0 & 5992 & 1653 & .27 \\
\hline $20-21$ & 15 & 161 & 0 & 6085 & 2194 & .36 \\
\hline $30-31$ & 12 & 582 & 23 & 6953 & 1398 & .20 \\
\hline $40-41$ & 22 & 342 & 22 & 6324 & 1435 & .22 \\
\hline $50-51$ & 16 & 432 & 16 & 7208 & 1842 & .25 \\
\hline $60-61$ & 0 & 534 & 0 & 6571 & 1247 & .19 \\
\hline $70-71$ & 0 & 556 & 64 & 8137 & 1430 & .18 \\
\hline $80-81$ & 18 & 998 & 0 & 10869 & 1604 & .15 \\
\hline $90-91$ & 0 & 191 & 0 & 2544 & 408 & .16 \\
\hline $93-94$ & 0 & 105 & 0 & 2304 & $?$ & $?$ \\
\hline $94-96$ & 0 & 336 & 0 & 3487 & 461 & .13 \\
\hline $101-102$ & 0 & 170 & 0 & 1330 & 277 & .21 \\
\hline $110-111$ & 0 & 293 & 0 & 3463 & 429 & .12 \\
\hline $120-121$ & 0 & 186 & 0 & 1134 & 357 & .32 \\
\hline $130-131$ & 0 & 209 & 0 & 2122 & 205 & .10 \\
\hline $140-141$ & 0 & 79 & 1 & 633 & 55 & .09 \\
\hline $150-151$ & 0 & 25 & 1 & 437 & 22 & .05 \\
\hline $159-160$ & 0 & 2 & 0 & 86 & $?$ & $?$ \\
\hline $169-170$ & 0 & 5 & 0 & 135 & 5 & .03 \\
\hline $181-182$ & 0 & 17 & 1 & 230 & 16 & .07 \\
\hline $189-191$ & 0 & 75 & 0 & 770 & 69 & .09 \\
\hline
\end{tabular}

Table B-6: Total faunal counts for core Knr51 29GGC, continued 